


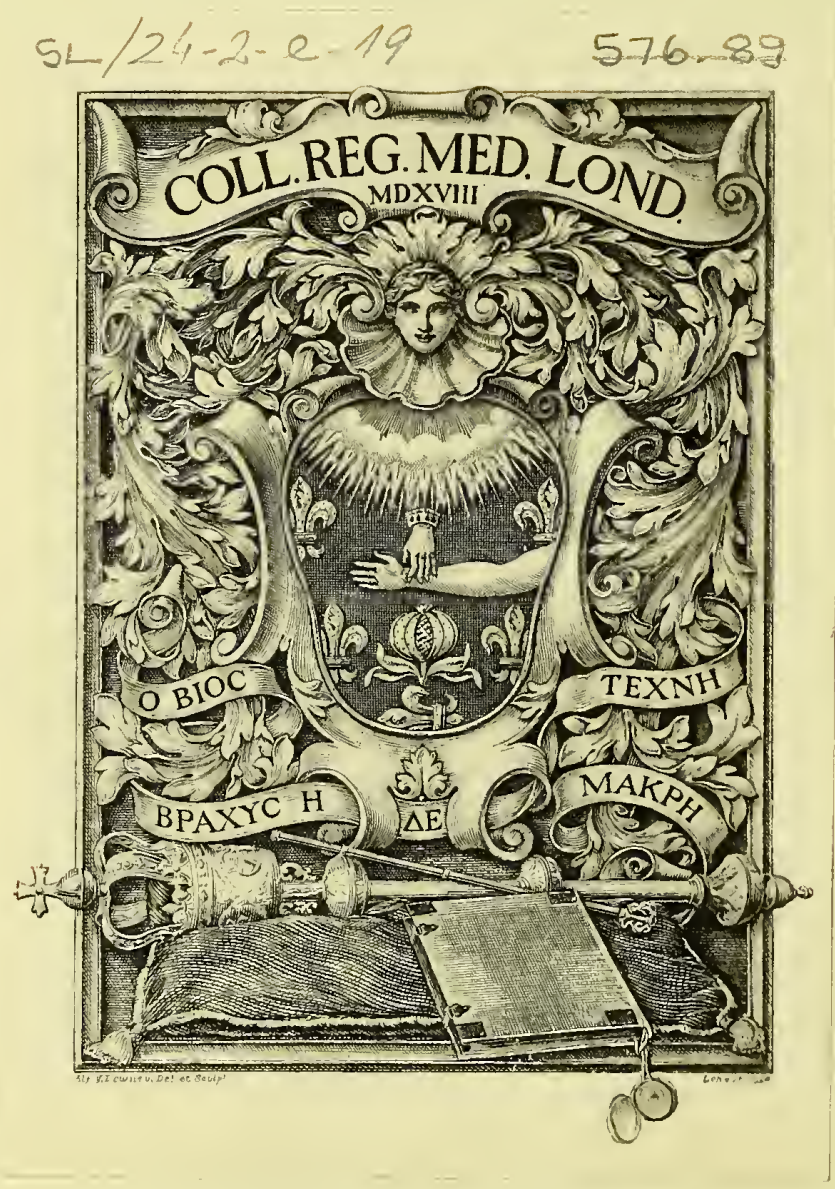



THE

\section{MICROSCOPIC ORGANISMS}

FOUND IN THE BLOOD OF MAN AND ANIMALS,

AND THEIR RELATION TO DISEASE.

BY

TIMOTHY RICHARDS WEWIS, M.B.,

ARMY MEDICAL DEPARTMENT,

SPECIAL ASSISTANT TO THE SANITARY COMMISSIONER WITH THE GOVERNMENT OF INDIA.

CALCUTTA :

OFFICE OF THE SUPERINTENDENT OF GOVERNMENT PRINTING.

1879. 
CALCUTTA :

PRINTED BY THE SUPERINTENDENT OF GOVERNMENT PRINTING, 8. HASTINGS STREET.

\begin{tabular}{|c|c|}
\hline \multicolumn{2}{|c|}{$\begin{array}{l}\text { MOFAL COLLEGE OP PHMIGIAME } \\
\text { LIBRASY }\end{array}$} \\
\hline CLASB & \\
\hline$A C C N$. & $2 t+1+t=51+21$ \\
\hline SOURE: & \\
\hline DATE & \\
\hline
\end{tabular}




\section{CONTENTS.}

Introductory remarks - The varieties of organisms found in the blood - The (probably) pseudo-organisms of the blood - The supposed organisms of healthy blood - MM. Béchamp and Estor's Microzyma sanguinis —Supposed real character of Microzyma sanguinis - Syphilis-corpuscles or micrococci . . .

\section{PART I.}

THE ORGANISMS OF A VEGETABLE NATURE WHICH HAVE BEEN FOUND IN THE BLOOD.

The lower forms of plant-life - Nägeli's three groups of lower fungi - The limited range of transformations anong fungi - The schizomycetes distinct from the other groups and do not germinate - Cohn's classification and views - Terms by which various forms of the schizomycetes are known - Conditions under which fungoid organisms are found in the blood - Healtly blood not conducive to the growth of bacteria, \&c. - The diseases in which fission-fungi have been found in the blood - The fermentation theories of the causation of disease - The vital theory, Pasteur's - The physico-chemical theory, Liebig's . .

\section{A.-The Organisms found in the Blood in Splenic Fever.}

M. Davaine's researches - Bacteridia - Discovery of bacteridia in man - Professor Cohn's Bacillus anthracis - Dr. Koch's researches : some objections which had been raised against Davaine's conclusions - The effect of the virus on mice - Cultivation of the bacilli - The 'spores' of bacilli - Vir'us, according to Koch, inert in alimentary canal - Dr. J. Cossar Ewart's experiments - Recognition of 'spores' of

Bacillus anthracis in the intestine - Bacillus anthracis no longer to be considered motionless, nor capable of resisting boiling water or compressed oxygen - Mons. P. Bert's researches - Effect of compressed oxygen on scorpion venom, vaccine, and glanders matter - Effect of compressed oxygen on charbon-blood - Effect of absolute alcohol on charbon-blood - M. Pasteur's researches as to charbon: cultivation. experiments - The vitality of the 'spores' of bacillus antluracis - M. Bert is convinced that the 'spores' can withstand the action of compressed oxygcn and alcohol - Bacilli a common accompaniment of the decomposition of urine.

\section{B.-The Vegetable Organisms in Septicæmia.}

Septicæmia - M. Bert and MM. Jaillard and Laplat's results - Davaine on effects of successive inoculations of septinous exudations - M. Pasteur on the 'vibrions' of septicæmia - The action of compressed

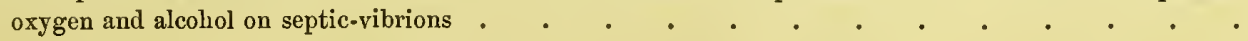

C.-Vegetable Organisms in Pneumo-enteritis or 'Typhoid-fever' of the Pig.

Dr. Klein on a bacillus in pneumo-enteritis of the pig - Character of the bacilli previously found associated with Pig-typhoid - Cultivation-and inoculatior-experiments - The 'spores' of the pig-bacillus . .

\section{D.-The Vegetable Organisms in the Blood in Recurrent Fever.}

The spirillum of recurrent fever - Obermeier's researches - Spirilla not invariably present in recurrent fever.

\section{F.-The question of the relation of Mycrophytes to Disease.}

The questions to be considered before accepting the doctrine that diseases are caused by Microphytes - In. nocuous character of ordinary schizomycetes when introduced into the system - Disease-schizomycetes assumed to be morphologically different from the others - The bacteridia of charbon said not to be a peculiar plant 


\section{F.-The Vegetable Organisms found in Healthy Blood after death considered in relation to the Bacteria and Bacilli of Diseases.}

The bacilli of ordinary decomposing blood - Bacillin anthracoid disease in Calcutta - The rapid appearance of bacilli in the blood of aspliyxiated animals - The relation of the blood-bacilli to the alimentary canal - Paraffine-preparations - Tracing of micro-plotogiaph of the bacilli of healthy tissues - Charactel. and size of these bacilli - Cultivation of the bacilli of ordinary blood - 'The 'spores' of bacilli - The question of specific distinctions among bacilli based on size — 'Cultivation' of small bacilli : First day : Second day: Thirl day — Large size bacilli : modifying influences of cultivating medir; Cultivation : First day - Slide with salt solution added to it: Second day — Slide with aqueous humor added to it:

PAGES.

\section{G.-The relation of the Spirillum of Recurrent Fever to other known Spirilla.}

Spirillum Obermeieri - Synonyms - Spirilla observed under various conditions - The spirillum-fever of Bombay - Osmic acid-preparations of spirilla - Comparison of micro-plotographs of Bombay-spirilli with Weigert's drawings and Koch's photographs - The supposed causal connection betwecu the 'Spirillum-fever' of Bombay and the famine

\section{H.-The probabilities in favour of considering the Bacilli and Spirilla of the Blood as Epi-phenomena.}

The transformation of spirilla into rosary-chain-like organisms - The disappearance of spirilla immediately before or shortly after death suggests that the initiatory changes occur in the blood itself - Drs. Murchison and Bastain on the development of microplytes in the system as a result of disease - Bacilli not detected in the earlier stages of diseases .

\section{I.-The evidence which has been adduced shewing that the virulence of Septinous Substances is not dependent on vegetable life.}

Facts shewing that certain microphyte-free flnids will induce disease - MM. Brauell, Bollinger, and Colin's experiments - Septinous fluids filtered through porous porcelain, \&c., not innocuous - Panum's researches - Richardson's and Bergmann's rescarches - Exndation witl septinous properties induced by purcly chemical irritants, shewing the paramount influence of the cells of the body itsclf .

\section{PART II.}

\section{THE PROTOZOA WHICH HAVE BEEN FOUND IN THE BLOOD.}

Fermentation formerly supposed to be induced by aninaleules by Pastcur, \&c.

\section{A.-Flagellated Organisms in the Blood of healthy Rats.}

The supposed absence of organisms in the blood during health - Organisms in the blood of ordinary rats Microscopical appearance of the organisms dnring life $-\Delta$ ppearance of preserved spccimens $-\mathbf{M c a}$ surements - Action of re-agents on the organisms - Result of application of interrupted current Proportion and species of rats affected - Classification of the organisms - Their rescmblance to flagcllated protozoa found in intestine of a nematode - Probability of former observations of a like kind - The organisms often found in the blood of rats of the same brood - Pathological bearing of the obscrvation

\section{B.-Protozoa in the Blood of healthy Frogs, Deer, \&c.}

Lankester's Undulina in frogs' blood - Rätig on organisms in blood of frogs - Hrmatozoon of decr statements as to occurrence of 'infusoires' in blood of man 


\section{PART III. \\ HELMINTHIC HEMATOZOA OF MAN AND ANIMALS.}

A.-Trematoid Hæmatozoa.

PAGES.

69

\section{B.-Nematoid Hæmatozoa of Animals.}

Nematoid hæmatozoa of frogs - Hæmatozoa of the seal, of the whale, and of the carp - Hæmatozoa of birds - The hæmatozoon of the Indian crow - Hæmatozoa of horses, \&c. - Hæmatozoa of dogs - The mature parasites found associated with embryo hæmatozoa of dogs - Filaria immitis - Filaria sanguinolenta Ercolani's discovery of mature nematodes in subcutaneous tissue of hæmatozoa-affected dogs .

\section{C.-Nematoid Hæmatozoa of Man.}

The first record of nematoid hæmatozoa in man - Association of hæmatozoa with chyluria and nævoid elephantiasis - The question of the identity of the embryo filariæ of different countries - The hæmatozoa as urinary parasites - The urinary oviparous helminths found by Salisbury - The urinary oviparous helminths found by Cobbold .

\section{D.-Changes undergone by the Embryos of Nematoid Hæmatozoa when ingested by the IMosquito.}

Dr. Manson's investigations of the changes which hæmatozoa undergo in the mosquito in China - Similar observations made in India -. Changes undergone by the embryo filariæ: The first day: Second day: Third and fourth days: Fourth and fifth days - The subsequent history of the larva filariæ - The varieties of nematoid hæmatozoa ingested by the mosquito

\section{E.-The Mature form of Filaria sanguinis-hominis.}

Discovery of mature nematodes in the tissues of man by Dr. Bancroft - The mature forms of Filaria sanguinishominis : male and female - The male specimen - The female specimen - The ova and embryos - The translucent cæcal tube in which frce embryos are enclosed - The thread-like tissue-parasites of Africa and America and Australia - A colrection - Hæmatozoa and Hæmatophytes in their relation to disease .

\section{ILLUSTRATIONS.}

PLATE I.-Illustrating the developmental stages of Organisms found in the Blood of healthy Animals shortly after death . . . . . . . . . . .

" II.-Illustrating the mature Filaria sanguinis-hominis, $\delta$ and 9 , and some of the developmental stages of the Embryos . . . . . . . . . " . 81

"III-Micro-photographs of various Organisms found in the Blood . . . . . . . $\quad$ " $\quad 91$ 


\section{Digitized by the Internet Archive in 2015}

https://archive.org/details/b22651494 
THE

\title{
MICROSCOPIC ORGANISMS FOUND IN THE BLOOD OF MAN AND ANIMALS,
}

\author{
AND THEIR RELATION TO DISEASE. ${ }^{1}$
}

BY

\section{TIMOTHY RICHARDS LEWIS, M.B.,} ARMY MEDICAL DEPARTMRENT,

SPECIAL ASSISTANT TO THE SANITART COMMISSIONER WITH THE GOVERNMENT OF INDIA.

\section{INTRODUCTION.}

A FEW years ago my colleague, Dr. Douglas Cunningham, submitted a report on the microscopic organisms found in the air, ${ }^{2}$ and embodied, Introductory remarks. in the account of his own observations, a brief summary of the principal facts which had been recorded by previous writers. An attempt will be made here to deal in a similar manner with the minute organisms which have from time to time been found in the blood of man and of animals.

The space at my disposal precludes the possibility of giving anything like a complete account of all that has been written on this subject; the bibliography alone would occupy very many pages, for during recent years no medical subject has occupied more attention than the relation which may possibly exist between living organisms in the blood and some of the most fatal diseases. All that will be attempted will therefore be to give an abstract of what the actual workers in this department of research have observed, and of

1 Appeared as an Appendix to the Fourteenth Annual Report of the Sanitary Commissioner with the Government of India, $187 \%$.

2 'Microscopic Examinations of Air:' Appendix A, Ninth Annual Report of the Sanitary Commissioner with the Government of India, 1872. 
the conclusions which they have arrived at as the result of personal observation. An account of my own enquiries in the same direction will also be given as shortly as possible.

From earliest times physicians have been accustomed to attribute various The varieties of organisms found diseases to abnormal conditions of the blood, the in the blood.

blood being the connecting link between all the tissues of the body and the external world, furnishing them with the nutriment which they require, whether in liquid or gaseous form, and removing from them such products of change as are not required for the efficient exercise of their functions.

The circulation may become the habitat of minute organisms belonging to either the vegetable or animal kingdom, as also to that group of organisms so closely related to both as to render it, in the present state of our knowledge, impossible to say definitely to which they belong-the group which Professor Häckel has proposed to regard as a third organic kingdom and has termed Protista.

It will, however, be convenient in the present paper to assume, for purposes of classification, that the organisms which have been found in the blood are either plants or animals.

Before adopting such a classification, however, it may be as well to mention The (probably) pseudo-organisms that from time to time various particulate objects of the blood.

have been described as occurring in the blood in regard to which no sufficient evidence yet exists to warrant their recognition as independent beings. These have been generally described as connected with certain diseases, but bodies of an allied character are, not uncommonly, found associated with no perceptible disturbance of the normal condition.

Bodies of the latter kind have recently been very carefully described by The supposed organisms of Dr. William Osler. ${ }^{1}$ They had, however, long before
healthy blood. logists, Max Schultze, L. Riess, and many others having contributed towards our knowledge of their character. The bodies in question are granular masses, composed of aggregations of corpuscular elements, and not uncommonly referred to as 'micrococcus colonies' (fig. 1, A). As Dr. Osler says, 'There

\footnotetext{
${ }^{1}$ An Account of Certain Organisms occurring in Liquor sanguinis, - Proceedings of the Royal Society, 1874.
} 
are probably few observers in the habit of examining blood who have not at some time or other been puzzled for an explanation of their presence and nature. They are particularly plentiful in the blood of fœtal and newly born animals.' Max Schultze considered that they are derived from the degenerated white corpuscles of the blood. Riess is of a like opinion. Osler, however, considers them to be organisms in the liquor sanguinis, basing his opinion on the circumstance that certain changes take place in the masses when a saline solution ( $\frac{1}{2}$ or $\frac{3}{4}$ per cent.) or fresh serum is added to them, and the preparation kept at a temperature of about $37^{\circ} \mathrm{C}$. Along the margins of the masses (which

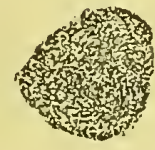

A

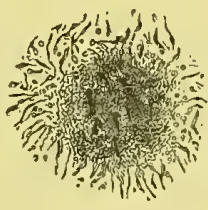

B

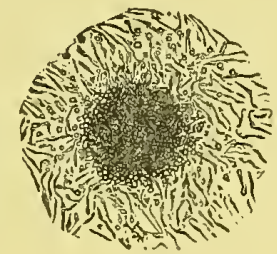

$\mathrm{C}$

FIG. I.-Development of organisms in human blood (Hartnack's Ocular 3, Objective 7).

A. A mass from healthy blood at IO A. M.
$\begin{array}{lll}\text { B. Ditto ditto at IO-30 A. M. } \\ \text { C. Ditto ditto at II A, M. }\end{array}$

(After Osler.)

previously presented a tolerably even appearance) there gradually appear fine projections ' which may be either perfectly straight or each may present an oval swelling (fig. 1, B). These projecting filaments soon present a waving motion and finally break off from the mass, moving away free in the fluid, and in a short time the whole area for some distance from the margins is alive with moving forms (fig. 1, C). . . . The variety of forms increases as the development goes on; and whereas, at first, spermatozoon-like or spindle-shaped corpuscles were almost exclusively to be seen, later more irregular forms appear, possessing two, three, or even more, tail-like processes of extreme delicacy. The more active ones wander towards the periphery, pass out of the field, and become lost among the blood-corpuscles. The process reaches its height within $2 \frac{1}{2}$ hours, and from this time begins almost imperceptibly to decline; the area about the mass is less densely occupied by the moving forms and by degrees becomes clearer, till at last, after six or seven hours (often less), scarcely an element is to be seen in the field, and a granular body, in which a few corpuscles yet' exist, 
is all that remains of the mass.' In 1872 Dr. Douglas Cunningham and myself described and figured somewhat similar masses in connection with a description of the changes undergone by the blood in cholera, ${ }^{1}$ but we did not notice anything to suggest that the molecular and filamentous particles manifested independent movements.

It is possible that the bodies described by Dr. Osler may ultimately prove to be closely related to those which were described by MM. Béchamp and Estor in 1869 and termed MM. Bechamp and Estor's Hicro syma sanguinis. Microzyma sanguinis. In that year these distinguished savants announced to
the French Academy ${ }^{2}$ that, as the result of numerous observations, they had ascertained that the blood of all animals contained an infinite number of mobile molecules. These were found to be particularly plentiful in the blood of very young animals and especially in blood which yielded a small proportion of fibrine. These microzymæ, on being added to starch or to cane sugar, \&c., and placed under suitable conditions as to temperature and so forth, set up fermentation, and, in doing so, gradually became transformed into beaded, filamentous, stellate bodies, and bacteroid rods : the last named were seen to become detached from a heap of such rods and to move in a characteristic manner. They continued to multiply so long as sufficient nourishment remained in the fluid. Moreover, they were described as retaining their vitality after prolonged boiling in creosoted distilled water. Somewhat similar mobile bodies were described by Medsvetzki a few years later and named hamococci. ${ }^{3}$

In $1872 \mathrm{M}$. Arloing submitted an account of the result of his investigaSupposed real character of Micro. tions as to the real nature of the Microzyma sanguinis, and shewed pretty conclusively that no such thing as proliferation of these bodies occurred; that whereas proliferation required some time, these could be produced instantaneously under certain conditions by treating the blood with alcoliol, and that consequently the supposed organisms were the result of simple chemical action;-the explanation being that the hæmato-globuline, having been removed from the blood-corpuscles

\footnotetext{
${ }^{3}$ A Report of Microscopical and Physiological Researches: Appendix A, Eighth Annual Peport of the Sanitary Commissioner with the Government of India.

¿ Comptes Rendus, t. 1xix, p. 713.

'Schuidt's Jahrbücher, vol. clis, p. 181.
} 
by the action of water, was subsequently precipitated by the action of alcohol. The addition of tannin to a mixture of blood and lukewarm water produced a similar result. The stellate appearance presented by some of the masses, described as organisms in process of formation, was due to granules adherent to the remains of blood-corpuscles.

Six or seven years ago a considerable stir was created in the medical circles of Vienna by the announcement that characteristic Syphilis-corpuscles or micrococci. molecular bodies had been discovered in the blood of syphilitic patients by Lostorfer, and that these were so constantly present as to be diagnostic of the disease. ${ }^{1}$ After some months of discussion in various learned societies as to whether these 'syphilis-corpuscles' were fungi-micrococci (for these also during 'cultivations' arranged themselves into threads), oil globules, or the remains of degenerated white corpuscles, Biesiadecki announced, as the result of numerous experiments, that the bodies in question were precipitated particles of paraglobulin.

1 Stricker's Medicinische Jahrbücher, Heft. 1, 1872. 


\section{PART I.}

THE ORGANISMS OF A VEGETABLE NATURE WHICH HAVE BEEN FOUND IN THE BLOOD.

BEFore entering on a minute description of the microscopic organisms found The lower forms of plant-life. in the blood which are more allied to plants than to animals, it will be advantageous to consider to what special subdivisions of the vegetable kingdom these bodies seem to belong. No small amount of confusion has arisen from want of a clear knowledge of this point, especially on the part of strictly medical writers who have discussed the subject of the connection of disease with vegetable parasites. Nägeli, in his remarkably suggestive work, ${ }^{1}$ recently published, has placed this matter in a very clear light, and, being an authority of the first rank, especially on the botanical phase of the subject which forms the text of this paper, his statements on this particular point are worthy of exceptional attention. The forms of plant-life which have been recognised as having been more or less closely associated with changes in living animal substances are the lower kinds of fungi. These Nägeli separates into three groups: (1) Moulds, characterised by branched, segmented or unsegmented filaments; (2) Sprouting-fungi, yeast cells of various kinds, consisting of more or less oval corpuscles which multiply by means of sprouts from their surfaces; and (3) Cleft-fungi or Schizomycetes-minute spherical or oval bodies which are multiplied by fission only, and which sometimes remain isolated, at others form unbranched rows (rods, threads, \&c.), but only occasionally present a cubiform aspect. To this group the bacterium, vibrio, vibrio-bacillus, spiril. lum, \&c., belong.

Nägeli writes: ' I have separated the lower forms of fungi into three groups. Nägeli's three groups of lower On account of many practical questions it is of importance to know whether specific differences really exist, or whether we have to do with the same species under different conditions, it being possible that different fungi possessed a "mould," a "sprout,"

1 Die Niederen Pilze in ihren Beziehungen zu den Infectionskrankheiten und der Gesundheitspflege, München, 1877. 
or a "cleft" form. This is a subject which has formed the subject of debate during the last sixteen years, and many observations have been recorded for the purpose of shewing that, as a result of cultivation-experiments, the most opposite forms have been seen to pass from one into the other.' With reference to this point Nägeli forcibly points out the fallacies to which men are liable in drawing conclusions from cultivation-experiments, and says that, in many respects, it would be as rational for the husbandman to assert that the weeds in his field were the result of transformations which the seed of wheat previously sown had undergone. No one would believe such a statement, for the seeds of weeds are large enough to be easily recognised, whereas the germs of fungi are of microscopic dimensions-those of the schizomycetes often barely distinguishable with the highest powers: hence the assertions which have been made regarding the transition of such minute organisms cannot easily be controlled. 'Moreover,' adds Nägeli, 'the rapid and superficial observer has a marked advantage : the conclusions which he has arrived at as the result of a so-called uncontaminated cultivation [Reinkultur] of a single week's duration may require years of labour on the part of the thoroughly competent observer to disprove.'

This question has of late years been investigated by many distinguished The limited range of transformsavants, notably by Professor de Bary of Strasburg. He has shewn that a fungus undergoes but a ations among fungi. very limited and well-defined range of changes. Nägeli, as the result of his the 'mould' and 'sprout' fungi are closely related, but that, with one exception, they have not yet been seen to pass from one form into the other. The exception consists in the circumstance that a certain species of mucor (a mould) has been observed to present the two forms of vegetation-the filamentous

The schizomycetes distinct from the other groups and do not germinate.

fungal forms nor originate from them: hence it is distinctly laid down that they do not germinate. In this it would appear that Nägeli and de Bary are completely in accord. Nägeli states that it is comparatively easy to demonstrate that the 'fission' group of fungi are not transformed into other groups from the circumstance that members of the latter when present in a solution are killed 
at a lower temperature than those of the former. This peculiarity, however, renders it much more difficult to shew that other (the 'mould' and 'sprout') groups do not give rise to schizomycetes, as it is impossible so to isolate the germs of other fungi as to exclude this group. Eventually, however, he was able to satisfy himself on this point also by first destroying by heat all the fungal forms in a nutrient solution, and then permitting a mould to extend its filaments into it. In this way he kept some solutions thus prepared for four years with only the 'mould' form of vegetation in them.

Of the foregoing three groups of organisms, the only one which requires to be dealt with here is the third-the schizomycetes-as it is only the various forms of this group of the fungal family which have hitherto been unequivocally found in the blood.

Another distinguished botanist, Professor Cohn of Breslau, has also paid Cọn's classification and views. much attention to these low forms of life, and has recently devised a new system of classification for them, taking as his starting point the dictum that the schizomycetes are more closely related to alge than to fungi, and suggests, therefore, the term schizophyte for the family, in place of the name given by Nägeli which has been in general use hitherto. Cohn has, moreover, advanced the supposed differences in physiological properties manifested by some of these low growths as sufficicnt grounds for assigning to them specific designations. In doing this, Nägeli says, Colm has given expression to a generally entertained opinion and one especially affected by the medical profession, but he (Nägeli) is unacquainted with any facts in support of such a view. 'I have,' he writes, 'during the last ten years examined some thousands of different forms of fission-yeast cells, but (excluding sarcina) I could not assert that there was any necessity to separate them into even two spccific kinds.' ${ }^{\prime}$ On the other hand, there is not sufficicnt evidence to shew that all the forms constitute in reality but one species. ${ }^{2}$

Notwithstanding the circumstances that the schizomycetes assume, within Terms by which various forms of the schizomycetes are known. certain limits, such different aspects (and the experience of such an authority as Nägeli on such a matier as this cannot be lightly set aside) it is nevertheless convenient, irre-

Op. cit., p. 20.

' Op. cit., p. 22. Also A. de Bary, 'Ueber Schimmel uud Hefe,' 1869. 
spective of any particular theories, that terms should be adopted which will suffice to distinguish the leading forms.

Dujardin suggested three terms for the group: (1) bacterium, (2) vibrio, and (3) spirillum. Notwithstanding the great advance which has been made in our knowledge of these organisms since the date of Dujardin's classification, there still remains very much to be done before anything like a satisfactory settlement of the matter can be accomplished. It will, therefore, perhaps be better for the present to accept these simple terms, especially as, with very trifling modifications, they are sufficient to indicate all the forms which have hitherto been found in the blood. The following brief description will suffice to explain what forms of this group of organisms are comprehended

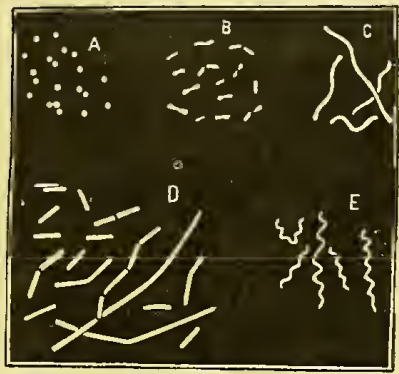
by the terms adopted: 1, Spherical bacteria-minute, vitalised bodies, barely visible with the highest powers (fig. 2, A); 2, Elongated bacteria-almost equally minute cylindrical rods (fig. 2, B) ; 3, Vibriones, short, undulating filaments manifesting somewhat screw-like movements (fig. 2, C); 4, Bacilli, or Vibrio-bacilli-fine, short filaments, indistinctly jointed, whicl, when they attain considerable length, are sometimes described as leptothrix filaments (fig. 2, D) ; 5, Spirilla-fine, more or less flexible, spiral filaments, which manifest well-marked screw-like movements (fig. 2, $\mathrm{E}$ ).

It may be mentioned, in passing, that examples of each of these forms may, commonly, be detected in the muco-salivary fluid from the mouth of healthy persons.

The question which naturally suggests itself now is: Under what condition Conditions under which fungoid are organisms of this character found in the blood? organisms are found in the blood.

M. Pasteur states that the blood in health is absolutely free from anything of the kind. His words are: 'Le sang d'un animal en pleine santé ne renferme jamais d'organismes microscopiques ni leurs 
germes.' ${ }^{1}$ Dr. Beale, on the other hand, says, 'The higher life is, I think, interpenetrated, as it were, by the lowest life. Probably there is not a tissue in which these germs are not; nor is the blood of man free from them.' ${ }^{2}$ It may appear strange that the satisfactory settlement of a question, apparently so very simple, should hitherto have proved impossible and that many eminent observers should have arrived at opposite conclusions regarding it. It may be that to a certain extent both classes of observers are in the right, for if, as is not uncommonly affirmed, very many of these extremely minute organisms constantly find their way into the circulation through the lungs and pass through the walls of the intestinal tract along with the food (that bacteria pass with fluids through a membranous septum is a well-ascertained fact, as also that they will pass through porous earthenware and other filtering media), it is very certain that their existence in the plasma of healthy blood is of comparatively short duration.

This point has been definitely settled as the result of observation by many Healthy blood not conducive to pathologists, and Dr. Douglas Cunningham and the growth of bacteria, \&c. myself were, some years ago, able to satisfy ourselves that bacteria, vibriones, bacilli, and so forth very speedily disappear from. the liquor sanguinis, even when introduced into it during life in considerable numbers. Out of forty-nine experiments which were conducted by us with a view of clearing up this matter, twelve of the animals were examined within six hours of the organisms being injected into the veins, and bacteria, \&c., were found to be present in seven, or at the rate of about 58 per cent.; and out of thirty examined within twenty-four hours, their presence was detected in fourteen, or 47 per cent.; whereas in nineteen specimens of blood derived from animals which had been inoculated in this manner from two to seven days previously, these bodies could only be detected in two of them, or a little over 10 per cent., just 6 per cent. higher than we had observed to be the case out of a number of ordinary preparations of healthy blood which we had examined. ${ }^{3}$ It is, however, obvious that though it is possible that the blood may be constantly replenished with a greater or less number of these organisms, yet

\footnotetext{
${ }^{1}$ Comptes Rendus, t. Ixxxv, p. 108 ; 16th July 1877.

2 Disease Germs, $187 \mathrm{C}$, p. 64.

${ }^{3}$ Cholera : A Report of Microscopical and Physiolngical Researches, Series I, Appendix A, Eighth Annual Report of the Sanitary Commissioner with the Government of India, 1872.
} 
they do not accumulate to any great extent therein, and it may be safely affirmed that their presence in appreciable numbers is, judging from experience, incompatible with a state of perfect health. It will hereafter be seen that the same remark does not hold good as regards parasites of, apparently, animal nature.

It may be affirmed, further, that in certain diseased conditions micro-

The diseases in which fission + fungi phytes are very generally present, though perhaps not invariably, nor is their number co-incident with the gravity of the malady. Omitting the cases in which these organisms have been found associated with disease in insects (on account of the difficulty of isolating and clearly identifying such organisms as are found in the blood in these cases, from those found in the tissues generally), it may be stated that it has been clearly established that one or other of the forms of fission-fungi have been found in the blood in two diseases, viz., in charbon, mal de rate or splenic fever; and in recurrent fever. M. Pasteur has recently maintained that a third should be added to the list-septicamia; and, still more recently, a fourth has been added by Dr. Klein, namely, the disease commonly known as 'typhoid-fever' of the pig.

These matters have, during the last few years, received great attention from thoughtful members of the medical profession, and probably at the present time no subject of a scientific character is being more closely investigated.

The importance of thoroughly sifting the evidence on which the interpretaThe fermentation theories of the causation of disease. tions which have been placed on the significance of such organisms in the blood can scarcely be overrated, seeing that, should the views now commonly advanced prove to be correct, the theory and practice of medicine would be radically affected, and, possibly, the future action of the State with regard to disease be materially modified. Before making an attempt to institute such an examination, it may be well to refer briefly to the more salient circumstances which have conduced to make the present doctrine of the causative relation to disease of these low forms of plantlife so attractive to botanists and to the medical profession. 'The foundations of the germ theory of disease in its most commonly accepted form,' writes Dr. Charlton Bastian," 'were laid in 1836 and shortly afterwards. The discovery at this time of the yeast-plant by Schwann and Cagniard-Iatour soon led to the

1 Prper read before the Patholngical Society of London, April 6th, 1875. Lancet, vol. i, page 501, 1875. British Medical Journal, vol, i, page 469, 1875. 
more general recognition of the almost constant association of certain low organisms with different kinds of fermentations. But it was not till twenty years afterwards that Pasteur announced, as the result of his apparently conclusive researches, that low organisms acted as the invariable causes of fermentations and putrefactions; that such changes, in fact, though chemical processes, were only capable of being initiated by the agency of living units.' These observations and the interpretations applied to them very rapidly caught the ear of the medical profession, as from a very early period in the history of medicine the supposition that disease was propagated by means of a ferment-a leavenhad taken a firm hold. Previous to the publication of M. Pasteur's observations, a physico-chemical theory had been almost universally acknowledged as sufficiently explanatory of the phenomena manifested by certain classes of disease. This was notably the case with regard to the fermentation-doctrine of Liebig, a doctrine the truth of which he strongly advocated until the day of his death in 1873 , and which, somewhat modified as a result of later researches, is still upheld by some of the most eminent chemists of our own time.

'The leading features the 'vital' and the 'physico-chemical' theories of

The vital theory-Pasteur's.

fermentation ${ }^{1}$ have recently been lucidly summarised by Mr. C. T. Kingzett in a paper read before the Society of Arts. ${ }^{2}$ With regard to the first of these views and in illustration of them this chemist remarks : "When a solution of sugar is exposed to the action of healthy yeast it suffers a change; the atoms comprised in its molecules are broken up and re-arranged into new forms which are recognised as alcohol and carbonic dioxide. Glycerine and succinic acid are also formed at the expense of the sugar, but the lactic acid which generally accompanies alcoholic fermentation is considered as proved to be due to the presence of a ferment distinct from, but accompanying, the yeast. . . . The fermentation alluded to is regarded as a particular instance of a biological re-action, manifest-

\footnotetext{
1 - Certain organic compounds, when exposed to the action of air, water, and a certain temperature, undergo decomposition, consisting either in a slow combustion or oxidatiou by the surroundFermentation and Putrefaction. ing air, or in a new arrangemeut of the elements of the compond in different
proportious (often with assimilation of the elemeuts of water), and the conscquent formation of new products. The former process, that of slow combustion, is called Evemacausis or Decay; the lat ter is called Putrefaction or Fermentation,--putrefaction when it is accorpanied by an offensive odour, fermentation when no such odour is evolvel, and especinlly if the process results in the formation of useful products : thus, the decomposition of a dend body, or of a quantity of blood or urine, is putrefaction; that of grape-juice or m.llt-wort, which jields alcohol, is furmeutation.'Watt's Dictionary of Chemistry, vol, ii, p. 624, 1872.

2 Journal of the Society of Arts, March 1878.
} 
ing itself as the result of a special force residing in organisms; or, in other words, fermentation is essentially a correlative phenomenon of a vital act, beginning and ending with it. On this hypothesis, where there is fermentation there is organisation, development, and multiplication of the globules of the ferment itself. The instance quoted above is by no means solitary; it is exemplary of many other changes, induced by the same or other fermented matters in media suitable for their growth and reproduction. Thus, we have mannitic, lactic, ammoniacal, and butyric fermentations, besides many others, all of them having one feature in common, viz., the reproduction of the ferment. ${ }^{1}$ It has not yet, however, been satisfactorily ascertained-a very essential matter to be settled before the foregoing interpretation of fermentative processes can be established-that the several processes are the result of the action of specifically distinct growths.

Baron Liebig vigorously opposed this doctrine, and, Mr. Kingzett suggests, The, physico-chemical theoryprobably ignored the influence, of vital action to too great an extent; all that was required in his opinion for inducing the fermentative change was contact with matter which was itself undergoing change. Mr. Kingzett thus sums up the physico-chemical doctrine of fermentation as advanced by Liebig: Mechanical or other motion exerts an influence on the power which determines the state of a body. Thus, a crystal of sulphate of sodium, a speck of dust, or grain of sand, when dropped into a saturated solution, say of sulphate of sodium, may determine the entire crystallisation of the fluid. Or, again, when fulminates of silver and mercury are tickled lightly by a feather or glass rod, they suddenly explode with violence. A still better instance is the re-action which occurs between peroxide of hydrogen and argentic oxide; these substances, when mixed, give rise to the production of metallic silver and free oxygen : the peroxide of hydrogen, being unstable, is constantly undergoing decomposition from the moment of its formation, and this decomposition results in the production of water and free oxygen; immediately, therefore, that this change comes into contact with oxide of silver, it gives to that body the same tendency to change.

\section{A.-The Organisms found in the Blood in Splenic Fever.}

On the assumption that certain diseases which are undoubtedly com-

M. Davaine's researches. municable by inoculation, and several others commonly believed to be communicable in otleer ways, 
are in reality the result of a ferment of some kind, the various theories of the causation of the fermentative processes have always proved an attractive subject of study to the more thinking section of the medical profession. As already stated, the physico-chemical theory of Berzelius, and subsequently of Liebig and his followers, was very commonly accepted as fairly sufficient in connection with the etiology of disease, so long as it was favourably received by the majority of the chemists of the time; but latterly Schwann's views, as expounded and amplified by Pasteur ard others, have undoubtedly taken the lead. Probably no.single incident has tended so much towards enlisting the attention of the medical profession to it than the publication of the experiments of M. Davaine, which went to shew that minute organisms were, to a greater or less degree, constantly present in the body of animals which had died of the disease known as malignant pustule in man-the 'Milzbrand' of Germany; the 'charbon' of cattle and pigs, and 'mal de rate' of sheep, in France. The terms 'splenic fever' or 'splenic apoplexy,' 'anthracoid disease,' \&c., are commonly adopted in England in describing the affection. Birch-Hirschfeld ${ }^{\mathrm{i}}$ states that the organisms found in this affection were first described by Brauell in 1849 and by Pollender in 1857 ; but, undoubtedly, it was M. Davaine's researches which were, the means of drawing serious public attention to the matter. In August 1850 M. Davaine, in conjunction with M. Rayer, published an account of these organisms, describing them as minute filamentous bodies, motionless, and about double the length of the diameter of a red blood-corpuscle. M. Pasteur ${ }^{2}$ maintains that the time just mentioned represents the date of the first publication of the existence of these bodies in charbon, but this idea is manifestly erroneous.

Instigated thereto by the publication of M. Pasteur's researches (which Bacteridia.

went to shew that butyric fermentation was not, as believed, due to an albuminoid body in process of spontaneous decomposition, but to vibriones, which presented the greatest resemblance to the 'corps filiformes,' found in the blood of animals dying of charbon) M. Davaine returned to the subject in 1863 and 1864. The organ: isms were at first considered by M. Davaine to be bacteria; but finding in certain cases that the filaments or rods varied in length, he modified the name, and they have consequently been, until lately, commonly designated bacteridia. At this

' 1 Schmidt's Jahrbüeher der gesammten medicin, Band. 166, S. 205, 1875.

${ }^{2}$ Eiude sur la maladie charbonneuse; par MM. Pnsteur et Joubert. Comples Rendus, t. 1xxxiv., p. 900, 1877. 
period it was supposed that they were more closely related to animals than to plants. He satisfied himself that they were found in the blood during life ; that they developed in this fluid and not in the spleen; in fact, he had been able to transfer the organisms to animals whose spleen had been removed. He also ascertained that bacteridia are not found in fœtal blood, although the blood of the mother and of the placenta was crowded with them. ${ }^{1}$ The disease was found to be communicable with the food by mixing with it some of the tissues of diseased animals; the effects were less rapidly induced, but the blood became equally affected with bacteridia. He refuses to accept the doctrine of identity of the poison of septicæmia and charbon, on the grounds (1) that the symptoms produced by inoculating animals with putrefying blood are not constantly the same, and that bacteridia do not develop in the circulation of the affected animal; (2) that animals which have swallowed fragments of putrefied tissue rarely died; and (3) that animals which had swallowed fragments of the fresh tissues of animals which had died of septicæmia had been in no way affected. He therefore concluded that the active principle of septicæmia was not regenerated in the animal economy as in the case of charbon, the latter in fact being a virus and the former a poison. ${ }^{2}$

In the following number of the Comptes Rendus (p. 429), MM. Davaine Discovery of bacteridia in man.

and Raimbert announce that they had demonstrated the existence of bacteridia in a man affected with pustule maligne, the excised pustule having contained a great number. ${ }^{3}$ Portions of this pustule-tissue having been introduced beneath the skin of some animals, the latter succumbed, and after death their blood was found to contain a considerable number of bacteridia.

Such, in a few words, were the observations which drew the special attention of pathologists to this question, and gave marked impetus to the doctrine of disease germs. Since this time very many observations have been recorded, but those of the past two or three years have been particularly valuable from the circumstance that distinct parts of the subject have been taken up by

1 Comptes Rendus, t. lix, p. 393, 1864.

2 Loc. cit., p. 396. As will subsequently be seen, some of these conclusions are no longer tenable.

${ }^{3} \mathrm{Dr}$. Crisp writes: 'As I deseribed in my work on the spleen (1852), dogs, cats, ferrets and pigs, that ate the flesil of these animals, died in a short time, and men that flayed the oxen were affected. In $1832 \mathrm{M}$. Barthelemy inoculated sheep from the biood of sheep that died of splenic apoplexy, and the inoculated animals died in from thirty-six to sixty lours.'-A footnote to the Remarks made regarding the 'Germ Theory' at the Pathologicul Society, 24 th April 1875. 
observers peculiarly qualified to deal with the different phases of the extremely complex phenomena which come under notice. In the first instance, notice will be taken of the principal observations which are considered to give support to MM. Davaine and Pasteur's views.

In 1875 Professor Ferdinand Cohn published the result of his examinations Professor Cohn's Bacillus anthra. of these or-

ganisms, and having pronounced them to be bacilli, suggested that they should bcar the name Bacillus anthracis. ${ }^{1}$ This term has been generally adopted in Germany and England, as, notwithstanding the theory implied in both words, it is convenient to have some such brief designation. Cohn's figure of this bacillus is reproduced (fig. 3), as a graphic representation from the hand

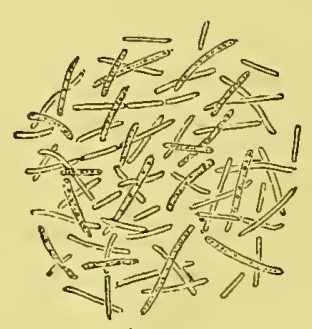

FIG. 3 - . $\times 600$ diam.

Bacillus anthracis, obtained, after death, in the blood of an ox which had died of splenic disease. (After Cohn.) of so accomplished a mycologist, is of special value, and will serve to aid in forming an estimate of the relation of these organisms to others found under other, though somewhat similar, conditions.

In 1876 an important contribution to our knowledge of these organisms was published by Dr. Koch of Wollstein (Posen), Dr. Koch's researches: some ob- who had had excellent opportunities of studying
jections which, had been raised who hand
against Davaine's conclusions.

the disease. ${ }^{2}$ Koch had observed that several of the statements and conclusions of M. Davaine had been called in question. Some observers had been able to induce fatal charbon by inoculating animals with bacteridial blood without obtaining any bacteridia ${ }^{2}$ in the blood of the animal thus affected, although the latter (bacteridia-free) blood had also induced the disease, and, moreover, given rise to bacteridia in the third animal, although none lad been present in the second. Others, again, maintained that the disease was not due solely to contagion, but was, somehow, dependent on the soil, seeing tliat the disease was only endemic in moist, swampy districts, valleys,

${ }^{1}$ Cobı's Beiträge zur Biologie der Pfanzen, Band. I, Heft. 3, 1875.

${ }^{2}$ Cohu's Beiträge, Baud. II, Heft. 2. 
and sea-coasts ; and that the mortality was greater in rainy years, and especially during August and September, months in which the temperature of the soil reached its highest. These circumstances could not be explained on Davaine's supposition that the organisms, retaining their vitality for a long time in dry air, were conveyed by air currents, or that inoculation was effected by insects, and so forth. Koch's experiments lead him to believe that Davaine's explanation of the mode of propagation of the disease is only partially correct. He found that bacteridia-staves were not so hardy as Davaine had supposed. Blood which contains only rods will retain its property in the dry state for but a few weeks, and when moist only for a few days. How, therefore, could the contagion remain dormant in the soil for months and years? If bacteridia had anything to do with the matter, it must be assumed that during some stages of their develnpment they were inert, or that, as Cohn had suggested, ${ }^{1}$ resting spores were formed which had the power of retaining their vitality for a long time, and of giving rise anew to bacteridia. The existence of such spores is what Dr. Koch believes he has been able to demonstrate. As this question is a very important one, it is necessary that the evidence adduced should be submitted to careful examination.

The experiments of Davaine and others were repeated, mice having been found to furnish the most satisfactory results. The tail The effect of the virus on mice.

was seized, and a small portion of its skin being abraded, a drop of the fluid containing the bacilli was placed in contact with the small wound. Such inoculations proved to be invariably fatal when fresh material was used. In order partly to ascertain whether the bacilli passed into some other form by successive inoculations, and also to provide himself with a constant supply of fresh material, he inoculated one mouse after another, the last mouse supplying the material for its successor, until eventually a series of twenty inoculations had been conducted: consequently twenty crops of bacilli had been cultivated without any marked change in their character being noticeable. ${ }^{2}$ The pathological results were always of the same character-enlarged spleen, and motionless, translucent bacilli (fig. 4). The latter in mice were more numerous in the spleen than in the blood, but different animals shewed different results as regards their distribution in the tissues-the blood of inocu-

${ }^{1}$ Cohn's Beiträge, Band. 1, Heft. 3.

2 Davaine had conducted a similar series of inoculations. 
lated rabbits, for example, being often so free from them as to be traced with difficulty, though the spleen and glands contained plenty, whereas in guineapigs the number of bacilli in the blood was often so great as to equal, if not exceed, that of the red blood-corpuscles.

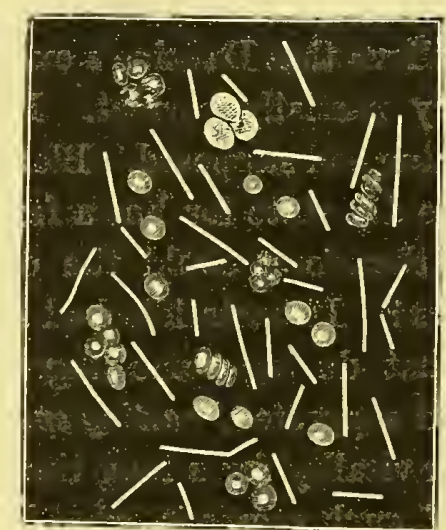

FIG. 4

Bacillus anthracis from the blood of a guinea. pig: Translucent bacillus-rods, undergoing segmentation. Blood-corpuscles are scattered throughout the field. (After Koch.)

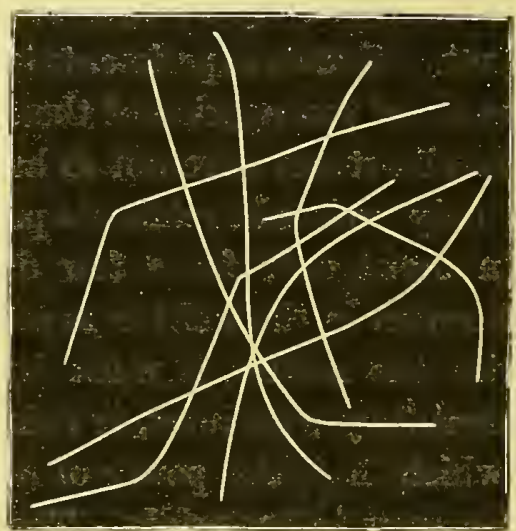

FIG. 5 . . $\times 650$ diam.

Bacillus anthracis from the spleen of a mouse after a 3-hour 'cultivation' in a drop of aqueous humor. (After Koch.)

On adding a little of the spleen affected with bacilli to perfectly fresh Cultivation of the bacilli. aqueous humor and subjecting the preparation to a temperature of $35-37^{\circ} \mathrm{C}$. for from 15 to 20 hours, the bacilli became elongated to from twice to eight times their original length, and gradually still further increased, till more than a hundred times this length (fig. 5). Some of the filaments now were finely granular, and, here and there, dotted, with strongly refractive molecules, which are believed to be the desired ' resting-spores.' Very soon nothing remained visible but these 'spores,' as the filament appeared to undergo solution, but the persistence of the arrangement of the former in rows is sufficiently marked to identify them. They will remain unaltered in this state for several weeks.

It will be remarked that the interpretation placed on the character of these refringent bodies clashes with what is so strongly The 'spores' of bacilli. maintained by Nägeli, who, as mentioned already, declares emphatically that the group of lower organisms to which these belong multiply solely by fission. It is, therefore, of greater importance to note 
precisely what the facts adduced are, to prove that in this special instance germinating spores are produced.

Dr. Koch states that the fact of his being able to induce splenic fever, together with a plentiful crop of bacilli in the blood, with fluid in which not a trace of a bacillus filament is any longer to be found-the minute refractive corpuscles alone remaining, is proof sufficient to shew that the latter are in reality spores, and not prorlucts of disintegration merely. Cultivation-experiments were, however, also undertaken, and it was found that in the course of 3 to 4 hours the development of these bodies could be observed under suitable conditions. On careful examination each 'spore' is seen to be an oval-shaped body embedded in a translucent substance which appears to surround the former in a ring-like fashion, but is seen to be in reality spherical, on being rolled over. This substance loses its spherical form and becomes elongated at one end in the direction of the long axis of the contained 'spore.' The latter remains at one end, and very soon the translucent tube assumes a filamentous aspect and, contemporaneously, the 'spore' becomes less refringent, pale and small, and possibly breaks down into fragments, until it eventually disappears completely.' Dr. Koch's figure (fig. 6), representing the various stages of the supposed germination-process, is reproduced.

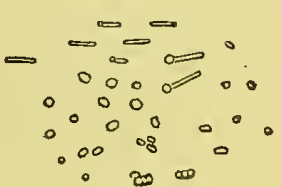

Fig. 6 .

Bacillus anthracis: Germination of the spores. (After Koch.)

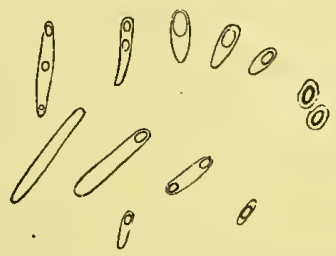

Fig. 7 . . $\times 1,650$ diam. Bacillus anthracis : Germination of the spores. (After Cohn.)

This interpretation of what occurs is made particularly important from the fact that it has been resorted to very. lately by M. Pasteur to account for the circumstance that, although it has been proved, beyond all reasonable doubt, that splenic fever, together with blood-bacilli, may be induced by inoculation with virus after the total destruction of the filament-bacillus which the morbid material had contained, yet because the 'spores' remained (it would seem that they are considered nearly indestructible) the virus had retained its property - the 'spores' in fact being the virus. 
Professor Cohn favoured Dr. Koch with a sketch of the same developmental process as seen undcr a higher power. This figure is also reproduced for purposes of comparison. Koch suggests that probably tlie 'spore' consists of a strongly refractive substance, probably oil, which is enveloped by a thin layer of protoplasm-the latter being the substance capable of germination, and the former, perhaps, serving as nourishment during the germinating process. The foregoing, according to various writers, represents the complete cycle of development undergone by Bacillus anthracis.

Davaine, it will be recollected, had found that animals eating diseased tisVirus, according to Koch, inert sues mixed up with their food became themselves affected, and he believed that the spread of the in alimentary canal.

disease could thus to some extent be easily accounted for. Koch, on the contrary, finds that animals very susceptible to infection by inoculation, such as mice and rabbits, may devour such a mixture with impunity. Attempts to inoculate two dogs, a partridge, and a sparrow, proved fruitless.

The latest contribution which has been made towards this enquiry is from the pen of Dr. J. Cossar Ewart. ' Dr. Ewart confirms Dr.J.Cossar Ewart's experiments. Dr. Koch's experiments in many points, and his description of the development of the rods into filaments [fig. 8, and fig. 9, (a)] corresponds with that of previous writers; but his description and figures of

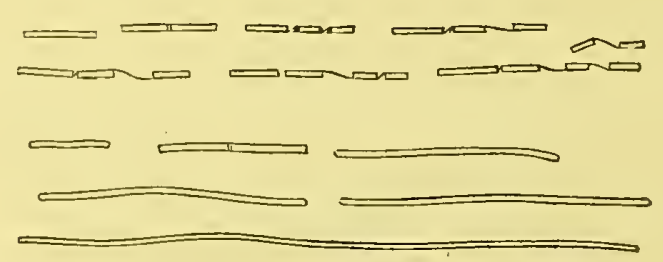

FIG. 8 . . . $\times$ ? diam.

Bacillus anthracis: Rods undergoing segmentation and lengthening into a filament. (After Ewart.)

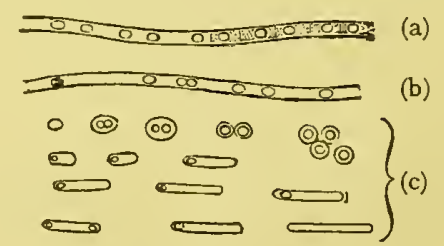

FIG. 9 . . $\times$ ? diam.

Bacillus anthracis: (a) A filament containing spores, becoming granular at one end, and shew. ing transverse lines between the spores; (b) Part of a filament containing a spore in process of division; (c) shews the different stages through which a spore passes in its development into a rod. (After Ewart.)

the germination of the 'spores' are totaliy different. 'The spores,' writes Dr. Ewart, ' when free, according to previous observers, at once grow into rods; 
and, according to Koch at least, the rod is formed out of a gelatinous-looking envelope surrounding the spore. My observations lead me to bclieve that the spore does not always at once grow into a rod, but that it divides into four sporules by a process of division, in which the envelope as well as the spore takes part. This division I have seen beginning before the spore escaped from the filament [fig. 9, (b)], and that it is not a degeneration is certain, for I have watched the sporules thus formed lengthen into rods [fig. 9, (c)]. Dr. Koch states that the rods are developed from the gelatinouslooking capsule, and not from the bright, shining spore. From what I have seen I think there can be no doubt whatever that the capsule takes no active part during the formation of the rod. The sporule thus slightly elongites [fig. 10], and then from one of its poles an opaque process appears, which, as it

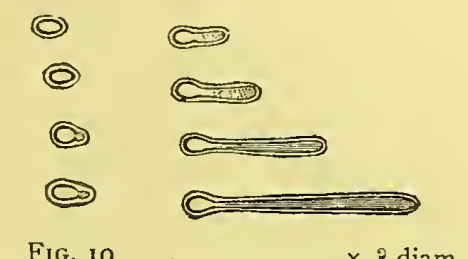

Bacillus anthracis: A sporule developing into a rod. (After Ewart.) slowly lengthens, pushes the capsule before it, as it would an elastic membrane. The capsule, as this stretching goes on, becomes at last so thin and transparent that it can no longer be distinguished from its contents.'

It is, I think, extremely probable that MM. Cohn and Koch may suggest as an explanation of the discrepancy between their description and figures and those given by $\mathrm{Dr}$. Ewart, that the latter has described and figured the spore (or conidium) of a totally different plant, accidentally present; and MM. Nägeli and de Bary would (in the absence of exact data as to size) in all probability pronounce the germination depicted in the last figure reproduced as being that of a conidium of one or other of our ubiquitous moulds.

Like Koch, Dr. Ewart found that mice could be fed with splenic-disease Recognition of 'spores,' of Bacil. material mixed with their food without any evil effects ensuing, and that 'the spores may be found in the alimentary canal of such mice, sometimes as if in process of development into rods and filaments.' With reference to the last remark, a person constantly engaged in microscopic work may question whether it is possible to distinguish these glistening free 'spores' from the myriads of other glistening molecules found in the intestinal canal of all animals. 
Contrary to the results hitherto obtained and published by others in support

Bacillus anthracis no longer to be considered motionless, nor capable of resisting boiling water or com. pressed oxygen.

at certain stages, they manifest active movements, so that the strongest argument which has hitherto been adduced in favour of these organisms being a peculiar species has disappeared. ${ }^{1}$

Dr. Ewart found also that the bacilli of splenic fever in guinea-pigs differed in size from similar bodies in affected mice, the bacilli of the former being always longer than those of the latter. It was also ascertained that the bacilli and their 'spores' were killed after being boiled for only two minutes, the fluid after this treatment becoming absolutely inert. A like result ensued on similar fluid being subjected to a pressure of twelve atmospheres of oxygen. ${ }^{2}$ Considering the position into which the supporters of the germ doctrine had latterly been driven by their antagonists, the announcement made above regarding the instability of the 'spores' will be unwelcome and none the less so by the circumstance of its having been made by one of their warm adherents.

A few years ago Mons. P. Bert announced that he had ascertained that compressed oxygen rapidly kills all living beings and Mons. P. Bert's researches. tissues. He had paid special attention to ferments in the investigations which he had conducted and had satisfied himself that such of the fermentation-processes as were dependent on living matter were immediately suspended when subjected to this influence, whereas those fermentations which were due to some material in solution, such as diastase, pancreatine, myrosine, emulsine, \&c., were in no way affected. He then turned his attention to certain poisons secreted in health or disease in animals, the venomous secretion of the scorpion, vaccine matter, \&c. ${ }^{3}$

\footnotetext{
${ }^{1}$ Since this was written I have observed that $\mathbf{A}$. Frisch had on three occasions seen independent movernents of the staves of Bacillus anthracis in blood obtained immediately after the death of the animals.-Centralblatt fur die wissensch. Medicin, April 7, 1877, page 247.

2 Since this was in type a note has appeared in the Comptes Rendus (15th July 1878) which confirms this observation. M. Felz found that compressed oxygen if applied for a sufficiently long period killed the 'germs' as well as the 'vibrions' of septic solutions.

3 Comples Rendus, t. Ixxxiv, p. 1130, May 1877.
} 
The venom of the scorpion, whether liquid or dried and re-dissolved in water, resisted the action of compressed oxygen, Fffect of compressed oxygen on scorpion venom, vaccine and gland. as was expected, since it owes its activity to a chemical substance akin to the regetable alkaloids. Fresh liquid vaccine matter was submitted for a week to the action of compressed oxygen and still retained its power undiminished. Pus from a case of glanders after being subjected to similar treatment rapidly killed a horse inoculated with it; hence M. Bert infers that the active principle in vaccine and in glanders is not a living being or living cell.

M. Bert then exposed some blood from a case of splenic fever (in which Fffect of compressed oxygen on were myriads of bacilli) to the action of compressed oxygen, and found that, although the blood had been exposed in very thin layers, it had retained its virulent properties intact, as was proved by its having killed several guinea-pigs inoculated one from the other, but the blood of these animals did not contain bacilli.

He submitted some other charbon-blood containing numerous bacilli to further examination. Some absolute alcohol was very cautiously added to it, drop by drop, until the Effect of absolute alcohol on
charbon-blood. volume of the original fluid was quadrupled, and the mixture thus obtained
was filtered. The coagulum, well washed in alcohol, was rapidly dried in vacuo. A fragment of this dried material, on being inserted beneath the skin of a guinea-pig, killed the animal in less than 24 hours. The blood obtained from this animal proved fatal to another guinea-pig, as also to a dog. Inoculations were conducted from one animal to another, but the virulent blood of none of these animals contained bacilli.

M. Bert went still further. A watery solution was prepared (by exhaustion) of the alcoholic precipitate, and having satisfied himself that this liquid contained the active principle in solution (for, on the addition of more alcohol, a white flocculent precipitate was induced), three successive inoculations of guinea-pigs were conducted. This rather severe treatment, however, had manifestly diminished the virulence of the material, as inoculation was not successful beyond the third animal, and the material proved too weak to kill a dog.

From these observations M. Bert concluded that the blood in splenic fever contains a toxic and virulent principle, which resists the action of compressed oxygen and can be isolated in the same manner as diastase. 
These observations had been published in an abbreviated form previous to M. Pasteur's researches as to M. Pasteur's researches as to
charbon: cultivation-experiments. their being submitted to the Academy. ${ }^{1}$ M. Yasteur had promptly taken up the subject, and, as he himself was not versed in the medical and veterinary arts, had associated himself with M. Joubert of the Collége Rollin for the purpose of more satisfactorily dealing with the matter. Their joint paper ${ }^{2}$ was published a few weeks before the publication of the details of M. Bert's experiments; it was their remarks, indeed, which led to the latter being published. They obtained charbon-blood and made numerous cultivations of it - transplanting it from vessel to vessel or from animal to animal. Outside the body it was found that almost any fluid adapted to the nourishment of minute organisms was suitable to the cultivation of the bacilli-' one of the best and most easily obtained in a pure state being urine made ncutral or slightly alkaline.' In this way, it is affirmed, poisonous bacilli could be prepared by the kilogram, if required, in the course of a few hours. When the material was filtered, the clear fluid was found to be inert, even though from 10 to 80 drops were taken, whereas a single drop of the same unfiltered proved fatal to the inoculated animal : licnce it is inferred that the organisms were left behind on the filter and were the cause of their death. ${ }^{3}$

The foregoing paper was followed by another in July $1877^{4}$ by the same

The vitality of the "spores" of bacillus anthracis.

authors, in which it is stated that they had repeated M. Bert's experiments and found that he was perfectly correct as to the destruction of the bacilli and of the poisonous property of charbon-blood at a certain stage under the influence of compressed oxygen, and that, too, even with but a moderate amount of pressure; but that when the bacilli had proceeded to the formation of spores, they withstood the heat of boiling water, the prolonged action of absolute alcohol, as also the influence of

1 Comptes Rendus de la Societé de Biologie, January 1877.

2 Comptes Rendus, t. lxxxiv, p. 900, April 1877.

3 A siuilar result was obtained by $\mathbf{M}$. Onimus, but the iuterpretation was very different. M. Ouimus found that if the blood of au ox, horse, or persou sufferiug from 'typhoid fever,' be placed in

Dialysis of putrid blood. a dialyser, aud the latter placed iu distilled water at a tempcrature of $35^{\circ} \mathrm{C}$., a prodigious quantity of organisms would appear, identical iu appearance with those iu the putrefying blood. But whereas all the animals which were inoculated with a drop of the blood contained in the dialyser died in a short time, those wlich were treated with the dialysed material (though crowded with organ. isms) were unaffected. The same result followed when putrefying blood from a rabbit was subjected to similar treatment. Hence M. Onimus iufers that the poisonous naterial is an albunoid substance, and therefore not clialysable (Bulletin de l'Académie de Médicine, March 1873. Cited by M. Cl. Robin in Leçons sur les Humeurs, p. 251, 1874). Cleusenti and Thin, Schmitz, Bergmann, and others, bave obtained more or less similar results.

${ }^{4}$ Comptes Rendus, t. $1 \times x \times v$, p. 101. 
compressed oxygen (=10 atmospheres for 21 days). The 'spores,' therefore, are most remarkable organisms, seeing that they withstand influences which are destructive to every other form of vegetable or animal life. True 'invisible germs' are accredited with this marvellous power, but, as yet these 'spores' are the only visible bodies for which such persistent vitality has been claimed by eminent authorities. Now, however, that it has been shewn by Dr. Cossar Ewart that they are not more exempt from ' the tendency to death' than other organisms of a like kind, seeing that they can neither withstand the action of compressed oxygen nor boiling, it is probable that MM. Pasteur, Koch, and their adherents will apply the doctrine at present fashionable, and aver that, though the 'spores' may be dead, their invisible germs still live, and, under favourable circumstances, will re-appear.

With the foregoing explanation as to the difference between bacilli and their 'spores,' in their power of withstanding agenM. Bert is convinced that the "spores' can withstand the action cies ordinarily destructive to life, M. Pasteur was able to convince his former pupil, M. Bert, of the cause of the discrepancies in their respective results, and this the more readily from the circumstance that when a little of the dried alcoholic precipitate of charbon-blood was placed in urine the fluid not only manifested virulent properties, but also gave rise to a plentiful crop of bacillus-filaments identical in appearance with those which had existed in the blood previous to its being treated with alcohol.

It does not seem to have occurred either to M. Pasteur or to M. Bert that under certain circumstances the addition of any dried organic substance to suitable urine would probably be followed by a crop of bacillus. Indeed, it not unfrequently-happens that such a crop may be obtained without intentionally adding anything.

Whilst this paper was in preparation it occurred to me to place such a Bacilli a common accompaniment sample of urine under different conditions as to temperature, \&c., and to carefully observe the results. Some specimens were made slightly alkaline, others made neutral, and others again left untouched. All the specimens were kept at temperatures varying from $35^{\circ}$ to $40^{\circ} \mathrm{C}$. (95 to $104^{\circ} \mathrm{Fahr}$.), and it was found on the following day that nearly half the specimens were coated with a thin pellicle consisting of 
bacilli in all stages of development, the spore-stage included, notwithstanding that considerable care had been taken to keep out particles and foreign matter of every description. These appearances are familiar to all who have devoted much attention to microscopic studies. It need hardly be added that organisms thus obtained would produce no effect on animals if freed from the decomposed urine.

\section{B.-The Vegetable Organisms in Septicæmia.}

The belief that septicæemia is produced by organisms belonging to the Septicæmia. lower group of fungi has had almost as many àdherents as the doctrine just considered; and the literature in support of it is even more extensive. The virus secreted by animals suffering from this disease is, when transferred to the circulation of other animals, as fatal in its results as that of charbon. It can, moreover, be transferred from animal to animal ${ }^{1}$ almost indefinitely. The symptoms induced by such inoculation are frequently so very like those witnessed in splenic fever that it is often impossible satisfactorily to distinguish them. There is, however, this marked distinction, namely, that whereas the presence of organisms in the blood before death is; to a greater or less extent, the rule in what is known as cliarbon, it is the exception in septic poisoning. The fluid exuded into the peritoneal cavity, and frequently also into the pericardial sac, is peculiarly prone to give rise to the development of various forms of fission-fungi, and the abundance with which they are sometimes found very shortly after death has given rise to the doctrine that they were the initiatory agencies by which the fatal results were produced.

The publication of Panum's experiments, which went to shew that the active morbid principle in such fluids could not by any possibility be vitalised, served for a time to diminish the popularity of such views, but they have since been revived again and again, and never with a greater shew of circumstantiality than has recently been the case in a paper submitted by MM. Pasteur and Joubert before the French Academy. This paper, notwithstanding

1 Observations illustrative of this have long been known. Hamnnt, for example, in 1827 injected matter from a gangrenous abscess from one horse to another aud from the inoculated horse to a second horse, and found that denth resulted with pretty much the same symptoms iu both cases.-MM. Coze and Feltz, in Les Maladies Infectieuses, p. $58,1872$. 
that it exceeded the prescribed length, was, on account of the importance attached to it by the Academy, published in extenso. ${ }^{1}$

The paper deals in the first place with M. Bert's experiments, and explains M. Bert and $\mathbf{M M}$. Jaillard and the discrepancies between M. Bert and M. Davaine's results in connection with charbon-blood, as already described. But it goes further than this. It will be recollected that the toxic material submitted to experiments by M. Bert did not give rise to bacilli in the blood, although its virulent properties were most marked, and the possibility of inoculating the disease from animal to animal without bacilli was quite as manifest as in charbon-fluid crowded with them. Similar results have been published by many observers ; for instance, ML. Jaillard and Laplat did so very soon after. Dr. Davaine's paper was read in 1863, and formulated their conclusions in this wise: (1) charbon is not a parasitic disease; (2) the presence of bacteridia is to be considered as an epi-phenomenon, and not as a cause; and (3) that the fewer bacteridia the blood in sang de rate contains, the more virulent it is. It thus became common to hear of cases of charbon with, and cases without, bacteridia.

Davaine has also shewn that the virulent properties of the virus of septicæmia manifest a marked increase when transferred Davaine on effects of successive inoculations of septinous exudafrom animal to animal. It had been found that after twenty-five such successive inoculations, a millionth, and even a billionth or trillionth, part of the original poison was sufficient to produce death. Rabbits were found to be very susceptible; guineapigs somewhat less so. Rats were found to be capable of resisting a considerable quantity. It was also observed by Davaine that decomposing blood lost its virulent properties when exposed to the air in a few days; out of 27 animals inoculated with 1 to $\frac{1}{100}$ th of a drop of blood, which had stood from 1 to 10 days, 12 died, whereas out of 26 animals inoculated with like material which had stood from 11 to 60 days only 1 perished. ${ }^{2}$

M. Pasteur, bearing in mind the difference between bacilli of charbon and M. Pasteur on the 'vibrions' of their 'spores' as regards tenacity of life, determined septicæmia. to ascertain whether a similar condition did not

1 Comptes Rendus, t. Ixxxv, p. 101, 16th July 1877.

2 'Inoculation de la matière septique :' Bulletin de l'Académie de Science, November 1872, January 1873; cited by Birch-Hirschfeld, loc, cit., page 173. 
exist in septicæmia. Three animals which had died of charbon were examined-a sheep, dead 6 hours; a horse, dead 20 to 24 hours; and a cow, dead over 48 hours. The blood of the sheep, which had only recently died, contained charbon-bacteridia only; that of the horse bacteridia, together with 'vibrions de putréfaction;' whereas that of the cow contained only 'vibrions' of the kind last mentioned.

Inoculations with the blood of all three animals were followed by death. The autopsies (conducted immediately after death) of the guinea-pigs which had died after inoculation with material from the two last-mentioned animals, revealed extensive inflammation of the muscies of the abdomen and limbs, with accumulations of gas lere and there, the liver and lungs discoloured, the spleen normal in size, but often diffluent; the blood of the heart not coagulated, although this characteristic was more evident in the liver-quite as evident as in any case of charbon. Strange to say, writes M. Pasteur, the inflamed muscles contained mobile 'vibrions;' these were still more numerous in the serosity of the abdominal cavity, and some of them were of great length. ${ }^{1}$ A drop of this fluid would rapidly kill an inoculated animal, but ten or twenty had no effect after it had been filtered. The 'vibrions' are not found in the blood till after or very shortly before death, and such blood is said to manifest no virulent properties if taken direct from the heart without contamination with the tissues outside it.

'The movements of these ' vibrions' were stopped on subjecting them to The action of compressed oxygen the action of compressed oxygen, but they were not and alcohol on septic-vibrions.

killed, because on coming into contact with the oxygen they were transformed into corpuscles-germes, the 'spores' of Dr. Koch. This, it may be remarked in passing, is a novel and rapid method of producing reproductive elements in plants.

Not only do these 'vibrions' of septicæmia withstand the action of compressed oxygen, or rather become transferred by its action from perishable filaments to apparently imperishable corpuscles-germes, but they, like the 'spores' in charbon, also withstand the action of absolute alcohol. Hence, M. Pasteur'

\footnotetext{
1 M. Pasteur, on noticing this condition, asks why it is that a circumstance so general in deaths of this kind had hitherto escaped notice; and replies to the query, that it was doubtless owing to the attention of previous observers having been devoted solely to the blood. It seems strange that M. Pasteur's specially selected collaborateur, and adviser in medical matter's, did not iuform him that this very appeuravee was about the best known of all the phenomena characterising septic poisoning.
} 
infers that septicæmia, as well as charbon, is caused by organisms-the parasite of the former being mobile, but that of the latter not.

It will be more convenient to analyse these results hereafter.

\section{C.-Vegetable Organisms in Pneumo-enteritis 'Typhoid-fever'-of the Pig.}

In February of the present year Dr. E. Klein, F.R.S., brought before the Dr. Klein on a bacillus in pneumoRoyal Society a portion of the result of an experimental enquiry (which had been conducted for the Medical Officer of the Local Government Board) into the etiology of a disease sometimes described as typhoid ferer of the pig, also as hog plague, mal rouge, red soldier, and malignant erysipelas. Dr. Klein, however, proposes to shew that the disease is not typhoid fever, nor anthrax, but an infectious disease of its own kind, which he proposes to call 'infectious pneumo-enteritis' of the pig (Pneumo-enteritis contagiosa). ${ }^{1}$ The disease appears to present considerable pathological resemblance to septicæmia and to charbon, except that, as regards the latter, the fresh blood does not, as a rule, contain any foreign matter, and in most instances does not possess any infectious property. Of five animals inoculated with the fresh blood, one only was affected, but the specimen of blood which produced this retained its activity when closed in a capillary tube for several weeks. The peritoneal exudation, however, always contains the virus in an active state, and solid lymph obtained from such an exudation will, if dried at about $38^{\circ} \mathrm{C}$., prove active. This accords pretty closely with what has usually been observed in septicæmia. Inoculation can also be effected by means of portions of diseased lung, intestine, or spleen, as also with the frothy sanguinous exudation in the bronchi, and infection may take place when the virus is introduced directly into the stomach.

It would seem that like organisms were discovered by Leisering some Character of the Bacilli previously found associated with Pigeighteen years ago, in apparently the same affection of the pig as that now described by Dr. Klein.

Dr. Falke, in referring to the bacilli of splenic-fever, and after alluding to the circumstance that Delafond had been able to induce the disease in other animals by inoculating them with $\frac{1}{20}$ th of a drop of bacillus-blood, states that

\footnotetext{
1 'Experimental Contribution to the Etiology of Infectious Diseases with special reference to the Doctrine of Contagium Vivum :' Quarterly Journal of Microscopical Science, April 1878, p. 170.
} 
Iueisering, in his Dresden Report for 1860, mentions that it is quite correct that such bacilli are found in the blood in splenic disease, but that he (Leisering) had also found that they were present in four pigs which had suffered from wellmarked typhus (abdominalis) with ulcers in the intestines and swelled follicles. ${ }^{1}$ There is no indication here that the bacilli seen by Dr. Leisering in pig-typhoid differed in appearance from those which he had seen in charbon; on the contrary, he seems to assume that they are identical, and hence questions their being pathognomonic of the latter disease.

Seven cultivation-experiments were conducted by Dr. Klein of the bacilli observed by him 'to prove that the virus can be cultivated artificially, $i$. e., outside the body of the Cultivation-and inoculation-ex periments. animal.' Minute portions of peritoneal exudation were added to aqueous
humor on a glass slide in the usual manner and kept at temperatures ranging from $32^{\circ}$ to $39^{\circ} \mathrm{C}$. for a day or two; then a portion of the cultivated substance was transferred to a second slide with fresh aqueous humor, and so on till from a third to an eighth generation was reached. With material thus obtained. seven animals were inoculated at different stages of the cultivations. All the animals are described as having been affected, but it would appear that death did not result. Doubtless further information as to the symptoms, \&c., manifested by the inoculated pigs will be furnished when full details of the experiments are published. In the meantime it may, however, be noted that it is not mentioned that bacilli were found in the blood of the inoculated animals.

Dr. Klein states that the cultivated liquids proved, on microscopic examination, to be 'the seat of the growth and development of a kind of bacterium which has all the characters of Bacillus subtilis (Cohn)'-a figure of which, copied from Cohn's paper, will be found on another page (fig. 14). The rods of the pig-bacillus (fig. 11) are referred to as being thinner than those described by Cohn as occurring in hay solutions, also thinner than those of the Bacillus anthracis, and, unlike the latter (according to Davaine, Pasteur, Koch,

\footnotetext{
1 'Bericht über die Thierurzneiwissenschaft,' Schmidt's Jahrbücher. Band. 114, p. 131. The original is as fol. lows: 'Leisering sngt im Dresdner Bericht f. 1860, dass man nach den vorliegenden Beobachtungen mit Recht annehmen könne, dass im Milzbrandblute diese eigenthümlichen Körperchen stets vorkoınmen. Er habe jedoch dieselben auch bei vier Schweinen gcfunden, welche an ausgeprägtem Typhus litten, der mit Darmgeschwüren, geschwelten Follikeln, blassgraulicher Färbung dcr Musklen und keiner Blutüberfüllung der Eingcweide einherging.'-Cited by Professor Klob in his Pathologisch-Anatomische Studien über das Wesen des Cholera-Processes : Leipzig, 1867.
} 
and others) possess a moving stage. ${ }^{1}$ It will, however, be recollected that $\mathrm{Dr}$. Ewart has shewn that Bacillus anthracis may also manifest very active movements. Under favourable circumstances the filaments grow into leptothrix-like filaments (fig. 12) just as other bacilli are known to do.

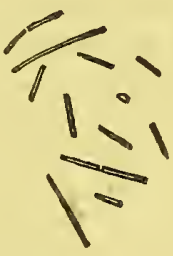

FIG. II.

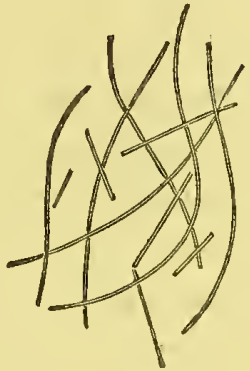

FIG. 12

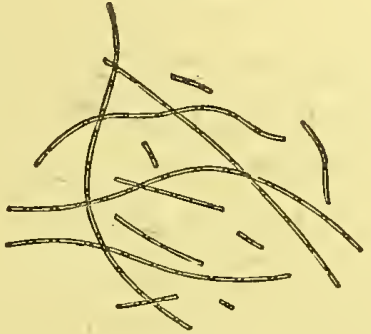

FIG. I3.

FIG. II. - The Bacillus of infectious Pneumo-enteritis of the pig, cultivated in aqueous humor of rabbit, shewing spores germinating into rods, isolated rods, and series of rods.

FIg. 12.-From a similar specimen, as in fig. II, at a later stage; most of the rods have grown into long filaments.

FIG. 13.-Shewing the formation of bright cylindrical spores in the filaments at a later stage.

The drawings are represented as the objects appear when seen under a Zeiss's F objective; and Hartnack's III eye-piece, fitted to a Hartnack's small stand. (After Klein.)

'In these filaments,' writes Dr. Klein, 'highly refractive spores make their The 'spores' of the pig-bacillus.

appearances (fig. 13). These become free after the disintegration of the original filamentous matrix. The fully developed spores of our bacillus differ from those of hay-bacillus and anthrax bacillus by being more distinctly cylindrical and much smaller.' In a footnote it is mentioned that in the figures accompanying Koch's first paper in Cohn's Beiträge (1876) 'the spores are represented in many places as more or less spherical in shape;' but if the very valuable micro-photographs of these bodies accompanying Koch's subsequent paper ${ }^{2}$ be referred to, it will be found that the 'spores' are very decidedly of a long-oval form. The pig-bacillus 'spores' have according to Klein a long diameter of $0.0005 \mathrm{~mm}$. , whereas those of anthrax $=0.0015$ - $002 \mathrm{~mm}$. 'At first,' writes Dr. Klein, 'I misinterpreted

1 The letters A, B, used in the original figures (as given in the Microscropical Journal) appear to have become accidentally transposed by the lithographer, as what is referred to in the text under ' $\Delta$, Bacillus of infecticus $P$ neumo. enteritis of the pig, cultivated in aqueous humor, shewing spores germinating into rods, isolated rods, and series of rods,' evidently refers to $B$ in the plate, and not to the figure marked $\mathbf{A}$.

${ }^{2}$ Cohn's Beiträge, Band. II, Heft. 3, Taf. xvi 1877. 
the spores, regarding them as a kind of micrococci, and only after repeated observations have I succeeded in tracing them through their different stages of development.' Unfortunately Dr. Klein has not detailed the grounds on which this very important statement is based, nor are figures given. It can scarcely be supposed that any of the figures in the plate are intended to represent the germination of a particular spore. As this distinguished observer well knows, it is not what takes place before the supposed germination, or after it, which has been the subject of debate for so many years in connection with the development of the schizomycetes, but the act itself. None of the figures furnished by Dr. Klein present any resemblance to Dr. Ewart's germination-figure (fig. 10) in which this process is unmistakeably depicted, but some of them are somewhat like those of Koch (fig. 6); on the other hand, Dr. Klein writes regarding the conclusions of the observer who first ventured to pronounce these bodies in Bacillus anthracis to be spores, 'I entirely differ from Dr. Koch with regard to the mode of germination of the spores of bacillus.' The points of difference are matters of secondary moment and need not be specially referred to here.

Dr. Klein concludes his paper thus: 'Seeing that splenic fever, pneumoenteritis, and specific septicæmia possess a great affinity in anatomical respects, and seeing that in splenic fever and pneumo-enteritis there is a definite species of bacillus,-the difference of species being sufficiently great to account for the differences in the two diseases,-we may with some probability expect that also the third of the group, viz., specific septicæmia, is due to a bacillus. ${ }^{1}$ This, however, remains to be demonstrated.'

Dr. Klein, therefore, believes that whilst the evidence adduced by himself in support of the cause of pneumo-enteritis in the pig being a bacillus is sufficient to warrant a positive statement in the affirmative, that adduced by Davaine, Pasteur, and others in favour of a like cause for septicæmia is not.

\section{D.-The Vegetable Organisms in the Blood in Recurrent Fever.}

There is one other disease in which vegetable organisms have been found in the blood, namely, recurrent fever (Febris The spirillum of recurrent fever. or Typhus recurrens). In this affection also the organisms belong to the lower fungi-group, the schizomycete,-that is to say, 
the fungi which multiply by cleavage, in contradistinction to the groups which multiply (1) by sprouting or (2) by germination. The fission-fungi, however, present themselves in this disease in a different form from that witnessed in the preceding, anthracoid, class of affections. In the latter the organisms recognisable range from the spherical bacterium to the bacillus or vibrio-bacillus form, -the bacillus being by far the predominating form; but in recurrent fever the representative of the schizomycetes is a spirillum-a form of the fission-fungi which, so far as I am aware, has not hitherto been detected in any of the anthracoid affections referred to in the preceding pages.

We owe the discovery of this organism in the blood to Virchow's former Obermeier's researches. assistant, the late Dr. Obermeier. They were found in the blood and also in the mouth of persons suffering from this form of fever, and minutely described by him in 1873. ${ }^{1}$ It would appear that this observer had already seen them as far back as 1868. In all the cases observed by him they were present in the blood during the height of the fever, but were absent during the remission or intermission, as the case might be; nor were they observed, except rarely, after the crisis. Obermeier describes them as fine fibrine-like threads, equal in length to the diameter of from $1 \frac{1}{2}$ to 6 red blood-corpuscles; and manifesting screwlike, progressive movements, which may continue from one to eight hours after removal from the body. The inoculative experiments which he undertook, consisting of the injection of spirillum-blood of fever patients into the veins of dogs, rabbits, and guinea-pigs, proved abortive, nor was there any effect produced by the injection, by means of a subcutaneous syringe, of small quantities of such blood into the bodies of healthy persons.

Obermeier's observations as to the existence of the spirilla in blood in this kind of fever were speedily confirmed by numerous observers, and the negative results which followed his attempts at inoculating persons and animals likewise characterised the attempts of several who followed in his footsteps. Motschutkowsky, however, states that, although he also had failed to inoculate animals, yet he had succeeded in inoculating persons with the blood of patients suffering from the fever, no matter whether it contained spirilla or not. ${ }^{2}$

\footnotetext{
1 Centralblatt für die medivinische. Wissenschaften, No. 10, March 1873, and in subsequent numbers during the same year.

2 Heydcureich : 'Ueber den Parasiten des Rückfallstyphus,' S. 38, 1877.
} 
It was, however, soon found that whereas spirilla could generally be detected Spirilla not invariably present in in cases of fever of this kind, nevertheless cases every now and then occurred in which perfectly competent observers failed to detect them in the blood from first to :last, and this too in cases not a whit less severe than those in which the organisms abounded and which were under the care of the same observers during the same period.

Some discrepancy exists in the results of different observers as to the presence of spirilla during apyrexia periods, as well as regards their absence during the height of the paroxysm; Birch-Hirschfeld, for example, observed them two days after the crisis ${ }^{1}$; and Laskousky, basing his observations on thirty-two cases, says that they increase contemporaneously with increase of temperature ${ }^{2}$; whereas Heydenreich maintains that high temperature tends to destroy themhe having found that not only were they most numerous in the blood shortly before the fever was at its height, but that, also, outside of the body they would retain their movements longer in a room at $18^{\circ}$ to $21^{\circ} \mathrm{C}$. than at a higher tempcrature. He had been able to keep active spirilla in a preparation from a weck to a fortnight at this temperature, whereas the spirilla died in from $\mathbf{1 5}$ to 21 hours when kept at blood heat $\left(37^{\circ}-38^{\circ} \mathrm{C}\right.$.). At $40^{\circ}-41^{\circ}$. C. they were found to perish still sooner,-namely, in from 4 to 12 hours. ${ }^{3}$

Although, as above shewn, they can be preserved alive for a comparatively long time outside the body, nevertheless every attempt which has been made to 'cultivate' them has proved abortive; no change has been observed to take place in them either in size or in number, notwithstanding that they have been 'cultivated' in media of various kinds and at different temperatures.

\section{E.-The relation of Microphytes to Disease.}

In the preccding sections the leading facts regarding the connection of living organisms with the occurrence of disease The questions to be considered before accepting the doctrine that have been detailed; it now remains to consider what grounds there are forbidding the adoption of the doctrine of a germ theory of disease;-why, for example, we should not at

\footnotetext{
1 Schmidt's Jahrbücher, Band. 116, S. 211, 1875.

${ }^{2}$ Heydenreich's Rückfallstyphus, page 39.

${ }^{3}$ Loc. cit., pages $100 \& 101$.
} 
once admit that splenic disease is caused by bacteria-rods, and that the aim of treatment should be the destruction of the vitality of those rods; or that recurrent fever is caused by screw-bacteria, and such remedial measures resorted to as tend to destroy them.

Before such views can serve as the basis of anything like rational treatment it must be shewn: (1) either that these organisms, as ordinarily met with, are injurious when introduced into the animal economy; or, (2) that the forms found in disease are in some respects morphologically different from those known to be innocuous, - such a difference, at least, as Virchow suggests, as exists between hemlock and parsley. ${ }^{1}$

With regard to the first point, it has been shewn over and over again that all the representatives of the group of fission-fungi Innocuous character of ordinary schizomycetes when introduced into the system. can be introduced into the system with the greatest impunity. Not only is their complete innocuousness practically put to the test by every individual at every meal, but observations have been published which have conclusively demonstrated that they may be introduced directly, into the blood by injection into the veins, or indirectly, through the lymphatics in the subcutaneous tissue, without the slightest evil consequences. These facts are so well known and generally accepted that it is not necessary to refer to special observations.

With regard to the second question, however, diametrically opposite opinions are held,-all the advocates of the germ Disease-schizomycetes assumed to be morphologically different from the others.

theory, with very few exceptions, maintaining that the particular organism, in the particular disease in which they are specially interested, is wholly distinct frorn all others ; that is, if the organism happens to be anything more definite than a granule or molecule. The diseases which have been specially cited in the previous pages as being associated with microphytes may be divided, roughly, into two classes according to the form of the attendant microphyte-the septinous group, consisting of malignant pustule, septicæmia, and the malignant erysipelas or 'typhoid' of the pig on the one hand; and a low form of fever commonly known as Typhus recurrent, Bilious remittent, \&c., on the other. 
With reference to the organisms which have been found associated with The Bacteridia of Charbon said the first-named group, taking Malignant Pustule as not to be a peculiar plant. the type, it is to be observed that M. Robin ${ }^{1}$ in 1865 pronounced the bacteridia of Davaine to be identical with Leptothrix buccalis; and the well-known botanist Hoffmann has stated his opinion that they do not differ from like bodies which appear in milk and in meat solutions. ${ }^{2}$ Ferdinand Cohn, ${ }^{3}$ again, in his observations as to the growth of bodies of the same character in hay solutions, declares that the bacilli in the latter are identical in

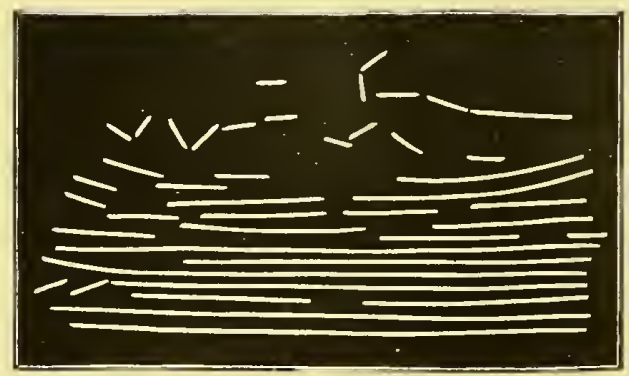

FIG. 14 . . . $\times 650$ diam.

Bacillus subtilis: formed on the surface of a boiled infusion of hay which had stood 24 to 48 hours. (After Cohn.)

form and size with those found in splenic disease, and that the various stages in their development correspond in every particular-the only difference which distinguished them being that, whereas Bacillus anthracis presented no movements, the bacillus of hay solutions did. This distinction, as lias already been stated, has disappeared. Colnn's figure of the hay-bacillus is reproduced (fig. 14), as it may, in the absence of the original paper, prove useful to such as would wish to get a clear conception of what Bacillus anthracis itself is like by examining so easily obtainable a substance as a little of the scum which forms on the surface of an infusion of hay.

F.-The Vegetable Organisms found in Healthy Blood after death considered in relation to the Bacteria and Bacilli of Diseases.

Several years ago Dr. Cunningham and myself were, whilst conducting The Bacilli of ordinary decomposvarious observations together, frequently struck with the rapidity with which organisms appeared

2 Birch-Hirschfeld, loc, cit., page 206.

${ }^{3}$ Cobn's Beiträge, Band. II, Heft. 3, 1877. 
in the blood and tissues of animals after death in this country. These microphytes were not limited to minute spherical and elongated bacteria, but there were also present well-marked staves and filaments. In a report submitted by us in 1872, and again in 1874, ${ }^{1}$ we drew attention to this matter and suggested the similarity between them and Davaine's bacteridia. A figure of these organisms, which were published by us at the time, is here reproduced (fig. 15).

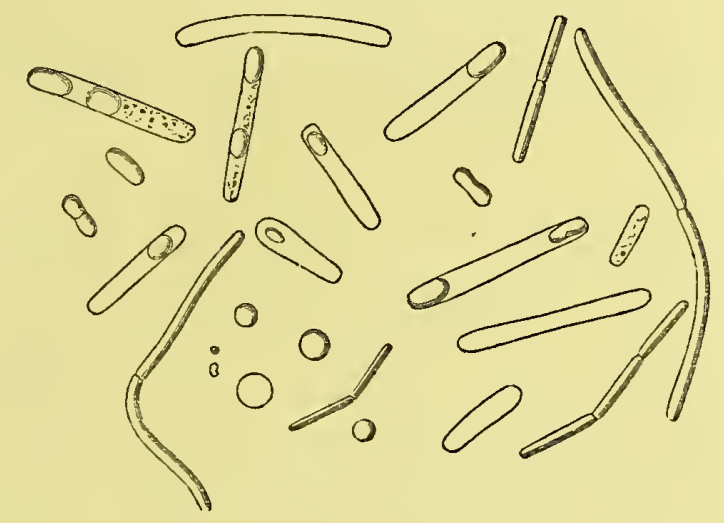

FIG. 15. . . . . . . 1,500 diam.

Organisms found in the tissues of healthy animals a few hours after death.

A short time ago a circumstance occurred which drew my attention again Bacilli in Anthracoid disease in in a special manner to these organisms. Mr. Hart, a Veterinary Surgeon in Calcutta, forwarded to me for examination a little perfectly fresh blood which he had removed from a horse which had died that day of well-marked anthracoid disease. His curiosity had been aroused as to the microscopical characters of the blood by perusing an account, in the Veterinary Journal, of 'worms' having been found in the blood of horses suffering from a similar affection in the Punjab. A slide was prepared and examined under the microscope at once, but no marked peculiarity could be detected, but when this and other slides were re-examined twelve hours later, having in the meanwhile been kept under a bell-glass, numerous staves and filaments were observed, which, as to size and form, accurately corresponded with the description of like bodies characterising the blood in anthracoid diseases in Europe. 
Several 'cultivations' were started by adding a little of the blood to fresh aqueous humor. The preparations were then set aside for a few hours in a moist chamber. As the temperature of the atmosphere at that time was generally over $90^{\circ} \mathrm{F}$., no special appliances were necessary for supplying artificial heat. The development of the rods into filaments and subsequent appearance of highly refractive oval bodics in the latter corresponded so completely with what Cohn, Koch, Ewart, and others have described, that it is not necessary to give figures of the changes that took place. A series of such cultivations was conducted by transferring a little of the last cultivation to fresh aqueous humor, and so on from one preparation to another.

It was then determined to ascertain whether the bacilli found in the blood The rapid appearance of bacilli in of animals which had been set aside for a few hours the blood of asphyxiated animals. after death would manifest, under like conditions, similar changes during their growth. Rats were obtained, killed by means of chloroform, and set aside for from three to twenty-four hours, or longer, according as the temperature of the atmosphere was high or low. The result proved that, almost invariably, bacilli were to be found in their blood, in the spleen, and in other organs. On one occasion the rapid appearance of organisms after death was exemplified in a somewhat remarkable manner, and possibly the mode of death was not without some influence in determining their exceptionally early and plentiful appearance.

The man employed to procure the rats determined that he would get a sufficient number to last for some time, and proceeded to a large granary with his rat-traps. Having, however, found that he could procure more than could be accommodated in the cage which he had brought with him, he obtained a large earthen vessel, transferred twenty-seven rats into it, and tied a piece of cloth over the mouth of the vessel. As may be supposed, the rats had perished before he got home-all except one.

I cxamined the blood and the spleen of twenty of these rats within about six to eight hours of their having been caught, and found in each case that there were innumcrable bacilli present, in every way morphologically identical with Bacillus anthracis. In some of the cases the number was astonishing. They were present chiefly in the form of rods, but here and there some were seen to have grown to such a lengtlı as to cover two fields of the microscope. 
This experience tends to give support to the statement made by M. Signol before the French Academy to the effect that motionless bacilli, identical with those found in charbon, will be found in sixteen hours or less after death in the blood of animals which have been asphyxiated by means of a charcoal fire. M. Signol, moreover, found that eighty drops of this blood would kill a goat or a sheep very rapidly, notwithstanding that putridity could not be detected, so far as appearance and odour went; but that bacilli would not be found in the blood of the inoculated animals, either bcfore or immediately after death. ${ }^{1}$

It has been urged that the microphytes which appear in the blood after The relation of the blood-bacilli death simply make their way into it from the intestinal canal as a result of the breaking down of the tissues. This objection is certainly no longer tenable, for many observers have shewn that if some of the organs be removed from the body immediately after death, or indeed isolated from the circulation whilst the animal is still alive and under the influence of chloroform, these organisms will nevertheless appear if the preparation be kept for some hours at a suitable temperature.

Some of the specimens of blood which furnished several of the preparations about to be described were obtained in this manner.

Paraffine-preparations. Rats, mice, kittens, \&c., were placed under chloroform, and either killed and placed on one side for some hours; or, whilst still under the influence of the chloroform, ligatures were passed around the several viscera so as to isolate them before death had taken place. Finally a ligature was passed around the vessels at the base of the heart, and the organ severed from the body.

The specimens thus procured were repeatedly dipped into either melted paraffine or wax, by means of the string attached to them. In this way they became coated something after the manner of the cotton wick of a candle. Preparations thus made were set aside for from 12 to 24 hours, according as the average temperature of the atmosphere was over or under $90^{\circ} \mathrm{F}$., and it was almost invariably found that organisms appeared in them, almost, if not quite, as rapidly as they appeared in the bodies of animals which had been simply set aside under like conditions. In the former case, however, the supposition that they were derived from the alimentary canal after death is not possible; nor can it 
well be maintained that they derived their germs from contact with the scalpel, string, \&c., seeing that the entire surface was exposed to the influence of melting paraffine or wax.

The first figure in Plate I represents a tracing of a micro-photograph of Tracing of micro-photograph of the bacilli obtained in the manner above described the bacilli of healthy tissues.

from the blood of a mouse, to all appearances perfectly healthy when killed. A little of the blood was spread in a thin layer on a glass cover and allowed to dry, then, a drop of a solution of aniline-blue, was added to the slide, so as to stain the microphytes and thus render them more distinctly visible when focussed in the camera. The photographs were obtained by means of a $\frac{1}{16}$ " object glass (immersion) made by Messrs. Powell and Lealand.

When first seen in the blood, the majority of these bacilliare motionless; in Character and size of these ba. some preparations completely so, but in others they can be observed to manifest more or less distinctly marked, independent movements. They vary in size-in length chiefly, according as their development into filaments has advanced. The average length of each rod is found to be either $5 \mu$ or $10 \mu{ }^{1}$ In the latter case a more or less distinctly marked bend will be recognisable indicative of a joint. In more advanced stages of growth, two, three, or more such joints may be detected, especially on the addition of re-agents, such as tincture of iodine. In this case the bacilli will measure either $15,20,25$, or more micro-millimeters. The length of these segments, whether attached or free, varies considerably in preparations from different animals, and even in preparations from the same animal; so that stares may be seen to range from 3 to $6 \mu$ in length, and occasionally eren to exceed these limits. The average width of the staves was $1 \mu$, but deviations from the average were equally evident in these measurements also. Sometimes it was found that the specimens present in one organ are smaller or larger than they are in another belonging to the same animal.

If a very minute quantity of blood of this character be placed on a slide with a little aqueous humor, it will be found that Cultivation of the bacilli of orin the course of 4 or 5 hours, if the temperature be

\footnotetext{
${ }^{1} \mu=$ micro-millimeter $(\cdot 001 \mathrm{~mm})$. This mode of stativg the measurements is adopted in connection with this series of observations for convenience of comparison with like observations regarding Bacillus anthracis. It will be convenient to remember that the average size of a human red blood-corpuscle $=8 \mu$.
} 

PLATE I.

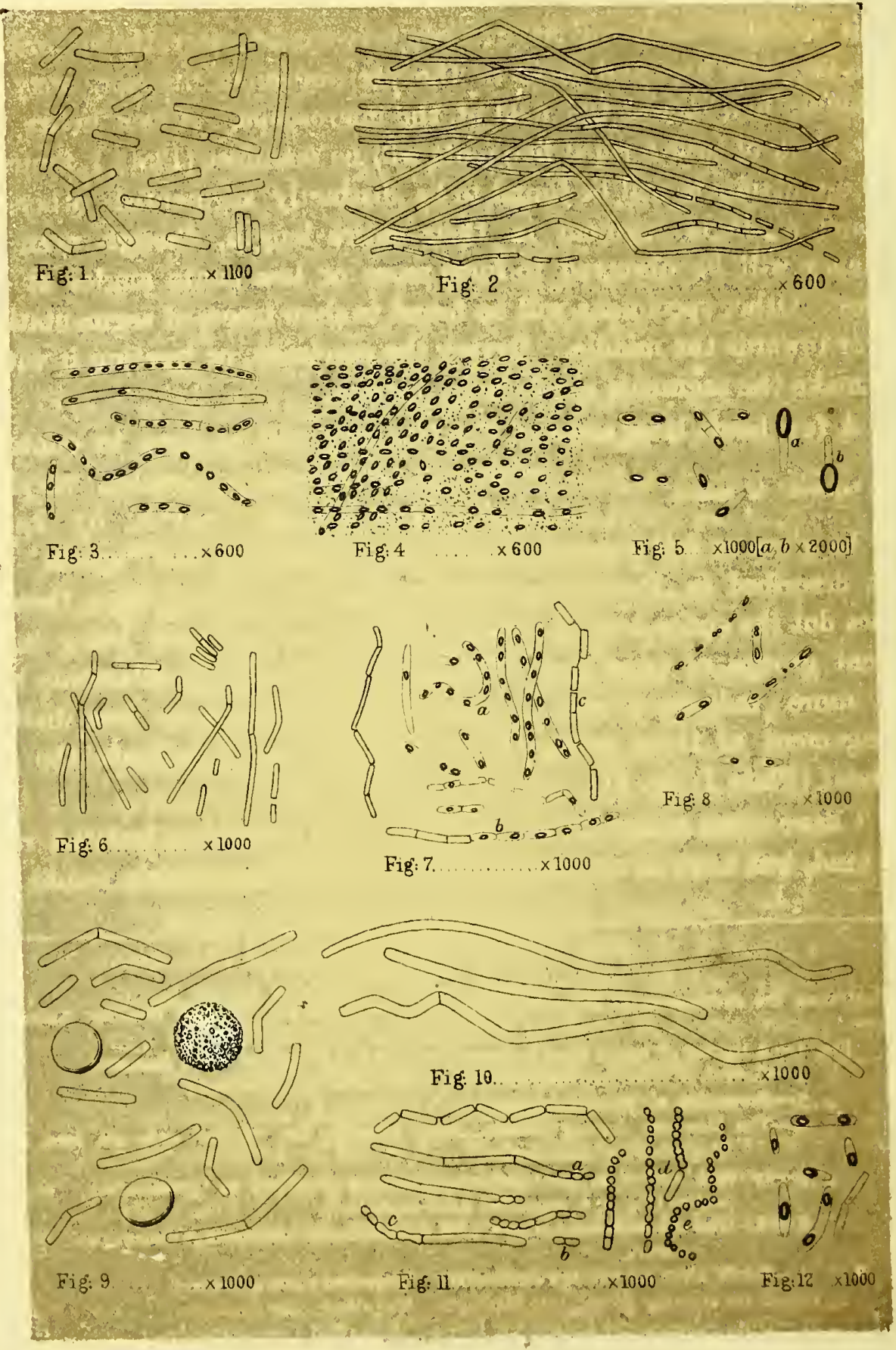

T R. Lewis, ac̀ nat. del.

DEVELOPMENTAL STAGES OF ORGANISMS FOUND IN THE BLOOD OF IIEALTHY ANIMALS SHORTLY AFTER DEATH. 
about $90^{\circ}$, the bacilli will have grown very considerably, the majority measuring 20 to $60 \mu$, and here and there in the preparation a filament may be observed stretching half across the field of the microscope. A few hours later still, a mesh-work of well-formed filaments will be manifest (Plate I, figure 2). Some of these filaments will be found to be distinctly segmented, others apparently without a single segment in their entire length, though even in these a tendency will be observed to form more or less acute angles at certain distances. Other specimens will be found to shew traces of segmentation at either end or towards the middle. Drying the specimen, or treating it with re-agents, will make the segments much more distinct.

A few hours later some of the filaments will be seen to contain brightly refringent, long-oval molecules, varying slightly The 'spores' of bacilli. in size, but $1 \cdot 2 \mu$ in length, by $1 \mu$ in width, may be given as fair average dimensions. These are the 'spores' which have been described in Bacillus anthracis, \&c. In a short time these refringent bodies dot the entire length of the filaments, a tendency being manifested to present groups of twos along the line. Gradually the filaments become more and more indistinct, until, finally, only the more or less distinctly linear arrangement of these refringent bodies remains to indicate the path of the filament (Plate I, fig. 3).

I have spent many hours, days even, in watching isolated molecules of this kind, but have never been able to see anything which would warrant my

PLATE I, death :-

Illustrating the developmental stages of Organisms found in the Blood of Healthy Animals shortly after

FIG. I.-A tracing of bacilli from a micro-photograph. Magnified I, 100 diameters.

„2.-Growth of ditto into long filaments. Magnified 600 diameters.

"3.-Formation of 'spores' in ditto.

" 4.-The filaments having become nearly invisible, the 'spores' only are seen, arranged linearly. Magnified 600 diameters.

" 5.-Isolated 'spores' in the condition sometimes described as 'germinating.' Magnified $\mathbf{I}, 000$ dia. meters (Fig. $a, b$, magnified 2,000 diameters).

„6 to 8. - The developmental stages of a bacillus below the average dimensions. Magnified I,000 diameters.

" 9.-Bacilli above the average dimensions. Magnified $\mathrm{I}, 000$ diameters.

"1 10.-Ditto shewing growth into filaments. Magnified 1,000 diameters.

1, 11.-Ditto subsequently undergoing fission. Magnified 1,000 diameters.

"12.-Spore-like bodies which formed in a portion of the filaments delineated at fig. Io. Magnified $\mathbf{I}, 000$ diameters. 
saying positively that they germinated: I can only support what Nägeli, de Bary, and others have persistently affirmed, namely, that the Schizomycetes multiply by fission only. The bodies described and figured as germinating by Cohn, Koch, and others (figs. 6,7 ) may be seen in most preparations, some of which will be found figured by myself in Plate I, fig. 5, but, so far as my experience goes, none of the objects delineated represent the germination of 'spores' or conidia; certainly, here and there, bodies may be seen which at first sight appear very like it,- such, for example, as the refringent molecule figured at $5 a$ as seen by Powell and Lealand's one-sixteenth immersion,-but frequently the extremely translucent filament attached to it extends beyond the 'spore' at either end (fig. 5 b), thus shewing that the filament is not formed of plasma which had proceeded out of the spore, but is, in reality, a tube enveloping it. It has been observed already that the observers who maintain that these refractive bodies germinate, base thcir opinions on different grounds. Their figures in most cases agree, but their interpretations differ.

It may be suggested that, although the bacilli found in the decomposing blood of healthy animals do produce spores, they are not of the same character as the spores found in Bacillus anthracis. To this it may be replied that Cohn states that the spores in the latter are identical in appearance and run through the same developmental stages as the spores of the Bacillus subtilis of hay-solutions, so that the remarks which I have ventured to make regarding the 'spores' of the bacillus of ordinary blood apply equally to bacillus of hay-infusions, for I have been unsuccessful in witnessing anything like the germination-process in the 'spores' of the latter also. Nor were the 'spores' which formed in bacilli associated with the anthracoid-blood of the horse, observed to germinate.

With regard to specific distinctions which have been based on the differThe question of specific distincences of size which microphytes of this character tions among bacilli based on size. present-specific distinctions which, in all probability, will be still further advocated in the future-it is of intcrest to note that the bacilli found in the blood and tissues of animals which, at the period immediately preceding their death, had been perfectly healthy, manifest considerable latitude in this respect. The following extracts from my note-book may serve as illustrations of this, and, at the same time, furnish a brief epitome of the changes which bacilli-filaments undergo under very slightly varying circumstances. The first series of extracts will refer to bacilli of a smaller size than ordinarily 
seen. The notes run as follows:- Killed two mice yesterday and exam'Cultivation" of small bacilliined one of them to-day, 24 hours after death. The red blood-cells from blood taken from the heart fairly well preserved. Numerous short bacilli present-motionless. The spleen also crowded with similar bacilli. They appear to be of a smaller size than are usually met with, the segments averaging only $2.5 \mu$ in length by 8 to $\mathbf{1}_{\mu}$ in breadth; though, in many of the rods, indications of segmentation could not be detected, or detected only in parts of them. The segments became more evident on drying, so that measurements could be accurately made. The sketch opposite page 41 has been drawn accurately to scale (vide Plate I, figure 6). A drop of aqueous humor was placed on a cover-glass and a needle dipped into the spleen, and then applied to the droplet of humor. The cover was inverted and placed on a glass slide, hollowed in the centre, a little olive oil having been placed along the rim of the hollow to maintain the cover in its position. Another specimen was prepared and mounted on a slide in the ordinary way $(i . e$., without access to air except along the edge of the cover-glass), and both were set aside until the following day.'

The course taken by the latter preparation is described as follows: "The "ordinary" preparation of yesterday's note was Second day: found to have altered somewhat. At one side of the slide a number of bacterium termo had developed, forming a whitish rim; along with these were staves of the same character as described yestesday, but considerably grown, which were being knocked about in all directions by the bacteria. The greater portion of the preparation had gone on to "spore" formation, as figured at $a$, Plate I, figure 7. In others the filaments and joints were still distinct and presented a protoplasmic aspect (b). Many of the filaments were held together by very slender cords, sometimes as if by one corner only, probably owing to a twisting of the tube ; at others the continuation of the tube was distinct $(c)$. [Compare this description with the figures of bacillus anthracis reproduced from Dr. Cossar Ewart's paper, figures 8 and 9.] Here and there filaments could be seen in a transition stage, a "spore" having formed in each segment, the joint being still faintly visible, but the plasma disappeared except at one or two parts-generally the end-segments of a thread $(d)$. Commonly the separated segments contained two "spores," 
presumably coinciding with the original number of segments. The threads are wider when containing "spores" than previously. The "spores" $=1$ to $1 \cdot 4 \mu$ in length, by 8 to $l_{u}$ in breadth. The space allotted to each "spore" in a filament, presumably each segment, was from 6 to $7 \mu$ in length, so that a filament containing 2 "spores" would equal 12 to $14 \mu$, and 3 "spores" $=18$ to $21 \mu$, and so on, so that the filament manifestly swells out in all directions.'

The third day: 'Having set the slide in moist air under a bell-glass, evapoThird day: ration was prevented. Not much change has taken place, except that here and there it is seen that some of the "spores" within the filaments present a longer appearance, and have become correspondingly narrower. In some a constriction is seen, and others are completely divided and form two minute molecules (Plate I, figure 8). In some instances the molecules had become separated. [Compare with Dr. Ewart's figure of bacillus anthracis, figure 9.] That the refringent particles were in reality the "spores" of the previously distinctly seen filaments was evident from the circumstance that, although the hyaline tube which contained them was extremely translucent and only with difficulty brought into view, still it was sufficiently strong to be able to retain these refractive molecules in a row; any movement communicated to one part of the row was seen to be accompanied by movement of the entirc series. The movements were caused by the constant agitation of objects in the field on account of the presence of bacterium termo.'

No further changc could be detected in the 'spores.'

The foregoing description, though applying to the more generally observed Large-size bacilli : modifying inIarge-size bacilli : modifying
fluences of cultivating media; appearances which bacillus growths present, is by no means the only course taken by such organisms when transferred to nutritive media other than that in which they were developed, nor is it by any means a matter of certainty, at starting, what particular course will be followed by them. In illustration of this and also of the fact that, occasionally, exceptionally large bacilli are to bc found predominating in the blood (just as we have seen to be the case with regard to exceptionally small ones), the following extract from my note-book may bc instructive:A rat which had been killed at 10 o'clock in the morning was dissected at 5 in the afternoon of the same day. The temperaCultivation-first day. ture had becn about $94^{\circ} \mathrm{F}$. The heart was carefully taken out and a minute quantity of blood transferred, 
on the tip of a scalpel, to a slide. A small quantity of a half per cent. solution of salt and distilled water was added, in order to dilute the preparation, and, by separating the corpuscles, render it easier to see any foreign matters that might exist in the serum. There were numerous motionless bacilli varying from 4 to $20 \mu$ in length by 8 to $1 \cdot 4 \mu$ in width, the thicker variety predominating (Plate I, fig. 9). The majority consisted of short stiff rods, $5.5 \mu$ in length, or double this length; in the latter case often manifesting indications of a tendency to bend towards the centre. There were also a few thicker rods than these scattered throughout the preparation. An hour having been spent in the examination of this slide, it became apparent that the bacilli were more numerous on it than when the examination commenced. It was then set aside in a moist chamber.

A similar slide was prepared consisting of just a trace of the blood mixed with fresh aqueous humor, and placed in the same chamber.

On the following morning this slide, to which the half per cent. salt solution had been added, was re-examined, and it was found Slide with salt solution added to that the filaments had grown greatly in length and somewhat in thickness (Plate I, fig. 10); in some instances the filaments extended across the field of the microscope. All the filaments were motionless and almost translucent, quite devoid of granularity, and it was only in some places that a joint could be distinguished. No refringent molecule appeared in any of- these long filaments, but there were some short, pale, transparent rods rolling about in the preparation, and in these glistening bodies were found (Plate I, fig. 12). Some of these rods, or segments, were $8 \mu$ long and contained a bright blue (as seen with Hartnack's No. 9 immersion objective) 'spore,' $2 \mu$ in length by $1 \mu$ in width, and other segments, about the same length, contained two. Mixed with these were short, translucent stares, with a distinct joint, some with two 'spores,' separated by a partition, and others shorter $(4: 5 \mu)$ with only one. By the next day the filaments were broken down and the preparation consisted chiefly of a multitude of active Bacterium termo.

The other slide, which had been prepared with aqueous humor, was likewise examined on the following day. The filaments Slide with aqueous humor added were not so long as in the other preparation, and there appeared to be a decided tendency towards cleavage into small cuboid pellets of plasma (Plate I, fig. 11, $a$ ). Some of the 
filaments, though well preserved at one end, were secn to be undergoing the process of fission at the other, each fragment being equal to $1-1 \cdot 2 \mu$ in its longest diameter. It seemed as if the 4 to $5 \mu$-segments, of which the filaments were composed, had first become freed from the thread, and had, instead of giving rise to a 'spore,' undergone fission (fig. 11, b). In other cases cleavage of this kind took place whilst the individual segments maintained their linear arrangement (fig. 11, c). In some instances it seemed as if the two first halves of the originally 4 to $5 \mu$-segments had each become elongated (and correspondingly thinner) and undergone further division, thus forming four more or less spherical plastides (fig. 11, d). When the whole filament had undergone such a process and the plastides had retained their linear arrangement, it presented the appearance of a rosary chain (fig. 11,e). It was ascertained that four of the plastides forming a part of the particular chain sketched were equal to the length of one of the segments of the original filament, viz., $5 \mu$.

It will thus be seen that filaments of bacilli may disappear, at least, in two ways: (1) by giving rise to minute highly Bacillus-filaments may disappear refractive, long-oval molecules, the filaments themselves becoming at first transparent, and then, apparently, disappearing more or less completely ; and (2) by undergoing cleavage, and giving rise to minute plastides. These may, occasionally, be observed to present a rosary-chain arrangement, but usually their identification becomes impossible owing to their mixing with other molecules in the field.

I am not in a position to offer any suggestion as to which is the normal course for bacilli to take, seeing that bacillus-filaments may re-develop under suitable conditions from material derived from preparations in which either of the two foregoing processes has been observed to take place. Probably, to a greater or less extent, both processes occur together; at least it is seldom that filaments will give rise to the bright, refractive molecules, in a highly nutritious fluid, without a contemporaneous formation of plastides taking place at some part of the preparation.

G.-The relation of the Spirillum of Recurrent Fever to other known Spirilla.

Having thus endeavoured to prove that no sufficient grounds have been Spirillum Obermeieri. adduced for accepting the doctrine that bacilli have been found in splenic disease, septicæmia and 
so forth, which differ, not only in any material respects, but in any respects whatsoever, from bacilli which may be found under certain easily induced conditions, it remains to be seen what evidence there exists to shew that the other member of the schizomycetes group found in recurrent fever-Spirillum Obermeieri-differs from other spirilla known to be harmless.

On this point also considerable divcrsity of opinion exists, though perhaps not quite to so marked an extent as with respect to the microphytes which have just been considered. The matter is, moreover, made somewhat simpler from the circumstance that those who have had the greatest opportunities for personal observation are, on the wholc, the observers least inclined to claim for this spirillum specific characters in the ordinary botanical sense of the term.

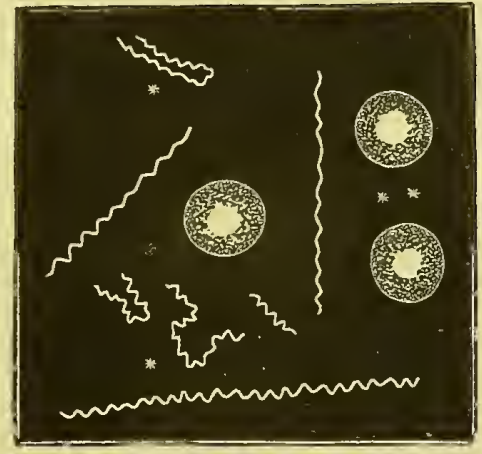

FIG. 16

$\times 600$ diam.

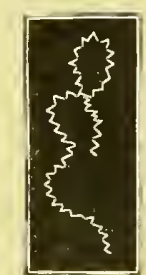

F1G. $17 . \quad \times 650$ diam.

Spirillum (Spirochaete) plicatile. (After Cohn.)

Spirillum (Spirochcete) Obermeieri. The spirilla among blood-cells * * in active movement. Those marked * sketched a short time before the cessation of the fever. (After Weigert; published by Cohn.)

Since the period of its discovery in the blood by Obermcier it has been Synonyms. referred to under various names: Spirothrix, Protomycetum recurrentis, in Lebert's article on recurrent fever and in Ziemssen's 'Handbuch' of Medicinc; Spirillum by Erichsen, Litten, Birch-Hirschfeld, \&c.; Spirillum tenue by Naunyn; and Spirochaete Obermeieri by Cohn (fig. 16).

The last-named observer, and the only one with an extended botanical experience, gave it a specific distinction solely on physiological grounds, as, after careful examination, he was unable to detect any difference, either of size or in character of movements, between the spirillum of recurrent fever- 
blood and Spirillum (Spirochaete) plicatile, which had been found by Ehrenberg in water many years ago. ${ }^{1}$ Cohn himself had subsequently found it in water, and also in the mouth-in the mucous surrounding the teeth. ${ }^{2}$ A, figure of this spirillum by $\mathrm{Cohn}$ is reproduced for convenience of comparison ${ }^{3}$ (fig. 17).

It will be recollected that the late Dr. Obermeier himself had recognised the spirillum in the mucous from the mouth of Spirilla observed under various conditions. recurrent fever patients, possibly having overlooked the circumstance that its presence in this fluid was not an abnormality. Manasseïn, ${ }^{4}$ whọ, at St. Petersburg, has had favourable opportunities for observation, expresses himself most strongly against the supposition that this microphyte is anything more than an epi-phenomenon in recurrent fever. Not only was it absent from the blood in certain of the cases of fever examined by himself and others, but spirilla precisely similar to those found in other cases were, during a period of some months, constantly present in the secretion which flowed on pressure from an abscess which opened into the mouth of a fever-free patient. Billroth also states that similar spirilla were found in connection with caries of bone.

Heydenreich, who probably has investigated this matter as carefully as any observer, and written the fullest account of it which has come under my notice, notwithstanding his manifest desire to claim for the spirillum a causative relation to the disease, is, nevertheless, compelled to own that sufficient reason has not been shewn to warrant its being described as specifically different from the spirillum of water and the ordinary spirillum of the mouth. ${ }^{5}$

In May 1877 I had an opportunity of observing cases of fever in Bombay in which Dr. Vandyke Carter had demonstrated the The spirillum-fever of Bombay. existence of spirillar organisms in the blood. Dr.

1 Cohn's Beiträge; Band. I, Heft. 3, 1875, p. 197.

2 Ditto, Band. I, Heft. 2, 1872, p. 180.

3 Ehrenberg suggested that the term Spirillum should be restricted to such of the Schizomycetes as manifested spiral movements without flexibility, and for those of the group which were distinctly flexible he proposed the term Spirochate. As, however, the distinction is merely a matter of degree, spirilla also manifesting a greater or less amount of flexibility, I have adhered to Dujardin's classification. Fomental (Etude sur les Microzoaires, 1874) adopts the older and simpler term for a like reason.

${ }^{4}$ St. Petersburg. medicin. Wochenschrift. No. 18, 1876.

5 Op. cit., page 31 . 
Carter has recently published an interesting account of his observations. These, as far as the abstract of the paper submitted to the Pathological Society shews, coincide closely with like observations in Europe. During my stay in Bombay I had an opportunity of examining twenty-five cases of the disease, and observed the spirillum in five of these on several occasions. It could not, however, be said that the other subjective symptoms in these cases were more grave than in other cases of the fever, in which not a trace of the spirilla could be found.

One of the preparations of blood, containing these organisms, which I was able to preserve, is a particularly good one, and as it Osmic acid preparations of spirilla. was obtained by exposing the fluid immediately on its removal to the fumes of a weak solution of osmic acid, it may be considered as representing the spirilla exactly as they appeared in a perfectly fresh slide. The fumes of this acid, as has been stated by several observers, are particularly useful in preserving the natural appearance of these microphytes, as, indeed, of blood-preparations generally. Professor Ray Lankester, when rccommending its use to English observers, wrote: 'It is sufficient to expose a thin film of blood on a glass cover to the vapour arising from a bottle containing a two per cent. solution of osmic acid, during three minutes, to ensure its complete preservation. Every corpuscle thus becomes "set," as it were, in its living form ; there is no coagulation, no shrinking, no dissolution; but as the corpuscle was at the moment of exposure to the vapour, so it remains. The white corpuscles even exhibit their pseudopodial processes arrested in the act of movement. It is as though the osmic acid bottle contained a Gorgon's head, which freezes the corpuscles, as they face it, into stone.' ${ }^{2}$

I have prepared several micro-photographs of this slide in the hope of being able to supply facsimile copies of some of them Comparison of micro-photographs of Bombay-spirilla with those of St. with this paper. I fear, however, that it will not be practicable to obtain reproductions of the negatives by any of the permanent photographic processes practised in Europe in sufficient time to permit of their publication at present. - I have therefore caused tracings

The Lancet, June 1878.

${ }^{2}$ Quarterly Journal of Microscopic Science, vol, si, p. 370, 1871. 
of some of the leading forms to be made and have had them engraved on wood ${ }^{1}$ (fig. 18).

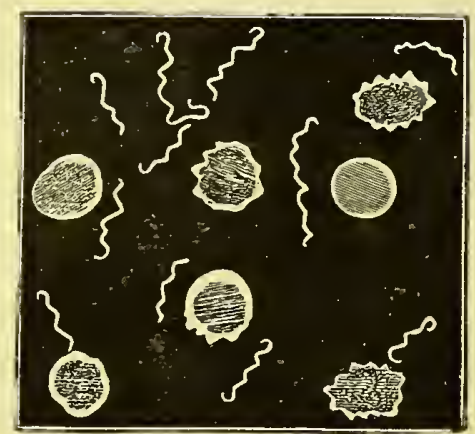

Fig. 18 - . . $\times 700$ diam.

Spirilla in the blood of fever-patients in Bombay: Traced from micro-photographs taken with Ross' $\frac{1}{12}$ " immersion objective. Some of the longer spirilla in the wood-cut are in the microphotographs seen to consist of two fibrils loosely attached at the ends. This peculiarity cannot be reproduced in the engraving. Several of the blood corpuscles present a stellate ap. pearance.

In the last number of Cohn's Beiträge (Band. II, Heft. 3), Dr. Koch has supplied some excellent permanent micro-photographs of the spirilla as observed at St. Petersburg. The spirilla in the osmic acid-preparation which I possess, though presenting the same general characters as those in Dr. Koch's photographs, are somewhat thicker than those depicted in the latter; whether this points to any slight difference in the blood between the fever which prevailed in Bombay last year and the fever which prevailed in St. Petersburg I am not prepared to say, but this much, I think, I may venture to state, namely, that the difference between the spirilla in the preparation in my possession, and those received from St. Petersburg, as photographed by Dr. Koch, or the spirilla sketched by Weigert (fig. 16), is as great as the difference which exists between the Spirillum Obermeieri and the Spirillum plicatile on the one hand, and the Spirillum of the mouth on the other. As has already been seen, thesc differences are exceedingly trivial, and it is quite possible that such slight differences may exist in these microphytes in different persons during the same epidemic, and at different times in the same individual, as has 
been shewn to be the case in the preceding pages with regard to the bacilli in the blood.

It may be useful to say a few words, in passing, regarding the fever which was so prevalent in Bombày during a great part of As to the supposed causal connection between the Spirillum. 1877, as some misapprehension appears to exist as to its exact character. What is described as recurrent fever, and sometimes as bilious typhus or bilious remittent fever, and recurrent typhus, in Germany, is frequently assumed in England to be the same as the 'relapsing-famine fever,' which was witnessed some years ago in Ireland and elsewhere. Whether in reality the latter fever was or was not the direct offspring of want is not a matter calling for comment here, but what is very definitely known is that outbreaks of recurrent fever in various parts of Russia and Germany, and which were found to be associated with spirilla in the blood, have occurred in districts wholly unassociated with want of any kind. In some cases, indeed, the outbreaks occurred in districts and during periods in which the labouring classes were exceptionally well off. This is a point concerning which no doubt whatever can exist. With regard to the supposed connection of the fever in Bombay with the famine which prevailed in certain parts of the country, I can only state that, so far as I could gather as the result of personal observation and careful enquiry, no sufficient grounds existed to warrant any such supposition; and Surgeon-General Hunter, after a most careful analysis of the official records, and writing from personal acquaintance with the disease, thus sums up his report on this particular point: 'Any distinct causal connection, therefore, between the famine and the fever must be abandoned.' 1

It thus follows that the term 'relapsing-famine fever' is not applicable to the affection hitherto associated with spirilla in the blood, whether in Germany, Russia, or Bombay.

\section{H.-The probabilities in favour of the Bacilli and Spirilla of the Blood being Epi- phenomena.}

There is one circumstance in connection with the microscopic appearance

The transformation of spirilla into which these organisms sometimes present which deserves special mention, as it may serve as an explanation of their sudden disappearance from the blood; and that is that 
they may present a well-marked beaded or rosary-chain appearance (fig. 19). This feature I was able to observe on one occasion only. The spirilla of the ordinary character were plentiful in this person's blood on the evening previous to the day on which this observation was made but when examined on the following morning there were only linked or rosary-chain spirilla in his blood. They were not very numerous and their movements were not of that rushing character ordinarily observed,

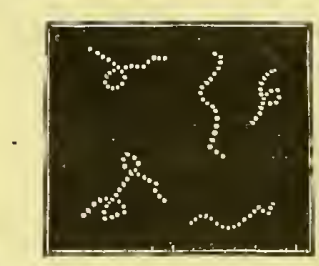

FIG. 19.-Beaded or rosary-chain appearance assumed by the spirilla found in the blood of a fever patient at Bombay (sketched as seen by Hartnack's immersion objective No. 9, ocular 4). but conveyed the impression of tumbling across the field.

The inference which such an observation appears to warrant is, that when the blood acquires a certain as yet undetermined condition it becomes unadapted to the existence of spirilla, and that the fibrils thereupon undergo segmentation, after the manner of other schizomycetes [compare with figure 11, Plate I], and the separated plastides become diffused throughout the circulation; possibly they then gradually disappear in the same manner as we have seen other plastides (minute bacteria, \&c.) disappear very rapidly after being injected into the circulation. This appears to me to be more probable than that they continue in the circulation until the blood re-acquires the state suitable to their growth into fibrils, seeing that the time for their return is so uncertain-it may be two days, may be six days or a fortnight even, and perhaps they may not return at all. Be that as it may, it is clearly evident that their existence as spirilla is dependent on the composition of the fluids of the body.

Heydenreich suggests that their disappearance is due to the elevated temperature of the blood at the height of a paroxysm. If that were the case, they ought to become more numerous with the fall of temperature after death, but it is well known that they disappear exceedingly rapidly when life becomes extinct, in this respect offering a marked contrast to other members of the cleftfungi group-bacteria and bacilli.

The fact of their total disappearance immediately after death, or probably

The disappearance of spirilla immediately before or shortly after death suggests that the initiatory
changes occur in the blood itself. even before death actually takes place, is very significant as shewing the extrcmely close relation which exists between them and the blood in living 
tissues, seeing that when the blood is removed from the body the spirilla will, under favourable conditions, retain their power of locomotion for several hours or days. What these subtle changes of the blood during fever-processes may be, chemistry and physiology have not yet revealed; wc can therefore only judge of them by the changes of the temperature, \&c., of the patient; and, in the particular condition under consideration by the occasional appearance and re-appearance of spirilla, whose presence is manifestly dependent on antecedent changes. That the temperature commences to rise and that other subjective symptoms are manifested before the appearance of spirilla testifies to this, for it cannot be that they can exert an influence bcfore they are themselves existent.

Dr. Charles Murchison, at the discussion on the germ-theory of disease at the Pathological Society, ${ }^{1}$ put this matter very Drs. Murchison and Bastian on the development of microphytes in the system as a result of disease. clearly when he said, "The fact that in relapsing fever and sheep-pox distinct forms of bacteria have been found in no way proves any causal relationship between these diseases and the bacteria, and is readily accounted for by the acknowledged fact that the form taken by many minute growths depends not upon the germ, but upon the nature of the medium in which it grows. Indeed, the observations which have been made on the spirilla of relapsing fever are strongly in favour of this view, for they are present in the blood during the first paroxysm, but disappear before the crisis; are absent during the intermission, but return with the relapse of fever, and again disappear before the crisis. It seems difficult to account for their appearance and annihilation twice over, except on the supposition that the soil was suitable for their development during the febrile process, and unsuitable when the febrile process was complete.' The remarks which Dr. Bastian made in opening the same discussion on his very interesting observation as to the presence of bacteria in the fluid of a blister-bleb of a febrile patient so long as the bleb remained intact for forty-eight hours, whereas in the fluid of a blister from a healthy person no such appearances would be seen, point in the same direction.

A like conclusion must be arrived at regarding the bacilli in malignant Bacilli not detected in the esrlier. pustule, septicæmia, and the so-called ' typhoid fever'. in the pig, horse, and other animals. With regard 
to the microphytes just named, it may be confidently stated that they are never to be detected in the earlier stages of the disease, but only at a brief period before and after a fatal termination. To my knowledge they have never been found in the blood of animals which have subsequently recovered; they have always been recognised only as one of the concomitants of impending dissolution. This is undoubtedly the case so far as the two diseases first cited are concerned, and judging from what is known regarding them, I presume that the development of such organisms in the blood of the inoculated pigs was not one of the symptoms which Dr. Klein had observed as indicative that the bacilli which had been introduced into the system of the animals had induced the disease. Should this inference prove to be correct, it is somewhat difficult to understand on what grounds so emphatic an opinion could have been expressed as to their specific action. It does not appear that Leisering in his account of like organisms, in apparently the same disease of the pig (as already mentioned), had found them in any but fatal cases.

\section{I.-The evidence which has been adduced shewing that the virulence of Septinous Substances is not dependent on vegetable life.}

Seeing that so much evidence can be adduced to shew that these organisms, whether bacilli or spirilla, are but epi-phenomena, Facts shewing that certain microphyte-free fluids will induce disthe specific change in the fluids of the body having taken place before the slightest indication of their presence can be detected, the question which naturally suggests itself is : whether sufficient evidence exists to shew that inoculations can be effected with like material in the absence of such living organisms. The reply to this question, so far as anthracoid and cognate diseases are concerned, is distinctly in the affirmative; but, with regard to recurrent fever, it cannot be as yet definitely stated that the malady is inoculable, so that for the present it may be left out of consideration.

When Brauell published his paper in Virchow's Archiv in 1858 detailing MM. Brauell, Bollinger, and Colin's his experiments to prove that splenic-fever was an inoculable discase, he further stated the opinion experiments. that the organisms found in the blood could not be the carriers of the virus,
seeing that blood not containing bacilli had been found to generate the disease. Bouley has arrived at a similar conclusion, and Bollinger, who has repeated 
Brauell's and Bouley's experiments, has also shewn that the disease may exist without the presence of bacilli in the blood, that such blood will induce the disease in other animals, and that even under such circumstances organisms may develop in the blood of the inoculated animal, and be detected during life, as well as after death. ${ }^{1}$

Similar observations have been made with regard to septicæmia, and the allied disease-conditions associated with the presence of bacilli, some of which have been already referred to. M. Colin, for example, found that $\frac{1}{100,000}$ of a drop of septicæmia-blood would kill a rabbit in 36 hours when inoculated by means of a lancet; that the virulent property existed before the appearance of rodbacteria ; and that the pernicious character of the fluid became evident contemporaneously with the advent of very minute spherical bodies, the consequences, as Colin believes, of the altered character of the blood. ${ }^{2}$

It has been repeatedly demonstrated that the poisonous properties of septinous blood and of other decomposing animal solutions Septinous fluids filtered through porous porcelain, \&c., not innogradually disappear towards the third or fourth day, a fact which is scarcely reconcileable with the doctrine that the poison resides in the apparently almost imperishable 'spores ' of the bacilli which existed during the earlier stages of decomposition. A like feature characterises the virus of splenic disease, of small-pox, and of syphilis. Hiller, ${ }^{3}$ in summarising the results of filtration of septinous fluids, writes that the most decisive experiments have demonstrated that after filtration through finely porous material, such as charcoal, porous earthenware, compressed wadding, \&c., until the fluids have been shewn to be absolutely free from visible molecules of every description, they are, nevertheless, still competent to induce all the symptoms which characterised their action before such filtration. These results, Hiller says, were arrived at by Panum, Bergmann, Weidenbaum, Wolff, Küssner, and others.

To the first named of these observers belongs the merit of having contributed some of the earliest and most valuable obPanum's researches. servations which have been, hitherto, recorded in

\footnotetext{
1 O. Bollinger: 'Zar Pathologie des Milzbrandes:' München, 1872. Quoted in Schmidt's Jahrbiicher. Bd. 166, p. $205 ; 1875$.

2 ' Nouvelles recherches sur l'action des matières putrides et sur la septicémie.' Bulletin de l'Académie, October 1873 ; cited by Birch-Hirschfeld, l. c., page 174.

3. Ueber putrides Gilt,' Centralblatt für Chirurgie, Nos. 10, 11, and 12, 1876.
} 
connection with the nature of the poison existing in certain solutions of decomposing animal matter. Panum's researches were published so far back as 1855 , but having originally appeared in Danish they had for several years been to a great extent overlooked. They were brought more prominently into notice on their publication in 1874 in Virchow's Archiv. In $1875^{1}$ Dr. Cunningham and myself drew attention to these experiments, as we had found that the results of observations made by us, with a like object, based on a series of experiments which included the inoculation and dissection of about 170 dogs, were, in so far as they were comparable, almost in complete accord with those which had been obtained by this distinguished experimentalist.

Panum found that the coagulum produced by boiling a septinous fluid was more virulent than the fluid itself. The principal facts demonstrated by him may be thus summarised :-

(1.) - That the perfectly clear fluid which may be obtained by filtering solutions of putrefying animal substances through several layers of filtering paper would induce the characteristic symptoms of the same kind as the unfiltered material.

(2.) - That boiling such a fluid for even 11 hours would not materially impair its toxic properties.

(3.) - That although an alcoholic extract of such a fluid proved to be inert, the virulent action of a watery extract of the same fluid was very intense.

Panum therefore concludes that a fluid which can retain its specific property after being filtered, boiled, evaporated to dryness, and the residue digested in cold and in boiling alcohol, then re-dissolved and again filtered, cannot owe this property to living organisms of any kind.

In 1865 Dr. W. B. Richardson shewed that the sero-sanguineous fluid Richardson's and Bergmann's re. from the peritoneal cavity of a person suffering from pyæmia would communicate fatal disease searches. from one animal to another in a direct series, and that the poison (designated
'septine') which effected this could be made to combine with acids so as to form salts which retained the poisonous qualities of the original substance. 
A few years later (1868), Bergmann succeeded in obtaining apparently a similar substance and named it Sepsin. ${ }^{1}$ This poison induced symptoms of a like character to what are induced by putrifying solutions, and was frequently even more fatal, in very small doses. Still it appears not to reproduce symptoms exactly similar to the original material, in this respect differing slightly from Panum's 'putrid-extract,' which reproduces the ordinary symptoms of septic poisoning without any modification whatever.

To Pasteur and his adherents, who ascribe what may be almost termed

Exudation with septinous pro. perties induced by purely chemical irritants shewing the paramount in. supernatural powers of resistance to the 'resting' spores' of anthracoid and other diseases, the facts adduced in the foregoing paragraphs can carry but little weight. But another series of phenomena have been recorded which point in the same direction. It has been shewn that the living tissues of the body will under certain conditions, when irritated by means of purely chemical irritants,-such, for example, as a strong solution of iodine or liquor ammonia,-secrete a fluid which, when transferred from animal to animal, proves not one whit less virulent in its properties than an exudation which has resulted primarily from the introduction into the system of material which has swarmed with bacilli. Observations to this effect have been published by many observers, and Dr. Cunningham and myself have placed on record that we found a large number of bacteria in the blood of a dog which had died as a result of such chemical irritants. These bacteria could not have been the cause of death, nor, most assuredly, could they have derived their origin from the liquor ammonia which had been resorted to to excite the inflammatory process.

It would seem from these results that the living tissue elements of the body itself play a much more important part in the elaboration of septinous and allied poisons, than what has been of late ordinarily ascribed to them.

Such, so far as I have been able to learn, are the main facts which have been recorded with regard to the microphytes of the blood in health, and in diseased conditions.

Centralbl. f. d. medicin. Wissensch, 1868, p. 497 ; cited by Dr. Aruold Hiller, op, cit. 


\section{PART II.}

THE PROTOZOA WHICH HAVE BEEN FOUND IN THE BLOOD.

THE organisms which have been described in the former part of this paper, as is well known, were, until within the last few Fermentation formerly supposed to be induced by animalcules, by Pasteur, \&c. years, considered to be more allied to animals than plants, and were consequently classified as belonging to the animal kingdom. Häckel even now places them in his intermediate kingdom, the protista; and for a considerable time subsequent to the promulgation of the doctrine of fermentation by the agency of living cells, vibrionic fermentation, of various kinds, was supposed to be effected by animal life-the animalculæ, during the respiratory process, depriving the solutions in which they were found of the oxygen which they contained, and thus starting a series of complicated changes. It has, however, been for some time conceded that the schizomycetes are more akin to plants than to animals, and the adrocates of the vital theory of fermentation have adopted this view and demonstrated to very general satisfaction that a like explanation still suffices to account for initiating the changes in question. So far as I am aware, the view is no longer held that animalcules are competent to start fermentative processes, notwithstanding the circumstance that microzoa, tolerably high in the scale of beings, are very ordinary accompaniments of microphytes in solutions undergoing active changes of this character. They are not, however, such constant accompaniments as fungi, nor are they recognised so early in solutions of this nature-a more or less distinctly marked interval being observed between the occurrence of manifest chemical change in them and the appearance of protozoa. With regard to protophytes, however, very often no such interval can be clearly demonstrated, and it has been consequently concluded that no such interval occurs - that fermentation of suitable fluids and the advent of fungi are essentially synchronous.

\section{A.-Flagellated Organisms in the Blood of healthy Rats.}

It will be recollected that in a former chapter one of the fundamental tenets of M. Pasteur's creed was cited,-namely, isms in the blood during health. that neither microscopic organisms nor their 
germs were ever found in the blood of an animal in health. Doubtless our conception of what implies good health may differ, and especially so when it is the health of an animal, and not of a person, that may be the subject of debate. If it be maintained that an animal affected with either epiphytes or entophytes, with epizoa or entozoa, is not in the enjoyment of full health, then there can be but few perfectly healthy animals. The organs of some animals are almost never absolutely free from parasites. It would nevertheless be scarcely justifi. able to pronounce such animals as diseased in the ordinary sense.

So much being admitted, it is scarcely possible that this portion of $\mathbf{M}$. Pasteur's doctrine can be correct. For some years Organisms in the blood of ordin. past I have taken considerable interest in this matter, and my attention was drawn to it in a special manner in May last year, by my having been directed by the Government to make enquiries regarding the spirillum of Bombay-fever, already referred to. Whilst doing this I had occasion to examine the blood of a considerable number of animals, and eventually (July 1877) detected organisms in the blood of a rat which, at first sight, I took to be of the nature either of vibrions or spirilla. The blood when transferred to the microscope appeared to quiver with life, but for some considerable time nothing could be detected to account for this animated condition, as the blood corpuscles were somewhat closely packed. On diluting the blood with a half per cent. solution of salt, motile filaments could be seen rushing through the serum, and tossing the blood corpuscles about in all directions. Their movements were of a more undulatory character than are the movements of spirilla, and the filaments were thicker, more of a vibrionic aspect. They were pale, translucent beings, without any trace of visible structure or granularity ; but, as their movements were so rapid, exact information as to their microscopical characters could not be ascertained at the time. The slides were therefore placed under a bellglass until these should diminish.

On the following morning the activity of the filaments was much less. Microscopical appearance of the Their movements were more restricted and more organisms during life : undulatory in character, and the blood-corpuscles, having become somewhat agglutinated, had apparently squeezed out the organisms, so that the latter occupied the serum-areas of the preparations. After watching their movements for some time under a Hartnack's No. 9 immersion objective, it was observed that every now and then blood-corpuscles, some con- 
siderable distance from any visible motile filament, would suddenly quiver. On carefully arranging the light, it was eventually observed that this movement was due to the existence of a very long and exceedingly fine flagellum, apparently a posterior flagellum, as the organisms seemed generally to move with the thicker end forwards-the flagellum being seen following it, and lashing the fluid during the moment it remained in focus. I have not been able to detect any flagellum at the opposite end. The greater number of the figures reproduced in the woodcut (fig. 20) jepresent these organisms as they are observed a few hours after the blood has been obtained, when their movements are not so rapid and the flagellum becomes recognisable. They may sometimes be kept alive for two or three days, but generally the greater portion will have died within twelve or twentyfour hours; and not only have died, but also disappeared from view.

When very carefully watched, the plasma constituting the thicker portion of their substance may be seen suddenly to swell out at certain places-sometimes so as to divide the 'body' into two parts, as shewn in the middle figure; at other times two or three such constrictions and dilatations may be detected, the dilatations being possibly observable only on one side. At other times they assume an arrow-shaped aspect, as shewn in the lowest figure. Occasionally something like granularity may be observed before their disappearance, but not a trace of them is left after their disintegration: it seems as though they had been dissolved in the serum in which they were found.

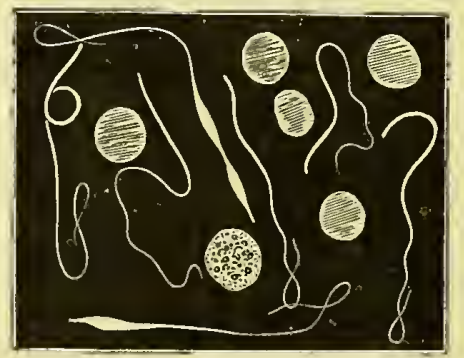

Fig. 20 . . . $\times 700$ diameters.

Flagellated organisms in the blood of healthy rats. A few red blood-corpuscles and one white corpuscle are included in the figure.

They may readily be preserved by spreading out a thin layer of the blood containing them over a thin covering glass and mens. inverting it over a weak solution of osmic acid. The preparation should be removed as soon as it presents a dry, glazed appear- 
ance, and may be thus mounted in the dried condition or in a saturated solution of acetate of potash. I have, however, never been able to detect the flagellum in such a preparation; apparently the refractive index of the substance forming the flagellum and that of the serum approximates so closely that the last can only be detected when creating a current by its movements. The 'body' remains nearly as translucent after the action of the osmic acidfumes as it was in the living condition, so that the presence of the protozoa in such a preparation may readily be overlooked owing to the absence of any movements to direct attention to them.

When, however, a preparation of blood of this kind is dried in the manner ordinarily suggested for preserving specimens of blood, and especially if a little of a weak solution of aniline-blue be afterwards poured over the dried slide, the body of the protozoon will present a very different appearance. It will be found to have contracted irregularly, and to manifest a somewhat granular and shreddy appearance, suggestive of a coagulated, fibro-albuminous substance. The 'body' portion becomes flattened towards its middle to double its original width, and both ends become almost acutely pointed. The flagellum part is only visible for about half its true length, and this portion of it appears to consist of the same substance as the body. Possibly the now invisible portion of the flagellum may consist of a substance slightly different from that of the body; or may have been retracted during the drying. I have made microphotographs of slides prepared in both ways, hoping that possibly an image of the entire lash might thus be obtained, even though the eye could not distinguish any, but have not succeeded, notwithstanding that the rays of light were caused to pass through glass of various colours. ${ }^{1}$ The logwood solution recommended by Koch for this purpose also failed in my hands.

It is impossible to secure accurate measurements of these organisms during the period of activity, nor of the lash at any time, Measurements. seeing that the latter becomes for the most part invisible in preserved preparations. The body portion, however, may readily be measured after they have been killed by means of osmic acid. The width of the anterior half, or body portion, averages 8 to $1_{\mu}$, or precisely that of ordinary blood-bacilli, and its length from 20 to $30 \mu$, or an average of $25 \mu$.

${ }^{1}$ Facsimiles of two of these unicro-photographs will be found in Plate III. 
The flagellum, so much of it as is visible, is somewhat of the same length, so that the total length of the organism equals about $50_{\mu}$, or about $\frac{11}{50}$. The lash, however, may be considerably longer than this, as the slope from the body portion is very gradual, and when the eye follows it to the bounds of visibility an impression is conveyed that there may be still more of it, beyond the power of either Ross' $\frac{1}{12}$ " or Powell and Lealand's $\frac{1}{16}$ " to reveal.

They are not very sensitive to the action of re-agents; a weak solution of Action of re-agents on the organammonia did not affect them for some time, but a stronger solution of potash affected such of them as it came into contact with at once: others in the middle of the field continued to exhibit movements for several hours; probably they had not been touched by the potash. A weak solution of bichloride of mercury in acetate of potash and camphor water (as used for preserving preparations) did not seem to affect them materially, seeing that they maintained their activity in such a solution for eight hours. They retain their vitality longer in a weak salt-solution than in pure distilled water. A cover-glass with an aqueous solution containing them was inverted over a bottle of chloroform for several minutes, but the movements of the organisms were unaffected; if, however, a drop of blood containing them be similarly placed over chloroform they disappear, probably owing to the action of the chloroform-vapour on the blood itself.

A drop of the blood was placed on a slide arranged for the application of Result of application of inter-
rupted current. electricity to microscopic preparations, and it was found that an interrupted current of such a strength as could not be comfortably borne by an individual was tolerated by these beings for several consecutive hours. The only difference appreciable between a preparation thus dealt with and one not so treated was, that the movements ceased a few hours sooner in the former than in the latter, possibly owing to the chemical change induced in the blood itself by the current.

I have examined the blood of a great number of rats for the purpose of Proportion and species of rats ascertaining what proportion of them contains these organisms in their blood, and find that of those affected. specially examined for this purpose their existence was demonstrated in 29
per cent. Sometimes, however, the numbers detected were very few, not more than one or two in a slide, but in the greater number of cases they were very numerous, every slide containing several hundreds. 
Being anxious to ascertain precisely the species of rats in which these organisms were found, I consulted an accomplished naturalist, Dr. John Anderson, Superintendent of the Indian Museum, and he was so good as to identify the specimens for me from time to time. The result has been that it has been definitely ascertained that these organisms may be found in two species, viz., Mus decumanus and Mus rufescens.

It would appear that they are not found in mice. I have examined the blood of a large number, but never detected any organisms of the kind; nor have $I$ seen them in any animals other than rats.

It is possible that these minute organisms ought to have been described in Classification of the organisms. the part of this paper devoted to the description of microphytes, as they present many features in common with motile organisms undoubtedly of vegetable origin; on the other hand, taken as a whole they appear to approach more closely to the forms of life usually classified as protozoa; such, for example, as several of the species of Dujardin's genus Cercomonas. It should, however, be noted that many believe that these organisms are zoospores and not animalcules.

The nearest approach to a description of these hæmatozoa which I can find is in a recent paper by Bütschli, ${ }^{1}$ in which he refers to Their resemblance to flagellated protozoa found in intestine of a a flagellated parasite which he has often observed in the intestinal canal of a free nematode (Trilobus gracilis). He refrains from giving it a name owing to the uncertainty which exists with regard to organisms of this kind. He generally found them in large numbers, often forming stellate colonies owing to their being attached by their non-flagellated ends. They readily became detached and then presented a somewhat spindle-shaped body, about $11 \mu$ in length and with a somewhat thick flagellum about double this length, so that the total length of the protozoon would be $33 \mu$, something more than half of the length of the flagellated organism found in the rat's blood. Near the base of the flagellum of Bütschli's protozoon a contractile vacuole could be distinguished, but I have not been able to detect any such vacuole in these rat-hæmatozoa.

1 'Beiträge zur kenntniss der Flagellaten und einiger verwandten Organismen' : Zeitschr. für vissensch. Zoologie. Band. XXX, Heft. 2, Taf. XI, Fig. 9, Jan. 1878. 
Seeing that the blood of such a large proportion of rats contain these Probability of former observaorganisms, I can hardly suppose that their existence tions of a like kind. has hitherto escaped notice, unless it be that rats in Europe do not harbour like parasites. Davaine ${ }^{1}$ in the recent edition of his work makes mention that M. Chaussat had found minute nematodes in the blood of a black rat (Mus rattus), but I have not seen any nematode in the blood of rats in this country. In the tissues, bladder, \&c., of rats such parasites are very common, but their description does not come within the province of this paper.

The nearest approach to the flagellated hæmatozoa of rats which I have seen described is to be found in a foot-note in Dr. Bastian's 'Beginnings of Life," ${ }^{2}$ where it is stated that Dr. Gros had seen minute worms (vermicules) in the blood of a field-mouse (mulot) which were so numerous as to cause the blood to present an animated appearance; and that the blood of the mole was often found to be in a similar condition. They were so small as to be barely visible under a power magnifying 400 diameters. I have not been able to obtain any minute description of these vermicules, but I anticipate that it will be found that they closely resemble the flagellated protozoa found in the blood of Indian rats.

With regard to the health of the rats in which these flagellated organisms The organisms often found in the blood of rats of the same brood.

were detected, there was nothing to suggest in any way that they were less healthy than others not so affected, and I have repeatedly kept rats for a considerable time for the purpose of observing whether any special symptoms would be manifested suggestive of the existence of such organisms in the circulation. It should be mentioned that it frequently happened that the rats caught in a particular room would be affected, whereas the blood of rats in another part of the building would not contain them. The servants had ultimately come to recognise this, as, whenever they learnt that a particular rat's blood contained the desired organisms, they diligently endearoured to secure the rest of the family.

When it is considered that thousands of active beings of this character can Pathological bearing of the obexist in the blood without in any appreciable manner affecting the health of their host, and when it is further considered that these organisms must consume at least as much, if not

${ }^{1}$ Traité des Entozoaires, Edit. II, pp. 11, 957 : 1877. Leuckart's 'Pn'asiten,' vol, ii, p. 626.

2 Vol. ii, p. $338: 1872$. 
far more, oxygen than bacteria, bacilli and spirilli, it becomes difficult to understand how it comes about that to a like action on the part of the latter is ascribed the asphyxia and the other morbid conditions which characterise death from splenic disease and allied affections. ${ }^{1}$

\section{B.-Protozoa in the Blood of healthy Frogs, Deer, \&c.}

Scarcely higher in the developmental scale is the protozoon described by ProLankester's Undulina in frogs' fessor Ray Lankester as being found in the blood of blood.

frogs. ${ }^{2}$ These organisms were at first taken by this distinguished observer to be exceptionally active white blood-corpuscles, as they are but very little smaller than the red corpuscles of the frog's blood. Owing to the protozoon's great activity there was some difficulty in making out the nature of its locomotive organs until it had been killed by acetic acid vapour. It was seen to be a pyriform sac, coarsely striated, and containing a pale, clear nucleus. One portion of the sac is spread out into a broad thin membrane, which at one end produced a flagellum; the former undulates in a series of waves, which, with the action of the flagellum, 'tend to urge the animal in a wide circle' (fig. 21, $a$ ).

Numerous oblong bodies (fig. 21, b) were also noticed in the blood of one frog attached in many cases to the end of the red bloodcorpuscles. These, it is considered, judging

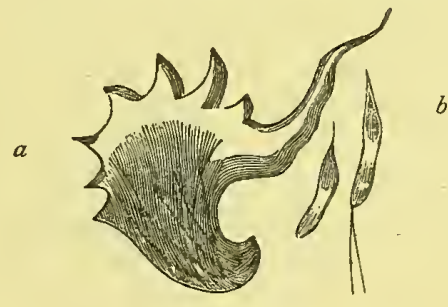

Fig. 21. $-a$, Undulina ranarum; $b$, Minute oblong bodies associated with it.

(Magnified by Hartnack's No. X Objective. Original figure reduced to half size : After Lankester.) from their being associated with the parasite, may be genetically connected with it.

${ }^{1}$ M. Toussaint commeuces a recent paper, subınitted' to the French Academy, with these words : 'Les expérience: entreprises dans ces derniers temps ont démontré que la bactéridie est la cause du charbon, "La bactéridie provoque l'asplyxie en enlevent aux glokules l'oxygène nécessaire à l'hématose;" telle est lı conclusion des expériences de MM. Pasteur et Joubert. Telle était aussi l'explication que j'avais cru devoir deduire des faits contenus dans la Note que M. Bouley avait bien voulu présenter en uon nọı a l'Acadéliie le 14 aô̂t dernier.'-Comptes Rendus, t. lxxxy, p. 1076 ; Dec. $3,1877$.

On the other hand, Professor Virchow is unable to accept such a doctrine as is referred to by M. Toussaint. Iu some experiments conductel with charbou-material by this celebrated pathologist it was found (among other thing:) that the proportion of bacteridia present in the blood at autopsies bore no relation to the severity of the disease, so that for this and other reasons Virchow came to the conclusion that the special morbid material must be of the nature of a chemical poison. Op. cit., page 30.

${ }^{2}$ Quarterly Journal of Microscopical Science, vol. xi, p. 387 ;-1871. 
Professor Lankester considers it improbable that this hæmatozoon has not been previously seen and described. He speaks of it as a mouthless infusorian closely allied to the Opalinida, but possessing no cilia, the latter being replaced by an undulating membrane and a flagellum. It is therefore believed to represent the type of a new group of infusoria, and is named Undulina ranarum.

Some years ago Auguste Rättig ${ }^{1}$ described an 'amoboid' organism which $\underset{\text { frogs. }}{\text { Rätig on organisms in blood of }}$ he had found in the blood of some frogs. Judging from the description and figures, it is evidently identical with Lankester's Undulina. Lieberkühn² appears to have described a somewhat similar protozoon in the frog's blood under the designation Amoba rotatoria, and which, according to Waldeyer, ${ }^{3}$ was named Trypanosoma san. guinis by Gruby.

In the same paper Rättig describes another hæmatozoon, which he liad often seen in the capillary vessels whilst examining the frog's mesentery during the months of May and June; they were of elliptical form and of granular aspect, with a length equal to the long diameter of about $1 \frac{1}{2}$ of a frog's red blood-corpuscles. Channels with cæcal terminations could be distinguished in them ; these, however, disappear in the course of a few hours, and thus the appearance of the animalculæ becomes completely changed (fig. 23, $a, b$ ). They moved
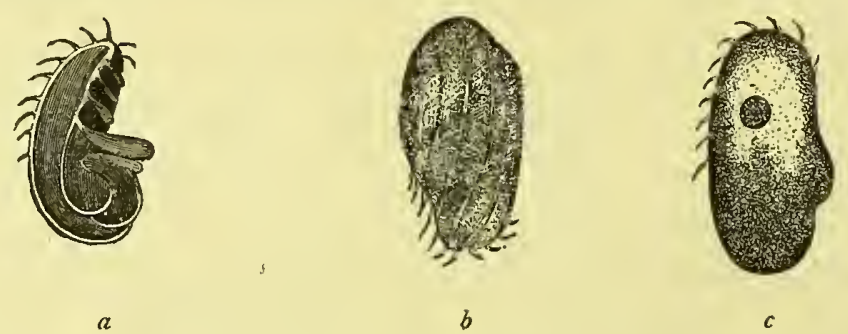

Fig. 22.- $a, b, c$, Changes undergone by a protozoon found in the blood of frogs in the course of a few hours: Magnified 500 diameters. (After Rättig.)

rapidly in the serum, propelled by means of cilia placed along the dorsal aspect of the body, and it was observed that they could travel in both directions of the

1 “ Oeber Parasiten des Froschblutes;' Inaugural-Diss, Berlin, 1875.

${ }^{2}$ Lieberkühn: 'Ueber Bewegungserseheinungen der Zellen:' cited by Rättig, op, cit., p. 16. I'ide also Dariniue’s 'Butozosires,' II Edit., p. XVI (foot-note).

${ }^{3}$ Virchow and Hirsih's Jahresbericht, vol. i, p. 96, 1875. 
blood-current. It would appear that these organisms were only found in frogs obtained from certain localities. Occasionally specimens were observed which manifested a distinctly striated appearance, in which no canalicular system could be distinguished, and whose movements were somewhat slower. These are considered to be the same parasite as the last described, as occasionally this change of appearance has been seen to take place during the time of observation (fig. 22, c).

Akin to the foregoing hæmatozoa of the frog, though considerably larger, are those which were described by Dr. Boyd Moss Hæmatozoon of deer, \&c.

in 1871 as being found in the Ceylon red deer (the Muntjac of India ${ }^{1}$ ). Dr. Moss speaks of them as oval, ciliated bodies, capable of swimming actively in the serum, two or three being seen at a time in the field of a $\frac{1 \text { " }}{8}$ objective. They are colourless and perfectly translucent; and all present two or three large ova-like spherical bodies 'towards the posterior half, the remaining portion being filled with small cells and granules.' The anterior pointed half of the body is furnished with cilia, which 'are raised on a substructure of a wave-like appearance' (fig. 23). They were found on three occasions apparently each time the blood of this deer was examined. Unfortunately measurements have not been furnished, but they are described as being too large to pass through the capillary vessels. In the same plate a figure is given of the red

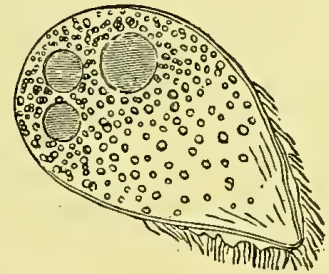

Fig. 23.-Protozoon obtained in the blood of a deer. Original figure reduced to half size. (After Boyd Moss.) blood-corpuscles of the same deer, and their diameter is stated to be $\frac{1}{6500}$ inch. If the figures of the hæmatozoon have been drawn to the same scale as the corpuscles, it may be inferred that the length of the parasites would correspond to the diameter of about 20 human red blood-corpuscles, or about $\cdot 16 \mathrm{~mm}$., and the greatest width about $\cdot 1 \mathrm{~mm}$.

They will continue alive under the microscope for about an hour. After death three bands, resembling muscular fibre, are seen to traverse the body longitudinally, but these are not visible during life. 
It does not appear that either the frogs or the deer had been in any way inconvenienced by the presence of these protozoa in their circulation.

Protozoa have also been found in the blood of the carp by Wedl. They are spoken of as being Globularia radiata, and were observed to have been especially abundant during the summer. ${ }^{1}$

The foregoing section contains a brief account of all the protozoa of this Statements as to occurrence of character, regarding which I have been able to col'infusoires' in blood of man. lect information, unless it be considered that the organisms referred to by M. Davaine in his well-known work on parasites as having been observed by Klencke and Gros belong to the same category. According to M. Davaine, Klencke detected in the blood of a person suffering from vertigo 'des animaux semblables aux infusoires;' and M. Gros is said to have obtained them in the blood of persons affected with syphilis. ${ }^{2}$ This description is not sufficiently precise to warrant any opinion being expressed as to their character.

The remaining hæmatozoa of man and animals belong, so far as I am aware, to the helminthic group. As it is proposed specially to refer only to such of them as are of microscopic dimensions, their description need not occupy more than a few pages.

${ }^{1}$ Jahresbericht Von. J. Victor Carus, Zeitschr.f. d. wissen. Zoologie. Band. VII-'Supplement-Heft.' $1856-$-p. 35.

: O!. cit., 11 Edit., p. 317 . 


\section{PART III. \\ HELMINTHIC HEMATOZOA OF MAN AND ANIMALS.}

A.-Trematoid Hæmatozoa.

WITH regard to the helminths which have been found in the blood, it may be stated generally that, with one exception, they all Distomum hæmatobium. belong to the nematoid group. The exception is Distomum hamatobium, a fluke-parasite discovered by Bilharz ${ }^{1}$ in the venous system of the abdominal viscera of persons in Egypt in 1851; in 1857 by Dr. Spencer Cobbold in the portal vein of a monkey ${ }^{2}$; and lately by Dr. Sonsino ${ }^{3}$ in like situations in oxen and sheep. These parasites appear to affect about a third of the entire population of some parts of Egypt. The female is a filiform parasite something less than an inch in length; and the male thicker, but only a little more than half the length of the female. The anatomy and the pathological significance of these worms are so well known that it is not necessary to give details, especially as nearly every text-book of medicine supplies full information regarding them.

\section{B.-Nematoid Hæmatozoa of Animals.}

The nematoid hæmatozoa are far more numerous, although to some extent Nematoid hæmatozoa of frogs.

the number has been increased by the circumstance that nematoid embryos which have accidentally got into the circulation have been classified as hæmatozoa, though, in such cases, the blood can scarcely be considered as their normal habitat.

These parasites have been found in nearly all classes of animals either in the mature state, or as embryos, or as both combined.

Not uncommonly the parents may be found in the tissues and the embryos in the blood. Vogt, for example, found two large filariæ, over two inches in length, in the ventral cavity of a frog. These were distended with ova and embryos, the latter being also found in the blood of the frog. ${ }^{4}$

Under the designation Filaria cordis phoca M. Joly describes numerous female nematoid parasites which he had discovered in Hematozoa of the seal, of the the heart of a seal, $6^{\prime \prime}$ to $8^{\prime \prime}$ in length, and about $\frac{1}{25}{ }^{\prime \prime}$

1 Zeitschr. für wissen. Zoologie. Band. IV., 1853.

2 'Entozoa : An Introduction to the Study of Helminthologv,' 1864.

3 'Sugli Ematozoi come contributo alla Fauna Entozoica Egiziana,' 1877.

4 Archiv für Anat. und Physiol., 1842, S. 189 ; cited by Leuckart, 'Die Menschlichen Parasiten ;' Band. 1., p. 52. 
in width, and which were stuffed with ova and embryos. Towards the anterior third of the body the latter were frce and measured from $4_{40}^{\frac{1}{0}}$ " to ${ }_{3}^{\frac{1}{5} 0}$ " ("06 to $.07 \mathrm{~mm}$.) in length. The male was not seen. ${ }^{3}$

Dr. Cobbold also describes a parasitc, Filaria hebeta, which was found in the heart of a seal. The length of the female in this case also was 6 inches; that of the male, distinguished by the possession of a spirally curved tail, was up to 4 inches. The embryos were considerably larger than the measurements given by M. Joly as those of his parasites, being $\frac{1}{90}$ ", and about the width of a human red blood-corpuscle. ${ }^{2}$

Wedl found a filaria with a broad head and a filamentous tail in the blood of a whale, together with a peculiar body ('aus acht in einander geschobenen Ringen bestehende Körperchen') double the length of a blood-corpuscle.

This observer likewise, on two occasions, found nematoid worms in the blood of a carp (Cyprinus tinca). They were $\frac{6-8}{1 ;, 000}$ of a Vienna inch in length and 0001 in width.

It las long been known that the blood of many birds is infested to an extraordinary extent with the emHæmatozoon of birds. bryos of nematoid helminths. The first record of them is by Sclimidt, who appears to have discovered them in 1826. They have since been frequently described; and, according. to Virchow, ${ }^{5}$ they liave also been found by Herbst in the blood of hawks, jackdaws, jays, \&c. Borell ${ }^{6}$ writes regarding a condition which he describes as "Trichiniasis of the Crow.' The parasites found were $13 \mathrm{~mm}$. in length by '004 in width, but as they appear to have, for the most part, only been found in the blood vessels, the term 'trichiniasis' is scarcely applicable; moreover, the worm is manifestly not a trichina. It is worthy of special note that specimens of precisely the same size as those in the blood were also found in the aqueous crow.

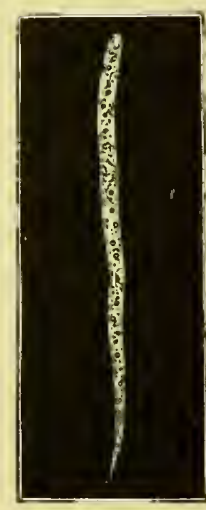

FIG. $24 \cdot \times 500$ Filaria from the blood of the Indian

1 Annals and Magazine of Natural History, wol. I, 1858.

a Procedings of the Zoological Society, Nov. 1873, p. 741 .

3 Wedl cited by Curus, loc. cit.

4 Gervais and Van Beneden : 'Zoologie Medieale:' 1859; quoted iy Sonsino, op. eit.

5 Virchow's Archiv, vol. Ixv, 1875. p. 400.

6 Idem, page 399. 
humor and in the corpus vitreum of one eye. Sonsino ${ }^{1}$ has likewise often found them in the crow in Egypt, and states that they are $\frac{1}{8}$ of a millimeter in length. One of the crows in which he found these embryos contained three examples of Filaria attenuata in its ventral cavity. Ecker suggests a genetic connection between the lattcr and the former ${ }^{2}$; and Leuckart, in his standard work on the Parasites of Man, appears to coincide in this view. ${ }^{3}$

I have examined a considerable number of the ordinary Indian crow The hrmatozoon of the Indian (Corvus splendens), and have found that the blood of nearly half of those which have come under my notice have contained cmbryo hæmatozoa of this character. Sometimes they are in such numbers as to make it a matter of surprise how it is possible that any animal can survive with so many thousands of such active organisms distributed throughout every tissue of its body. The birds did not appear to be affected in the slightest degree by their presence. In their movements they are very similar to the nematoid embryos found in man; they are, however, considerably smaller, and manifest no trace of an enveloping sheath (fig. 24). Those measured by me were found to be $.09 \mathrm{~mm}$. in length by 004 in width, which is, roughly, more than one-third the length and one-half the width of the embryo of Filaria sanguinis-hominis, to be subsequently referred to.

They were not in the least affected on the addition of half per cent. saltsolution, and continued to manifest active movements in it for from 6 to 8 hours. A drop of blood containing numerous hæmatozoa was placed on the slide arranged for the application of electricity; and an induced current of considerable force was passed through it for two hours without the slightest appreciable effect on the filaria being observed. As the current applied was stronger than could be tolerated by a man for any lengthened period, it would seem that the application of such a remedial agent to persons affected with organisms of a like character is not likely to be followed by any satisfactory results.

The blood of several of the crows examined was, when perfectly fresh, strained through linen, but no parental form was caught on the strainer, nor were any ova to be detected.

\footnotetext{
Op. cit.

2 Diesing's 'Systema Helminthum,' vol. xi, pp, 266.7, 1851.

3 'Die weuschlichen Parasiten,' Band, I, pr 52; Band. 1 , p. 61t; Leipzig, 1876.
} 
In Solipeds-the horse, ass, mule, \&c--aneurismal dilatations of the Hæmatozoa of horses, \&c.

mesenteric arteries are very commonly observed, the result of an arteritis set up by the palisade worm (Sclerostomum equinum) during one of the stages of its growth. As, however, it does not appear to take up its abode in the blood itself, the matter does not call for further reference here. It would seem, however, that occasionally the blood of the horse does contain bonâ fide nematoid hæmatozoa. Leuckart ${ }^{1}$ refers to a case of the kind as having been observed by Wedl in which the nematoid hæmatozoa were associated with the presence in the abdominal cavity of Filaria papillosa, the ordinary worm of the anterior chamber of the eye in horses, \&c.; and Sonsino ${ }^{2}$ found three minute nematodes in the blood which was drawn from the jugular vein of a horse. They were $23 \mathrm{~mm}$. in length, the length being to the width as 37 to 1 , and in general appearance they resembled the hæmatozoa of the crow.

Of all animals which have been found to harbour hæmatozoa, the dog, perhaps, takes the first place. Dogs affected in this Hæmatozoa of dogs. manner have been observed in nearly all parts of the world, notably in China, India, and some of the southern parts of Europe. It is, moreover, probable that the embryos of different species of nematoids are found in this animal's circulation: that mature helminths of different species are found in it is a well-ascertained fact.

The interest in this subject dates from the observations which were made more than twenty-five years ago by MM. Gruby and Delafond, which went to shew that 4 to 5 per cent. of the dogs in France harboured microscopic nematodes in their blood. In a paper entitled 'The Pathological Significance of Nematode Hæmatozoa' published by myself in $1874,{ }^{3}$ it was pointed out that more than a third of the pariah dogs of this country are similarly affected; and Dr. Patrick Manson has shewn that this kind of parasitism affects at least an equal proportion of $\operatorname{dog} s$ in China. ${ }^{4}$ The embryos which have been found in the dog's circulation appear to correspond. as to size, form, and character of movements

1 Op. cit., vol. ii, pange 635.

2Op. cit.

${ }^{3}$ Tenth Annual Report of the Sanitary Commissioner with the Government of India, App. B, 1874; Indian Annals of Medical Srience, No. XXXIV, July 1875; :1sn, in part, in Quarterly Journal of Mficroscopical Science, 1875.

4 'Report on Hrematozon' in China Customs Medical Reports, vol, xiii. Shanghai, 187\%. 
irrespective of the countries in which they have been found; and, were it not that discrepancies exist as to the relative prevalence of the mature forms of the nematoid parasites which have been found in different countries, an easy decision might be arrived at as to the parental form in all. As this is a subject having considerable bearing on the elucidation of the genetic relations of the embryos of an allied condition in man, it is necessary that the matter should be closely scrutinised.

Two, or possibly three, mature parasites have been observed as being more or less frequently associated with the preThesmature parasites found associated with. embryo homatozoa of dogs.

sence of embryos in the blood of dogs: they have been found in the heart, in the arterial walls, \&c., and in the subcutaneous tissues.

The earliest record of such mature parasites associated with the existence of embryos is found in the account of MM. Gruby and Delafond's experiments, where it is stated that on one occasion (out of a total of 480 dogs the blood of 20-24 of which had contained embryos) they found six white, filiform worms, in the right ventricle. They were from five to eight. inches in length (14 to 20-24 centimeters) and from $\frac{1}{25}$ to $\frac{1}{16}$ inch in width. Two of the specimens were male and four female, the latter being full of ova and embryos; the embryos identical in appearance with those found in the blood. ${ }^{1}$ This observation, as regards Europe, appears to have remained unique for many years, but latterly MM. Galeb and Pourquier say that they have found the heart of a bitch stuffed with such adult filariæ, the female specimens being 30 to 32 centimeters in length; and, the animal being pregnant, they further discovered that the blood of a fœetus, which was examined, contained many 'embryons hématiques.' The male examples of the parasite were thinner than the female, and only half the length.

These mature worms are considered to be identical with Leidy's Filaria immitis, ${ }^{2}$ for a very careful description of the Filaria immitis. minute anatomy of which we are indebted to Dr. Welch ${ }^{3}$; as also to Dr. Cobbold ${ }^{4}$ and Dr. Manson. ${ }^{5}$ They appear to be extra-

1 Comptes Rendus, t. XXXIV, p. 11-13, 1852.

2 Proceedings of the Academy of Natural Science, Philadelphia, vol. v, 1850.51.

3 Monthly Microscopical Journal, Oetober 1873, p. 157.

- Proceedings, Zoological Society, November 1873.

Sp. cit., pp. 1-11. 
ordinarily common in China. Manson found them, for the most part, coiled up in the right ventricle, sometimes extending through the tricuspid valve into the auricle, and even into the superior vena cava, and very generally through the semilunar valves, far into the pulmonary artery and its branches. He never found them in any other vessel, though carefully sought for. The female specimens measured from $8^{\prime \prime}$ to $13^{\prime \prime}$ in length by $\frac{1}{30}$ " in width; and the male, recognised by its corkscrew-like tail, from $5^{\prime \prime}$ to $7^{\prime \prime}$ in length and $\frac{1}{40}$ " in width. It seems somewhat strange that, notwithstanding the marked prevalence of Filaria sanguinolenta. embryo-hæmatozoa, the Filaria immitis has not, so far as I can learn, been recognised in India. I have often searched specially for it, but in vain. The only mature parasite which appears to affect the circulatory system of dogs in this country is the Filaria sanguinolenta, a description of which, together with an account of the pathological clianges which are caused by it during its development in the walls of the aorta and adjacent tissues, was published by me in $1874 . .^{1}$ This Filaria may be readily recognised by its pink hue, when fresh, and by many other characters which need not be specially referred to on this occasion. It does not appear to be viviparous, for, although living Filaria may readily be pressed out of mature ova, I have never found free embryos, either in the body of the female parasite, or in the fluid contained in the pouch in which it is usually lodged, although an abundance of free ova are always present. Notwithstanding the circumstance that this is the only mature helminth which I have found associated with the embryo-hæmatozoa in India, I cannot believe that there is a genetic connection between them, for it frequently happens that the mature worm may be present in abundance unassociated with blood-embryos of any kind, and sometimes it is found that the latter exists without any trace of the former.

Recently a very interesting observation bearing on this subject has been made by Ercolani-an observation which may serve Ercolani's discovery of mature nematodes in subcutaneous tissue at some future period to throw some light as to the origin of the microzoa of dogs in this country. ${ }^{2}$ Ercolani has, on two occasions, found sexually mature worms in the subcutaneous cellular tissue of dogs in Italy. In one of the cases they were very numer-

\footnotetext{
1 Loc. cit.

${ }^{2}$ A notice by Paul Güterbock in Virchow and Hirsch's Jahresbericht for 1875, vol. i, p. 379.
} 
ous and were associated with embryos in the blood. The writer suggests that possibly still other mature parasites may eventually be discovered, as the embryos in the blood are probably not derived from the same species. I have, on several occasions, endeavoured to find the mature form in the cellular tissues of various parts of the body of dogs, but have not been successful. This, however, by no means implies that such thread-like creatures were not present.

\section{C.-Nematoid Hæmatozoa of Man.}

There remain now to be considered the nematoid hæmatozoa which have The first record of nematoid been found in the circulation of man. The literahomatozoa in man. publication in 1872 of a paper submitted by myself to the Government, entitled ' On a Hæmatozoon in Human Blood.' ${ }^{\prime}$ Towards the beginning of July of that year, I found nine minute nematoid worms in a state of great activity on a slide containing a drop of blood from the finger of a Hindoo. They were about $\frac{1}{80}$ " in length, and $\frac{1}{580}$ "in width, or slightly less than the average diameter of a human red blood-corpuscle $(\cdot 3 \mathrm{~mm} . \times \cdot 007 \mathrm{~mm}$.).

Unfortunately, after the observation had been made the man could not bc found so as to be questioned as to his past history, so that the pathological conditions which might have been associated with this, the first recorded instance of the existence of nematoid hæmatozoa in man, must continue in obscurity.

This observation was, however, followed by several others which have gone to shew that the presence of this particular helminth Association of hæmatozoon with
chyluria and nævoid elephantiasis. in the blood is very generally associated with chyluria and with an allied affection known as lymph-scrotum or nævoid elephantiasis. The extent of this connection may, in some degree, be inferred from the circumstance that whereas filariæ may occasionally be observed in the blood of pcrsons apparently free from disease of any kind, they are, so far as my personal experience goes, invariably present when either of these diseases exist. It must be recollected, however, that the search for them sometimes involves very considerable labour.

\footnotetext{
1 Eighth Annual Report of the Sanitary Commissioner with the Government of India, 1872. Also Indian Annals of Medical Science, vol. xvi.
} 
These parasites, or parasites very closely allied, havc now been found in the blood of man in many parts of the world. Dr. Prospero Sonsino, ${ }^{1}$ in January 1874 (having no knowledge of previous observations of a like character), found them in the person of a Jew-lad at Cairo. 'They have been found in China by Dr. Patrick Manson ${ }^{2}$ of Amoy, and in Australia by Dr. Bancroft ${ }^{3}$ of Brisbane. They have also been found in the blood in Brazil; and, within the last few weeks, in England, by Dr. Hoadley Gabb of Hastings."

In considering the possible relation which may exist between the several parasites which have been found in different The question of the identity of the embryo-filariø of different latitudes, it will be well to bear in mind the history of somewhat similar organisms in the circulation of dogs, a brief epitome of which has been given above. There is another matter to be taken into consideration as regards the identification of like parasites in man,-namely, their association with diseased conditions. Are these conditions invariably of the same general character in all countries? If so, it would be sufficient to shew that a distinct relation of some kind existed between the disease and the parasite; but if it be found, notwithstanding the existence of a general correspondence between them, that nevertheless minor differences were more or less constantly present, this would indicate either that some slight difference existed in the parasite itself or that it bore no causal relation to the disease.

It so happens that nematoid hæmatozoa are found associated with a disease which, whilst manifesting a close general resemblance in different countries, is nevertheless characterised by a marked difference. In Asia, or at least in India, it is known by its most characteristic appearance, viz., milky or chylous urine; whereas in Africa and South America it is described as the 'hæmaturia' of various localities, or as 'hématurie chyleuse' or 'graisseuse,' a term doubtless adopted on account of its being a more correct description of the malady than chyluria. In India, however, although the term may be more or less applicable at some period or other of the disease, it is never-

\footnotetext{
1 'Richerche intorno alla Bilharzia hæmatobia in relazione colla ematuria endemica dell'Egitto e nota intoruo ad un nematoideo trovato nel saugue umano.' Naples, 1874.

2 Op. cit.

3 'On Urinary and Renal Diseases,' by W. Roberts, 3rd Edit. 1876, p. 342.

4 The Lancet, June 22, 1878, p. 921.
} 
theless not so appropriate in the great majority of the cases, and, indeed, in some instances is wholly inappropriate, as occasionally no marked traces of red colouring matter can be detected in the urine from the beginning to the close of the attack. There is an instance of this kind under my observation at present (a European born in the country) suffering from a third attack, who has never defected the slightest trace of blood at any time. It is of importance that this feature in the character of the disease according to its geographical distribution should be borne in mind, as it may hereafter be found that what at present are generally considered as merely two phases of one malady may each have a distinctive etiology.

When in March $1870^{1} \mathrm{I}$ - detected a microscopic nematoid in urine of the The hæmatozoa as a urinary latter character, I was under the impression that no nematoid of any kind had previously been found in any urine which could not be attributed to accidental circumstances. It proved, however, that the late Dr. Otto Wucherer had already found a parasite of a like character in 1868 in 'Hcematuria Braziliensis,' and had forwarded specimens to Prof. Leuckart for identification. ${ }^{2}$ Dr. Jules Crevaux succeeded in confirming Wucherer's discovery by finding (27th July, 1870) similar helminths in the urine of a young creole affected with a like disease. ${ }^{3}$ It is possible that the parasite discovered by Wucherer and described by him in December $1868^{4}$ may prove to be identical with the one found by myself in March 1870 ; in such an event it will be necessary to seek for some clue, other than specific differences in the helminths, to account for the circumstance that the disease with which they are associated presents different characters.

In order to complete the sketch of the history of nematoid urinary parasites The urinary oviparous helminths of this period it will be necessary to refer to two other observations, as it may be of assistance to future writers in deciding (1) as to the number of such helminths that may be found in the urine of man, and (2) whether any of them should be considered as pseudo-parasitic merely. In 1868 Dr. Salisbury published an account

- Annual Report of the Sanitary Commissioner with the Government of India, 1870. British Medical Journal, 19th November 1870.

2 Leuckart's 'Parasiten,' Band. ii, p. 640.

Idem; and Journal de l'Anatomie et de la Physiologie, t. xi, 1875.

- Gazitta da Bahia, December 1868. 
of a parasite which he had found associated with ova,in the urine of an insane old lady suffering from severe 'cystinic rheumatism,' and affected with partial paralysis of the bladder and of other parts of the body. A drop of urine frequently contained 10 to 15 ova. It was not a case either of hæmaturia or chyluria, although it is sometimes erroneously stated that she was suffering from the latter disease.

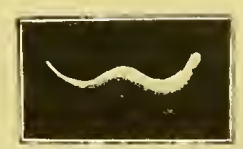
This impression has arisen from the fact of cystinuria having been confounded with chyluria, two totally different disorders. The helminth is described as Trichina cystica (fig. 25).

Writing in 1872, Dr. Cobbold, after describing the history of a little girl The urinary oviparous helminths
found by Cobbold. who had been suffering from hæmaturia associated with the Distomum hrmatobium, refers to the circumstance that he obtained from the patient some other urinary parasites in the egg condition. ' 'On five separate occasions,' writes Dr. Cobbold, 'I obtained one or more specimens of the eggs or embryos of a minute nematode. In one instance there were about fifty of these ova in the urine, their embryonic contents being well developed, and in a state of activity. Usually they were all in this advanced condition; but on the 25th of July 1870 several were observed in much earlier stages of development.' The fully grown eggs gave a longitudinal measurement of $\frac{1}{500} \overline{0}^{\prime \prime}$ by $\frac{1}{1000}$ " in breadtl. Judging from the description of the ova and their contained embryos, it would seem that the parental form must have been oviparous. The embryos, when freed artificially from the egg, measured $\frac{1}{300}{ }^{\prime \prime}$ in length by $\frac{1}{3500}{ }^{\prime \prime}$ in breadth. On two occasions free dead specimens were observed which had been lying in water some time, and these measured $\frac{1}{150}{ }^{\prime \prime}$ by $\frac{1}{3000}{ }^{\prime \prime}$. The parents of the patient had mentioned that the latter had 'passed three small vermiform entozoa by the urethra."

Dr. Cobbold writes: ' $I$ have been thus particular in recording these facts, because future discoveries may enable us to identify the species of nematode to which these ova are referable. I know only one set of observa-

\footnotetext{
${ }^{1}$ During the last seven years I must have examined the sediment of very many gallous of chylous urine, but never observed any ova of nematodes, though, from time to time, I bare found muny hundreds of embryos.
} 
tions on record which refer to this same species of parasite.' The parasite referred to is the above-cited trichina cys. tica. As it may be a convenience to future observers to be able to judge of these matters for themselves in the absence of the original papers, I have reproduced Dr. Cobbold's illustrations, together with a reduced outline of Dr. Salisbury's figure. The reduction has been effected by means of a camera lucida, so as to represent the hel-

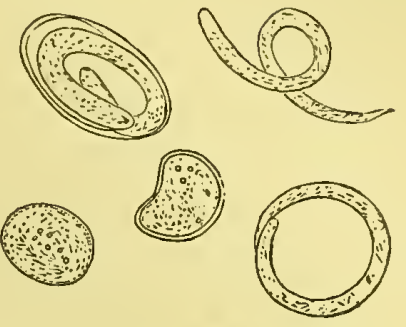

FIG. 26.-Ova and freed embryos of an oviparous nematode; obtained in urine. (After Cobbold.) minth as magnified 300 diameters instead of 1,000 as in the original. This will facilitate comparison with Dr. Cobbold's figure representing his nematoid ova parasites ${ }^{1}$ (fig. 26). Notwithstanding the discrepancy in size, Dr. Cobbold considers that the helminths are referable to one and the same species. ${ }^{2}$ They are both manifestly the offspring of some oviparous nematode; further than that it is, I think, hardly safe to carry the comparison.

The figures will also serve to elucidate another matter, as Dr. Cobbold has since asserted that his parasite is not only identical with Dr. Salisbury's, but also identical with the Filaria sanguinis-hominis, ${ }^{2}$ a figure of - which under a somewhat like magnifying power will be found in Plate II (figs. 3 and 5). Dr. Douglas Cunningham several years ago pointed out that such a view was untenable ${ }^{3}$; moreover, the mature Filaria sanguinis-hominis is not oviparous but viviparous.

D.-Changes undergone by the Embryos of Nematoid Hæmatozoa when ingested by the Mosquito.

It would occupy too much space to attempt an epitome of all that has been written regarding the Filaria sanguinis-hominis

Dr. Manson's investigations into the changes which hæmatozoa undergo in the mosquito in China. and the somewhat numerous diseases which have been ascribed to its influence, so that for the present the foregoing must suffice. It remains to be considered how it is that the embryos get into the circulation and what becomes of them afterwards. A most important step towards the solution of

\footnotetext{
1 British Medical Journal, July 27, 1872, page 92.

2 London Medical Record, No. i, vol. i, 1873; The Lancet, July 13, 1878, p. 64.

${ }^{3}$ The Lancet, Juue 14, 1873, page 835.
} 
these queries has recently been made by Dr. Patrick Manson of Amoy. ${ }^{1} \mathrm{He}$ has shewn that, immediately after a mosquito has fed itself on the body of a filaria-affected individual, the insect's stomach will contain living examples of the hæmatozoon; and that the latter will attain considerable progress towards maturity therein, in the course of a few days. It is believed that it then escapes from the mosquito when the latter dies in the water to which it betakes itself, and the filariæ thus find their way into the human body. Dr. Manson's highly interesting paper gives a full account of the various developmental stages, together with figures of the objects as they appear from time to time.

I have repeated many of Dr. Manson's experiments, and have been able to satisfy myself, from personal observation, that his statements as to what occurs in China may, in most particulars, be made applicable to India also. I had on many occasions examined the stomachs of mosquitoes and of other suctorial insects in a cursory fashion during the last few years, but had never detected parasites resembling the Filaria sanguinis. When, however, I learnt of Dr. Manson's success, I proceeded to make examinations in a systematic manner, and found, to my surprise, that 14 per cent. of the insects, caught at random and then examined, contained such embryos. ${ }^{2}$ It became, therefore, manifest that filarious blood must be a tolerably common occurrence.

At first I was not successful in being able to detect any but disinteSimilar observations' made in grative changes in the ingested parasite owing to India. the examination to the contents of the stomach only. This was done in order to diminish the risk of confounding the various stages which the embryo-filariæ might undergo with some other parasites which might exist among the tissues of this, as of other insects. The parasites were, in fact, found to be digested. Leuckart ${ }^{3}$ mentions that a similar result was observed by Fedschenko to follow the ingestion of dracunculus-embryos in the stomach of the Cyclops. The latter is believed to serve as an intermediary host for the development of the guinea-worm, the embryos getting into the body of the Cyclops by piercing the cuticle. When the embryos are swallowed they are digested.

${ }^{1}$ China Customs Report, No. XIV, 1878.

2 Proccedings of the Asiatic Society of Beugal, March 1878, p. 89.

${ }^{3}$ Op. cit., Baud. II, p. 706. 



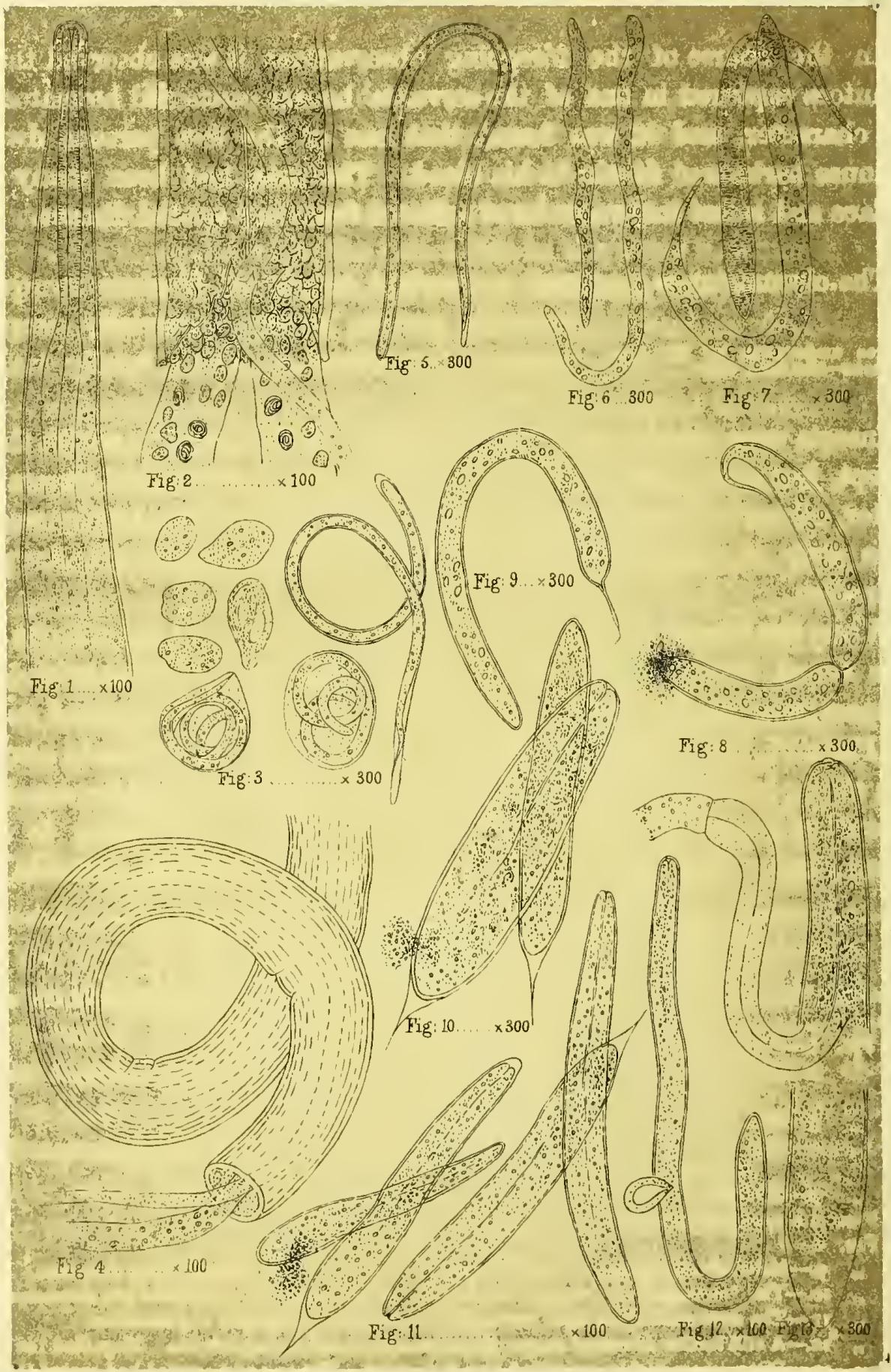

$T R$ Lew ad nat del

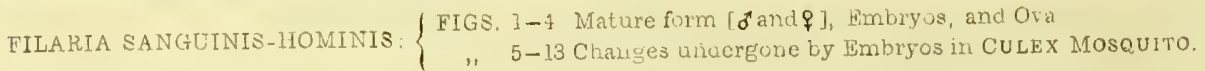


In the course of the foregoing observations it was observed that all the mosquitoes captured in one of the servants' houses contained hromatozoa of the same character, and it was found that one of the five persons dwelling in this house harboured filariæ in his blood. The man had been many years in the place and is not known to have suffered from any special disease.

The circumstance that such a constant supply of filarious mosquitoes, of tolerably certain history, materially simplified the Changes undergone by the em. bryo-filariæ-the first day:

course of investigation, which, briefly told, was as follows :-

Insects were caught early in the morning in the room in which this person had slept, just as Dr. Manson had done. Some were placed in bell glasses standing in water, others in test-tubes containing a little water at the bottom and covered with a strip of muslin. These were duly labelled and set aside for periodical examination.

When the insect was examined with recently ingested blood in its stomach, it was found that the hæmatozoa, when present, did not differ materially from the aspect presented by them when extracted directly from blood of its previous host (Plate II, fig. 5), although, not unfrequently, parasites would also be seen which either belonged to a more advanced stage of the one under consideration, the result of a previous ingestion of filarious blood, or belonging to a totally different kind. There is always, therefore, a risk of confusing different parasites

PLATE II,

Illustrating the mature Filaria sanguinis-hominis, $\delta$ and $q$, and some of the developmental stages of the Embryos :-

Fig. 1.-Anterior portion of mature helminth. Magnified roo diameters.

" 2.-Middle portion of parasite shewing alimentary canal; and the uterine tubules filled with ova. Magnified 100 diameters.

"3.-Ova and embryos. Magnified 300 diameters.

" 4.-A portion of the male worm, with alimentary and sperm tubules escaping at one of the torn ends. Magnified 100 diameters.

" 5.-Embryo recently ingested by a mosquito. Magnified 300 diameters.

Figs. 6 \& 7.-Early changes undergone by the embryos in the mosquito.

Fig. 8. -?

" 9.-More advanced stage of the development of the embryo. Magnified 300 diameters.

" ro.-The 'sausage-form' stage of development of the embryos. Magnified 300 diameters.

"11.-The embryos acquire more worm-like proportions. Magnified Ioo diameters.

"12.-A still further advanced stage : the alimentary canal distinguishable. Magnified soo diameters.

"13.-Ditto : more highly magnified (30o diameters). The re-agent applied had caused the contents of the caudal end to contract. 
in the same insect. Repeated examinations at the same periods tend, however, to minimise this source of error. During the first twenty-four hours no marked change takes place in the form of the organisms.

On the second day, however, it will probably be seen that the blood has, to

Second day.

a considerable extent, undergone digestion, and the stomach will no longer manifest the distended condition of the first day. Probably a few altered hæmatozoa will be observed in it moving very languidly, presenting the appearance of partially disintegrated fungal filaments when the movements are not manifested. Some of them may be actually dead; these will be found to be stained by eosin solution very readily.

Between the second and the third day further changes occur, but in order to be able to follow these it will be necessary to Third and fourth days.

examine the other tissues of the insect, as possibly the stomach may contain none; it will, however, probably be found that some of them have migrated into the tissues immediately outside this viscus. It will now be observed that some of the parasites have become considerably thicker (fig. 7); and occasionally specimens will be seen with the tail presenting the appearance of a lash (fig. 9) ; the movements are still very sluggish.

About the fourth day it is probable that examples in various stages of growth will be visible, rendering it extremely difficult or impossible to state precisely what it is that actually does take place; at least hitherto I have not been able to satisfy myself. About this period, however, I have sometimes seen bodies, apparently composed of precisely the same material as figs. 6, 7, 9, undergoing something so very like cleavage (fig. 8) that I hesitate to state that this act is not one of the stages in the development of the filaria. The figure given (No. 8) is very carefully sketched, and, like all the others, accurately to scale. It will be noticed that one end is partially hidden by some granular matter. This I was not able to press away from the preparation. Other preparations of a like kind were also more or less hidden by granular matter, and in some cases (unassociated, however, with any indications of fission) the parasite appeared to be covered with an encrustation. With regard to the process of division suggested by the appearance of No. 8 I can offer no opinion; it is quite possible that it forms a part of the developmental changes undergone by some other parasite,-such, for instance, as a gregarine. About the fourth day there will also be seen short, thick bodies (very appropriately described by 
Dr. Manson as 'sausage-shaped'), almost perfectly still (fig. 10), with a faint indication of a mouth; and, in some of them, a faint line may be detected suggestive of a commencing intestinal canal; the escape of a few granules on slight pressure towards the other, usually thicker, end, suggests the existence of an anal aperture. The chief difficulty which I have experienced in following these changes is to account for the transition of form at figure 7 to that represented in figure 10. They are all, up to this figure, sketched as magnified by 300 .

The larval forms at fig. 10 now rapidly increase in size, and gradually

Fourth and fifth days.

acquire a more elongated outline, and between the fourth and fifth days they may be found presenting the form shewn at fig. 11. The last figure, it will be noticed, is magnified 100 diameters only, and the length of the larvæ, therefore, is almost three times that of those delineated at fig. 10. They also manifest greater activity.

The highest stage of development which lias come under my notice is that figured at 12 as seen magnified 100 diameters. The anterior and posterior portions of a similar one, magnified 300 diameters, are delineated at fig. 13 . This measured $\frac{1}{33}$ of an inch in length, and its width towards the middle was $\frac{1}{640}$; near the anterior and posterior ends they measured $\frac{1}{800}{ }^{\prime \prime}$ across. The dimensions of anotler specimen which I measured were $\frac{1}{32}{ }^{\prime \prime}$ in length by $\frac{1}{1000} "$ in width at the broadest part. Dr. Manson mentions that he has on four occasions observed larger specimens than these.

Notwithstanding their activity and apparently robust condition, they nevertheless are extremely fragile, very slight pressure of the cover-glass being sufficient to crush them. When examined in the unbroken condition it is only with difficulty that the alimentary canal can be distinguished beyond the junction of the cesophagus with the intestine, but when carefully ruptured (as in fig. 12) the tube may be distinguished. I have not been able to distinguish any other differentiated viscus in any of the specimens which have come under my observation, and, certainly, nothing suggestive of differentiation of sex.

By the time that the larval filariæ have attained to this degree of development, the mosquito will possibly have already The subsequent history of the deposited its ova, and its own cycle will have been nearly completed. With the intention of following out the development still further, I have frequently kept insects until this stage was reached before examination, but all the attempts have proved fruitless, notwithstanding that 
the mosquito has been seen to go through its ordinary course of depositing its ova on the surface of water, and then perishing itself. Either no filariæ were found in its body, or if present they were dead, and careful examination of the water invariably yielded negative results in my hands. It would seem that the larvæ had perished. As the quantity of water used was so small, it is hardly possible, had filariæ in any stage of growth been present, that they could have so completely escaped observation. Possibly the more or less artificial conditions necessarily associated with the conduct of such experiments may account for these negative results. In the meantime $I$ cannot, as a result of personal observation, affirm that a sojourn in the body of the mosquito, and subsequent transference to water, suffice to bring the Filaria sanguinis-hominis to maturity.

A few words may be said regarding other hæmatozoic parasites which appear to find their way into the bodies of The varieties of nematoid hæmatozoa ingested by the mosquito. mosquitoes. In the first place, it may be mentioned that dogs appear to furnish a certain proportion, as I have repeatedly found filariæ in these insects in which not the slightest trace of the enveloping cyst, which characterises the human hæmatozoon, could be detected. Unfortunately the corpuscles of the dog's blood are so like those of man, as to size and appearance, that it is not possible to distinguish them with certainty, so that the examination of the fluid contents of the mosquito's stomach does not tend to throw any light on the source of the hæmatozoa in this instance. It is probable that other animals also contribute towards rendering the diagnosis more difficult.

It is not uncommon, for example, to find the blood-corpuscles of birds forming a portion of the contents of the mosquito's stomach, and I have on several occasions observed extremely small embryo-nematodes associated with such corpuscles. Some of these are represented in the accompanying wood-cut (fig. 27). If these helminths be

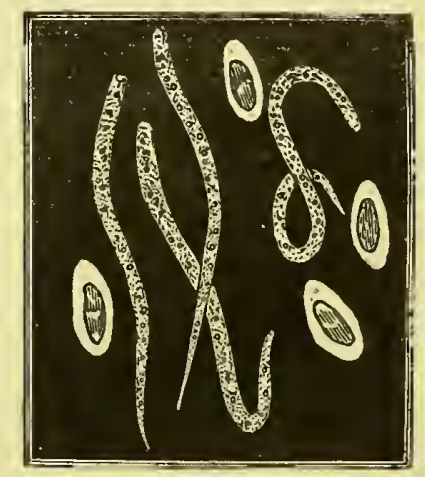

Fig. 27

Embryos of a nematoid helminth from a bird, obtained in the. stomach of a mosquito. A few blood-corpuscles are included in the sketch. compared with the figure given of the hæmatozoon of the crow (fig. 24), they 
will be found to bear a close resemblance to it. It is very possible that these embryos may not have been derived from the crow, but there can be but little doubt, judging from the character of the red blood-corpuscles, that they had been derived from some bird. Facts of this kind also tend to add to the difficulty of ascertaining precisely the various developmental processes which any particular species of hæmatozoon undergo.

\section{E.-The Mature form of Filaria sanguinis-hominis.}

A letter appeared in The Lancet of 14th July 1877 from Dr. Cobbold, anDiscovery of mature nematodes in nouncing the discovery by Dr. Bancroft, of Brisbane, the tissues of man by Dr. Bancroft.

Australia, of what were believed to be specimens of the mature Filaria sanguinis. They had been found on two occasions: on the first, a dead specimen was found in a lymphatic abscess of the arm; and the second time four living specimens were obtained whilst tapping a hydrocele of the spermatic cord. Regarding these Dr. Bancroft had written the following description: "The worm is about the thickness of a human hair, and is from 3 to 4 inches long. By two loops from the centre of the body it emits the filariæ described by Carter in immense numbers.'

During the last six years I have taken considerable interest in questions of this nature, and have, through the kindness of proThe mature forms of Filaria san. guinis-hominis : male and female.

fessional friends in India, had frequent opportunities of searching for the parental form of the Filaria sanguinis-hominis, but only succeeded in obtaining it on one occasion. This was a little more than a year ago-7th August 1877. Descriptions of the specimens were published at the time, ${ }^{1}$ but, in a paper dealing with the organisms of the blood, a brief account of these particulars should find a place.

For the opportunity of examining the particular case in which the filariæ were found, I am indebted to the kindness of the late Dr. Gayer. The patient was a young Bengalee affected with well-marked nævoid elephantiasis of the scrotum, associated with the presence of embryo-filariæ in the blood. The tumor and the sanguineous exudation which escaped on its removal were collected, and submitted to careful examination, and, after a continuous search of eight hours, the long-sought-for belminth was eventually obtained. The

1 Indian Medical Gazette, 1st September 1877; The Lancet, 29th September 1877, page 453; Centralblatt für die medicinische Wissenschaften, No. $43 ; 1877$, page 770. 
specimens were, however, so greatly mangled by the needles used in teasing a clot under a dissecting microscope, that the description of the parental forms cannot at present be so complete as desired.

The specimens consisted of portions of two worms, male and female (Plate II, figs. 1 to 4); the former, however, had unfortunately been torn across at two places, and the terminal ends could not be discovered. Both specimens manifested very lively movements, notwithstanding their mangled condition. They were of a white colour, the cuticle was smooth and devoid of transverse markings except such as were due to the contraction of the subjacent muscular walls.

The fragment of the male specimen which was found measured half an inch

The male specimen. in length, and $\frac{1}{180}$ of an inch ( $(14 \mathrm{~mm}$.) transversely; it was thinner than the female, but of considerably firmer texture,-so firm, indeed, that whilst endeavouring to make out its anatomy a considerable portion of it was lost by one of the needles used for dissecting, snapping and carrying a portion of worm along with it. On tearing the helminth across, the severed surface does not present a ragged edge, but an even outline (fig. 4, Plate II). The male manifested also great tendency to coil, and it was only with difficulty that it could be separated from the specimen of the female parasite, around a portion of which it had twisted itself. It is unfortunate that its caudal end especially could not be found, as the definite decision of the genus to which it should be referred depends in a great measure on the characters which the posterior end of the male worm presents. The intestinal canal measured $\frac{1}{633}{ }^{\prime \prime}\left(.039 \mathrm{~mm}\right.$.) across, and the sperm tube $\frac{1}{1500}{ }^{\prime \prime}(\cdot 016 \mathrm{~mm}$.)

The caudal end of the female worm also had been severed and could not be found; this, however, is of less moment. The The female specimen.

length of the portion of the helminth secured was $1 \frac{1}{2}$ inches, and its greatest width about $\frac{1}{1}-\frac{1}{0}$ inch. It was packed with ova and embryos in various stages of development; the latter, especially those of them which were mature, manifested active movements. The head is slightly club-shaped; the mouth does not manifest any very distinctly marked labial subdivisions, nor are there any chitinous processes evident either before or after death. The œsophagus is faintly striated and shades off imperceptibly into the intestinal tube, the latter being filled with moleculo-granular matter. ${ }^{1}$

1 A micro-photograph of this specimen is reproduced at fig. 5, Plate III. 
The following measurements may be useful to future observers :-

Oral aperture to end of œsophagus . . . . $\frac{1}{55}$ of an inch, or $45 \mathrm{~mm}$.

Diameter of oral aperture . . . . . . $\frac{1}{3000}, \quad, \quad 008$ "

Width of extreme end (anterior) . . . . $\frac{1}{517} "$ " " 047 "

Ditto anterior end at 'neck' . . . . - $\frac{T}{545} "$ " " 045 "

Ditto opposite junction of intestine with œsophagus . $\frac{1}{222} \quad, \quad$ ", $112 \quad$,

Ditto about $\frac{1}{4}$ inch from anterior end . . . $\frac{1}{153}, \quad$ " "162 "

Width where packed with ova and embryos - . $\frac{1}{100} ", \quad " 25$,

Width of uterine tube filled with ova . . . . $\frac{1}{222} ", \quad$ " 112,

Ditto alimentary tube . . . . . - $\frac{1}{666}$, " , 037 ,

The ova do not possess any distinctly marked 'shell;' from the smallest The ova and embryos.

to the largest nothing but a delicate pellicle can be distinguished as enveloping the embryo in all its stages; consequently the form assumed by the ovum depends to a great extent on the degree of the surrounding pressure. In fig. 3 (Plate II) ova of various shapes are depicted (spherical, triangular, oval), and with a considerable latitude as to size. The average of six measurements of the less advanced kinds of ova, $i$. e., those in which the outline of the embryo was not distinctly evident

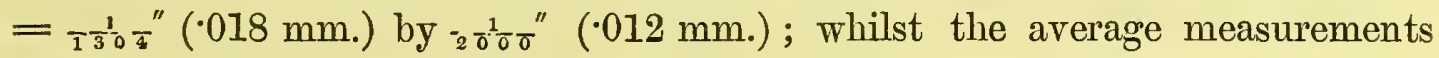
of three ova in which the embryos were visible $=\frac{1}{6} \frac{1}{6} \frac{1}{6}^{\prime \prime}\left(.037 \mathrm{~mm}\right.$.) by $\frac{1}{790} "$ (.030 mm.).

When the latter, after having arrived at this stage of development, are examined during life, it is in many instances difficult to state whether they are to be considered as freed embryos or not, as the 'egg-shell' has become so extremely attenuated and translucent as only with difficulty to be distinguished. By pressing the covering glass firmly the sac may often be ruptured. It, however, appears probable that, even when the embryo acquires worm-like appearances, the envelope is not lost in this species so long as it continues in the blood.

It is of importance to bear this in mind, as, contrary to what is seen with regard to the nematoid hæmatozoa of dogs, The translucent cæcal tube in
which free embryos are enclosed. the embryos in the blood of man are each contained in a translucent creal tube. This tube is readily recognisable during life whenever the embryos can be properly observed in fresh clear serum, as also in spirit-preserved preparations. I possess at the present time specimens thus preserved of both species, one being contained in blood 
removed from the heart of a person who, during life, was known to harbour hæmatozoa, and the other obtained from the blood-vessels of a dog similarly affected. In not a single instance have I been able to distinguish the least trace of an enveloping tube in the latter, whereas in the former this tube can be clearly demonstrated in the majority of instances. Hence, notwithstanding their almost complete accord as to dimensions, the character just referred to is sufficient to distinguish slides prepared from either of these two specimens. A like distinction has been ascertained to exist between the two kinds of embryo-filariæ in China by Dr. Manson; but, according to Dr. Sonsino, those of Egypt, and apparently those of the Brazils, do not present this distinguishing feature. As may be recollected, it was mentioned that a distinction also exists between the disease with which the human hæmatozoon is associated in the different countries,-not a great difference certainly, but, nevertheless, one which should be borne in mind when deciding as to specific distinctions between the parasites.

It must also not be forgotten that the inhabitants of Brazil and of certain parts of Africa are, as has been known for at least The thread-like tissue-parasites of Africa and America and Austra-

a century, peculiarly liable to be the hosts of tissueparasites. The minute thread-like sub-conjunctival filaria (Filaria loa), for example, though from two to six inches in length, has never been accurately described, and its precise thickness is not known yet, although it was discovered by Bajon so long ago as $1768,{ }^{1}$ and has since been frequently observed beneath the skin and conjunctiva of negroes and other persons. M. Guyon brought it before the notice of the French Academy in 1838, and again in 1864. On the former occasion, the specimens measured 30-40 mm., but the helminth described in 1864 was $150 \mathrm{~mm}$. in length. It is not quite clear that they belonged to the same species. It is not impossible that the embryos discovered by $\mathrm{Dr}$. O'Neill ${ }^{2}$ in a disease of the skin termed Craw-craw, on the west coast of Africa, may prove to have been the offspring of some such helminth.

Again, the minute, thread-like nematoid described in America by Leidy, 5 inches in length and $\frac{1}{66}$ inch in greatest breadth, is not to be overlooked. 
It was obtained from the mouth of a child, and derives its name-Filaric hominis-oris ${ }^{1}$-from this circumstance.

All these circumstances point to the necessity of exercising considerable caution in arriving at any decision as to the precise relation of any of these as yet obscure parasites.

With regard to the helminths discovered by Dr. Bancroft in Australia, I. am not in a position to offer an opinion. It has not yet been shewn that they are blood-worms in the ordinary sense of the term, nor is it known that the individual from whom they were obtained harboured embryo-hæmatozoa. It is further to be remarked that the affections under which the persons laboured from which they were derived were not of the character of the diseases with which these hæmatozoa have hitherto been known to be associated; indeed, it would appear that one of the principal morbid conditions with which they are associated in this country-nævoid elephantiasis-is unknown in Australia. It may also be noteworthy that no male worm was found among the specimens.

Dr. Cobbold is, however, of opinion that they are identical, and it would be A correction. superfluous to say that the opinion of one who has devoted so many years to the study of helminths is entitled to consideration. This observer has lately (The Lancet, July 13, 1878) given a summary of the bibliography, \&c., of these questions, in which I observe a slight error. It is with reference to the mature nematoid helminths found in Australia. These, Dr. Cobbold states, were 'first discovered by Dr. Bancroft and first described by myself.' It seems to me, however, that not only did Dr. Bancroft discover the parasite, but also furnished the first account of them which appeared. It is possible that the description supplied by Dr. Bancroft, which is quoted on a previous page, is not considered sufficiently precise to be accepted as such, from a naturalist's point of view. Allowing this, if, as Dr. Cobbold maintains, the Australian and Indian parasites are identical, the first full account of the mature Filaria sanguinis-hominis, as found in India, was published, both in this country and in London, previous to the appearance of Dr. Cobbold's description-having, indeed, been in the printer's hands before Dr. Cobbold had even seen the Australian parasites. Dr. Cobbold, moreover, refers to such prior publication in the appendix to his own article.

1 Proceedings of the Academy of Natural Science, Philidelphin, rol. y, 1850-51. 
This trifling oversight will, I have no doubt, be duly corrected should this distinguished observer have occasion to write regarding these subjects in the futurc.

In considering the question of the relation which may exist between the presence of organisms in the circulation and disease, the conclusion is forced upon us that in Hæmatozoa and Hæmatophytes in reality but little of a definite character is known. One thing, however, is clearly manifest, that the supposition that beings become asphyxiated as a result of the existence of living organisms in the blood, is untenable. The study of their natural history as they occur in man or animals does not afford the slightest support to such a view. Indeed, so far as we at present know, it would seem that the presence of embryos in the blood, no matter how numerous, exercises no marked deleterious effect on the organism. It is probable, however, that the parents of these organisms, especially when helminthic, do exert a deleterious influence on the well-being of their hosts,-as, for example, the lesions which exist in the walls of the blood-vessels caused by the Filaria sanguinolenta, would seem to indicate. With regard to allied conditions in man, it is to be inferred that the influence exerted by nematoid embryos in inducing disease is apt to be overrated, as it would seem that the parasites may sojourn for long periods in the system without inflicting obvious injury. That certain injuries are effected, however, cannot well be doubted,' but, judging from what we know of the like condition in animals, the injuries result, not from direct action of living organisms on the blood-current in which they dwell, but from their action on some of the delicate tissues through which the blood circulates-such injurious influence being probably exerted more especially during the migrations of the parents of future embryo-hrematozoa.

As it cannot be said that the vegetable organisms which may be found in the blood undergo any such transformations, the injury which their presence is supposed to occasion must be due to some other influence. What this may be it is difficult to conceive: the ordinary explanation that they consume the oxygen which is required by the blood itself cannot be regarded as sufficient. 

Plate. III.

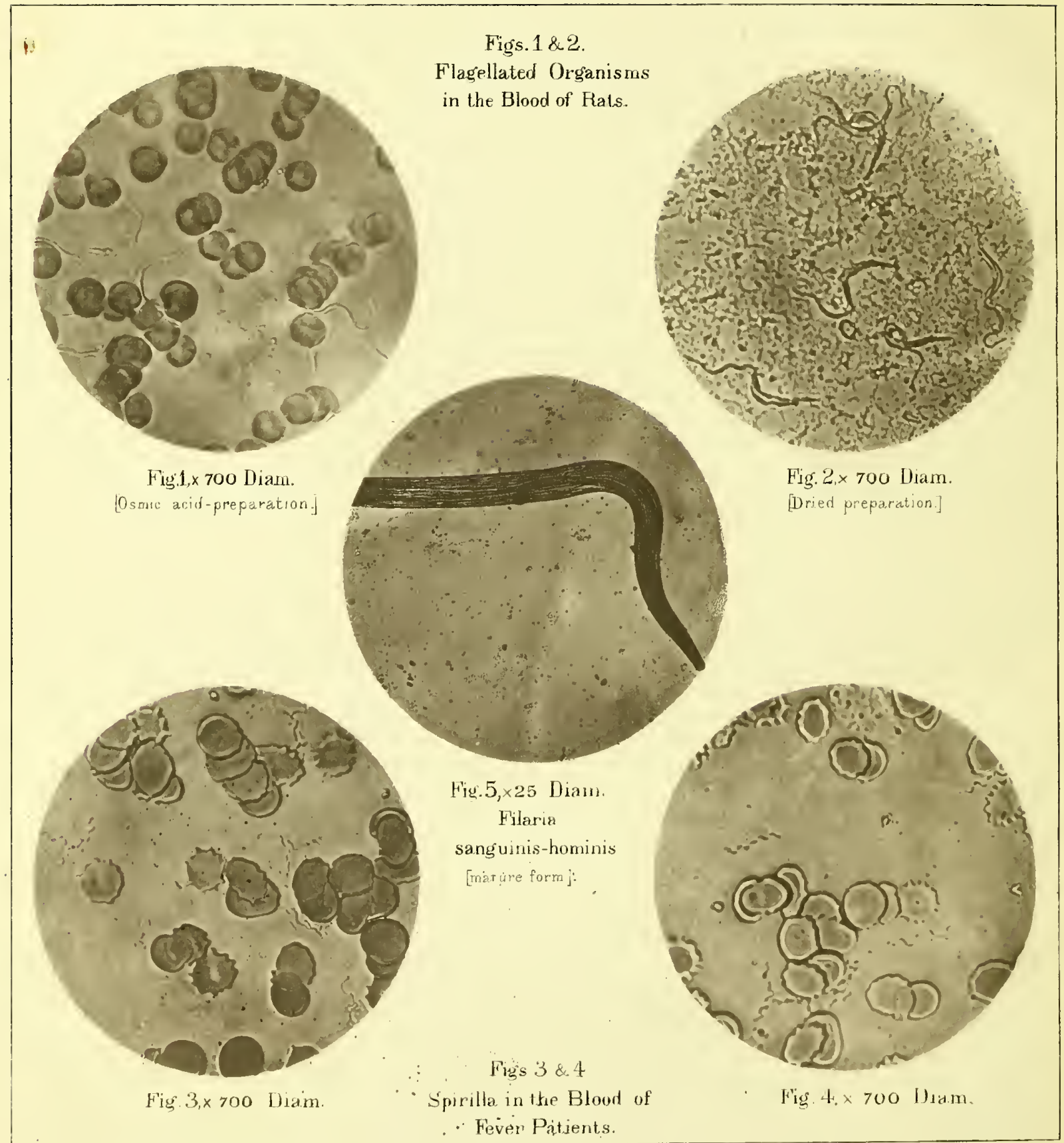

T.R.I,ewis ferit ...

Micro-Photographs of various Organisms in the Blood. 
ADDENDUM.

Since the foregoing was written it has been found practicable to furnish facsimile reproductions of a few of the micro-photographs referred to in the text. They have been reproduced as permanent photographs by the Autotype Company.

\section{PLATE III.}

Micro-photographs of various organisms in the Blood:-

Fig. 1.-Flagellated organisms in the blood of healthy rats. A thin layer of blood, having been spread over a cover-glass, was exposed to the fumes of osmic acid and subsequently mounted as a dry preparation in the ordinary manner. It was then photographed as seen under Ross' $\frac{1}{1} \frac{1}{2}$ immersion objective. (Vide Part II, A.) Magnified 7oo diameters.

FIG. 2.-A preparation of the same blood as in fig. 1. Instead, however, of exposing it to the influence of osmic acid, it was allowed to dry spontaneously. When dry the preparation was stained by means of a weak solution of aniline-blue and photographed as seen under a $\frac{1}{12}{ }^{\prime \prime}$ objective. (Vide Part II, A.) Magnified 700 diameters.

FIGS. 3 \& 4.-Spirilla in the blood of fever-patients at Bombay-two micro-photographs of osmic acidpreparations, mounted dry. Many of the red blood-corpuscles are seen to present irregular margins in both figures. A white amoboid corpuscle is visible towards the upper edge of Fig. 4. (Vide Part I, G.) Magnified 7oo diameters.

FIG. 5.-Anterior portion of the mature Filaria sanguinis-hominis, photographed under Ross' 3 " object glass. The width of the worm is slightly increased owing to the pressure exerted by the coverglass. (Vide Part II, E.) Magnified 25 diameters. 






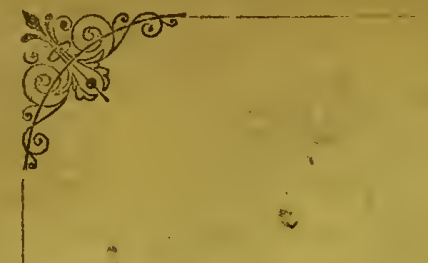

THE

\section{MICROSCOPIC ORGANISMS}

\section{FOUND IN THE BLOOD OF MAN AND ANIMALS,}

\section{AND THEIR RELATION TO DISEASE.}

BY

TIMOTHY RICHARDS LEWIS, M.B.,

ARMY MEDICAL DEPARTMENT,

SPECLAL ASSISTANT TO THE SANITARY COMMISSIONER WITH THE GOVERNMENT OF INDIA.

CALCUTTA :

OFFICE OF THE SUPERINTENDENT OF GOVERNMENT PRINTING. 